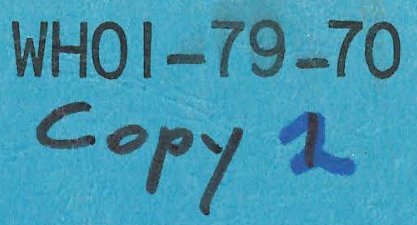

Woods

Hole

Oceanographic

Institution
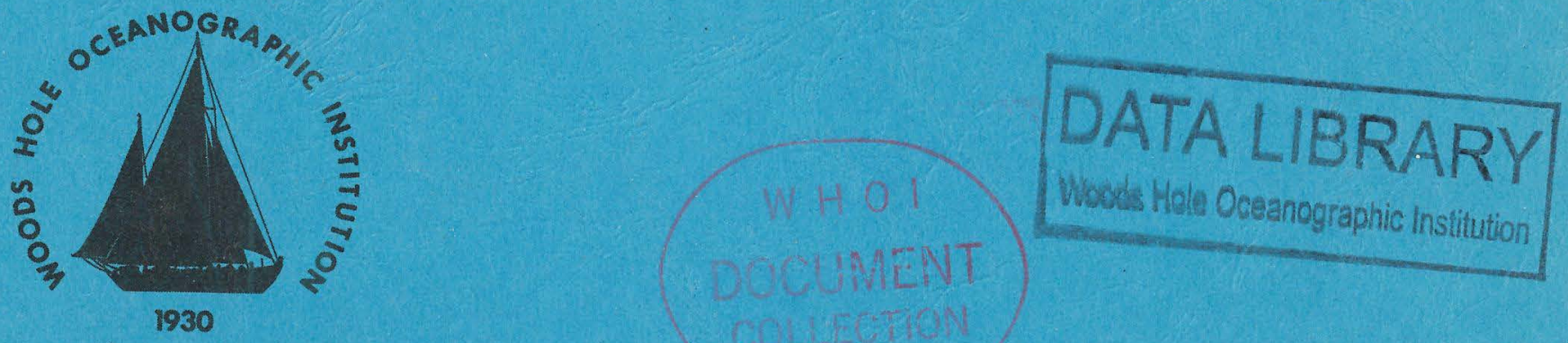

WOODS HOLE OCEANOGRAPHIC INSTITUTION

COLIECTION OF CLIMATOLOGY AND

AIR/SEA INTERACIION (CASI) DATA

by

Roger A. Goldsmith and

Andrew $F$. Bunker

August 1979

TECHNICAL REPORT

Prepared for the Office of Naval Research under Contract N00014-74-C-0262; NR 083-004 and for the National Science Foundation (Climate Dynamics Program, Atmospheric Sciences Division) under Grant ATM 77-01475.

Approved for public release; distribution uniimited.

WOODS HOLE, MASSACHUSETTS 02543 
WHOI $-79-70$

\title{
WOODS HOLE OCEANOGRAPHIC INSTITUTION COLLECTION OF CLIMATOLOGY AND AIR/SEA INTERACTION (CASI) DATA
}

by

Roger A. Goldsmith

and

Andrew F. Bunker

WOODS HOLE OCEANOGRAPHIC INSTITUTION

Woods Hole, Massachusetts 02543

August 1979

\author{
TECHNICAL REPORT
}

Prepared for the Office of Naval Research under Contract N00014-74-C-0262; NR 083-004 and for the National Science Foundation (Climate Dynamics Program, Atmospheric Sciences Division) under Grant ATM 77-01475.

Reproduction in whole or in part is permitted for any purpose of the United States Government. This report should be cited as: Woods Hole Oceanographic Institution Technical Report WHOI-79-70.

Approved for public release; distribution unlimited.

Approved for Distributionflul \& Wha

Earl E. Haf, Chairman
Department of Ocean Engineering

$A D \cdot A 075009$ 


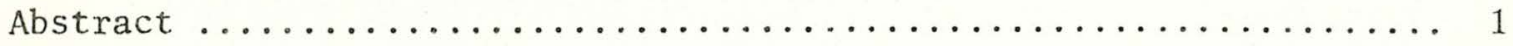

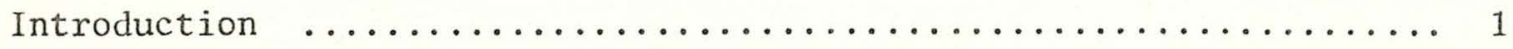

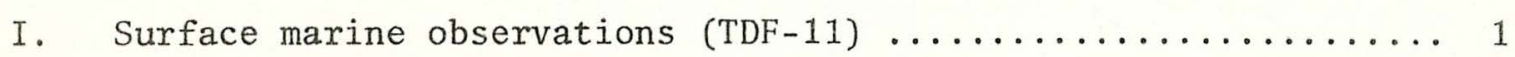

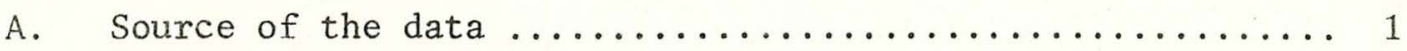

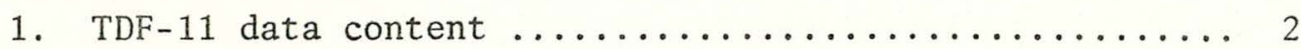

2. TDF-11 data format $\ldots \ldots \ldots \ldots \ldots \ldots \ldots \ldots \ldots \ldots \ldots \ldots \ldots \ldots \ldots \ldots \ldots$

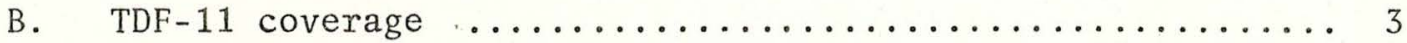

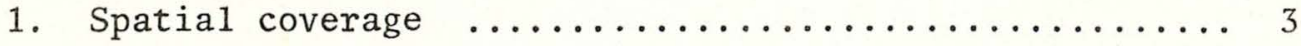

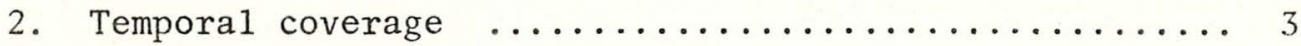

C. W.H.O.I. TDF-11 storage and access .............. 4

1. Index to W.H.O.I. TDF-11 collection $\ldots \ldots \ldots \ldots \ldots \ldots$

2. Additions to W.H.O.I. TDF-11 collection .......... 6

D. Using the W.H.O.I. TDF-11 observations $\ldots \ldots \ldots \ldots \ldots \ldots$

II. Air/sea heat flux analysis (Program ASHFLA) $\ldots \ldots \ldots \ldots \ldots \ldots \ldots$

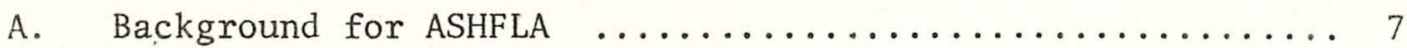

1. Heat flux spatial coverage $\ldots \ldots \ldots \ldots \ldots \ldots \ldots \ldots \ldots$

2. Temporal coverage of heat flux files $\ldots \ldots \ldots \ldots \ldots$

B. Parameters studied in heat flux program $\ldots \ldots \ldots \ldots \ldots \ldots$.

1. Input parameter acceptability $\ldots \ldots \ldots \ldots \ldots \ldots \ldots$

2. Equations and quantities calculated $\ldots \ldots \ldots \ldots \ldots$

C. Output of the heat flux study $\ldots \ldots \ldots \ldots \ldots \ldots \ldots \ldots \ldots \ldots$

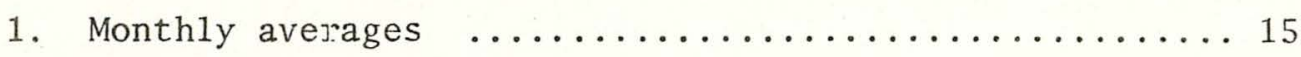

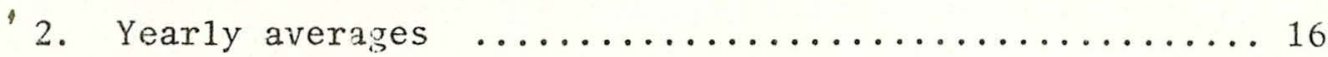

3. Seasonal region - wind sector summary $\ldots \ldots \ldots \ldots \ldots 17$

4. Annual summary $\ldots \ldots \ldots \ldots \ldots \ldots \ldots \ldots \ldots \ldots \ldots \ldots \ldots \ldots \ldots \ldots$

D.Storage and access to heat flux volumes $\ldots \ldots \ldots \ldots \ldots \ldots \ldots$

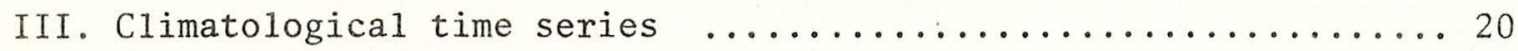

A. Storage and access to climatological data ............ 20

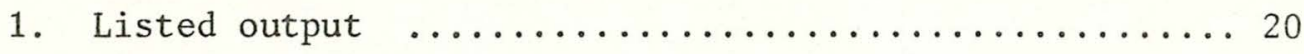

2. Computer storage of climatological data $\ldots \ldots \ldots \ldots 21$

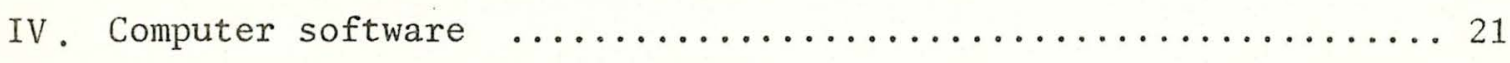

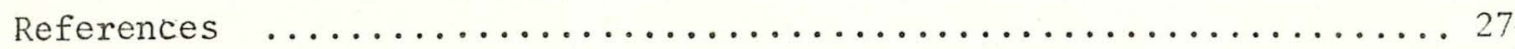

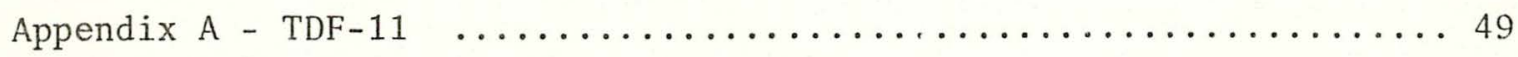




\section{LIST OF TABLES AND FIGURES}

Tables: I TDF-11 parameters most frequently available ....... 29

II TDF-11 data requirements for the heat flux

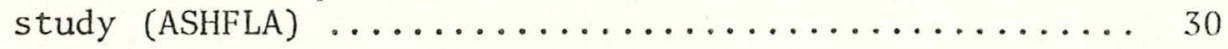

II Determination of wind direction from TDS-11

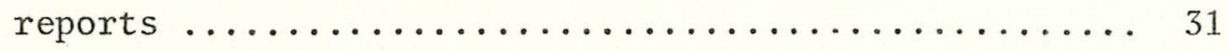

IV Exchange coefficients for latent and sensible heat flux calculations .................. 32

Va Sea surface albedo for northern hemisphere ....... 33

$\mathrm{Vb}$ Sea surface albedo for southern hemisphere ........ 34

VI Cloud cover coefficients, from Budyko ........... 35

VII Drag coefficients used in computing wind stress ..... 36

VIIIa Solar radiation received on earth's surface for northern hemisphere ................... 37

VIIIb Solar radiation received on earth's surface for southern hemisphere .................... 38

IX Incoming solar radiation cloud cover coefficient .... 39

$\mathrm{X}$ Variable key for monthly and yearly averages ...... 40

XI Variable key for seasonal summaries by region and sector ............................. 41

Figures: 1 Area coverage of TDF-11 at W.H.O.I. .......... 42

2 Example of WHOI/TDF-11 index .............. 43

3 Spatial coverage of the heat flux (ASHFLA) files

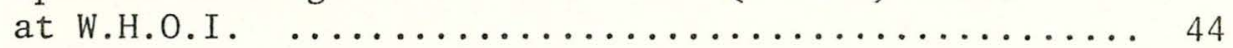

4 Example of monthly and yearly averages summarized in the ASHFLA volumes .................... 45

5 Example of seasonal region-wind sector summary produced in the ASHFLA study ............... 46

6 Example of annual and total summary of parameters and fluxes in the ASHFLA study $\ldots \ldots \ldots \ldots \ldots \ldots \ldots . \ldots \ldots$

$7 \quad$ Climate areas processed $\ldots \ldots \ldots \ldots \ldots \ldots \ldots \ldots \ldots \ldots$ 
ABSTRACT

Scientists at Woods Hole routinely collect and analyze a considerable amount of data relating to the oceans of the world. Of the many different kinds of data, one particular subset concerns those events occurring at the sea surface. A large number of sea surface environmental observations have been collected at Woods Hole. These data, and the subsequent analyses generated from the Air/Sea Heat Flux and the Climatology study projects, have been collected and archived. This document describes the W.H.O.I./ Climatology and Air/Sea Interaction (WHOI/CASI) data collection and provides an initial index to its various components. 
INTRODUCTION

During the last few years, several researchers at Woods Hole have used the National Climatic Center's Tape Data Family-11 (TDF-11), a collection of world-wide surface marine observations made by ships of opportunity. A variety of studies have been made using these data but the most extensive work has been done by Bunker. A series of related projects have performed a considerable amount of processing on a selected group of atmospheric and sea surface parameters. Energy fluxes and wind stresses have been computed by empirical formulas from those parameters. All the parameters have been averaged over a variety of climatological conditions, areal distributions, and time periods. These data have been assembled to build the Climatology and Air/Sea Interaction (CASI) collection. The information in this data set is available to all marine and atmospheric scientists. This document defines the contents of the WHOI/CASI archives, describes how to access and use the data, and reports on some of the analyses already done.

\section{SURFACE MARINE OBSERVATIONS (TDF-11)}

\section{A Source of the data}

The surface marine observations residing at W.H.O.I. have been obtained from the National Climatic Center (NCC) at Asheville, North Carolina. NCC is one of the centers in the Environmental Data and Information Service (EDIS) of NOAA. The major part of the data has been extracted from the Tape Data Family-11 (TDF-11). This data series is in a standardized format used to record observations of the surface marine environment from a wide variety of sources. The NCC data set, from 1854-1968, contains over 31 miliion observations from all over the world. The NCC is continually adding to this data base, although there is a lag of a couple of years before any group of observations becomes available to the public. If the region or time period of interest is not available in the W.H.O.I. collection, it may be obtained from the regional NOAA representative or directly from the National Climatic Center. We will make an effort to merge future W.H.O.I. users' acquisitions into the archive if they desire. 


\section{I.A. 1 TDF-11 data content}

Because the TDl:-11 has been assembled from a variety of sources, therc is available no uniform set of selected parameters. In general, only the data present in characters 1-72 of each record are available in sufficient enough quantity to be useful. These parameters are summarized in Table I. The last part of each record is apt to contain a wide variety of supplemental data whose content must be determined from a flag field. Appendix A gives a more complete description of the TDF-11 data content.

\section{I.A. 2 TDF-11 data format}

Most of the TDF-11 series obtained from the National Climatic Center is stored on 9-track, 800 bpi, magnetic tape. The data are usually stored as 140 character (byte), EBCDIC, blocked logical records. The blocking factor may vary from 1 to 40 ; the NCC label on the reel will give the blocking factor. The records are ordered by the $10^{\circ}$ square Marsden reference number. Within a $10^{\circ}$ square the observations are usually ordered chronologically by year, and within the year, by month. A tape may contain data for one or more $10^{\circ}$ squares. In general, there is no end-of-file mark between data from separate $10^{\circ}$ squares. It has also been found that there is not always an end-of-file mark before an end-of-tape signal.

Table I also summarizes the location of the more frequently used parameters within the record. Many of these fields contain additional information in the form of a logical byte addition, or "overpunch". This technique is used by the NCC to carry information such as minus signs. Users of the TDF-11 tapes are encouraged to first read the detailed format description contained in Appendix A, or documentation obtained from the National Climatic Center. 
I.B TDF-11 coverage

\section{I.B.1 Spatia1 coverage}

The TDF-11 series is arranged by areas 10 degrees square. As these are marine observations only, many areas will contain large areas of land, and thus represent only a relatively small area of sea surface. The subset of the TDF-11 series available at W.H.O.I. covers most of the Atlantic and Indian Oceans, the Mediterranean and the Red Seas, and selected regions of the Pacific. Figure 1 illustrates the spatial coverage of the current collection.

Within any single $10^{\circ}$ square the spatial coverage may vary considerably. Observations are generally confined to the established shipping lanes. A finer resolution of position may be obtained from the data records, either from the $1^{\circ}$ subsquare Marsden reference number, or from the latitude/longitude coordinates ( 0.1 degree). The WHOI/CASI collection also contains marine observations recorded from "stationary" weather ships. These are recorded separately and have not been merged into ship-of-opportunity files. These files are in TDF-11 format, ordered chronologically by year and month, but not by $10^{\circ}$ squares.

\section{I.B.2 Temporal coverage}

Observations of the marine surface conditions date from 1854 in some regions of the world. However, coverage in the early years tended to be infrequent. The frequency of observations varies widely over the ocean surface. Local, as well as global, events in the economic and policital environment have a large influence on the recorded observation rate for any given area. Thus, both World Wars saw a marked increase in the rate of observation. The closing of the Suez Canal produced a drop in the rate of observation in the Red Sea, and the advent of large oil tankers produced an increased rate of observation around the Cape of Good Hope. 
For most regions in the WllOI/CASI collection, the time range is commonly from 1942 to 1972. (Supplementary tapes have been obtained to update the record through 1976. These have not been appended to the existing series, but are grouped separately. See the TDF-11 tape index for tape identifiers and Marsden square ranges covered by these updates.) The index to the W.H.O.I. TDF-11 series (see section I.C.1 below) contains a time range for the observations on a tape. This range has been determined from several sources and represents the earliest and latest dates revealed using the various processing programs. It does not necessarily represent the full range of time.

\section{I.C W.H.O.I. TDF-11 storage and access}

An effort has been made to gather the W.H.O.I. TDF-11 series into a central storage facility. Most tapes are currently located in tape racks in room 358, Clark Laboratory. There does not exist any formal system for accessing the data. Users are requested to take only those tapes needed and to return them as soon as possible. A withdrawal form is located near by; please supply the tape identifier, your name, telephone extension, date of tape withdrawal, and date of return. For cases where only a small number of tapes, or portions of tapes, are needed, users may wish to copy the TDF-11 tapes to their own tapes or disc files. This procedure will increase the life of the TDF-11 tapes as well as make tham more readily available to others.

\section{I.C.1 Index to W.H.O.I. TDF-11 collection}

Located in room 358 along with the data tapes is an index of the data in the W.H.O.I. TDF-11 collection. The data are cross-referenced in two ways: 1) the first index lists the data by Marsden reference number. This is, for most purposes, identical to being ordered by latitude and longitude. 2) The second index lists the data by magnetic tape identifier. As these tapes were labelled in the order in which they were received, there is no reliable method of identifying the data from the tape identifier. This index is used as an aid in determining what else is on the tape. 
In addition to the Marsden reference number and tape identifier, the following data are available from the index (an example is shown in Figure 2) :

- Position: The position is expressed as the latitude and longitude of the center point of the $10^{\circ}$ square. Latitudes contain the suffix $N$ or $S$ to denote hemisphere and the longitudes are suffixed with $E$ or $W$ with respect to the Greenwich Prime Meridian.

- Storage location: The location where the data are stored. Some investigators may choose to keep custody of their tapes while still making the data available through the WHOI/ CASI archive. These tapes should be obtained from the associated investigator.

- Investigator: Identifies the contributor of the data tape. This person may be able to answer questions pertaining to the contents of the tape, or may have information bearing on your current project.

- Start and End Dates: An attempt has been made to estimate the temporal range of the data contained on the tape. These figures have been obtained as a by-product from previous processing efforts rather than from any specific search. The dates are in no way connected with the frequency of observations, and should be used only as a rough guide to the range. (Any new values encountered by users will be incorporated if made available to the authors.)

- Number of observations: In some cases a rough estimate of the number of observations has been provided. Again, these figures have been obtained as a by-product of other work and are merely an estimate. 


\section{I.C.2 Additions to W.H.O.I. TDF-11 collection}

It is hoped the W.H.O.I. TDF-11 collection will meet some of the need for obtaining oceanographic data quickly. If the desired TDF-11 data is not present in the archive, it must be obtained from the Nation Climatic Center. The NOAA representative at Woods Hole can aid you in obtaining these data. The subsequent addition of TDF-11 data to the W.H.O.I. collection would be welcome. Also, any information which would update the index, and make it more useful to others, would be appreciated.

\section{I.D Using the W.H.O.I. TDF-11 observations}

The TDF-11 data series represents a great many observations over a considerable span of time. As such, the observations may be used for constructing time series of events, such as monsoons, as well as for looking at long term (25 and 100 years) climatic trends. Most observations have been made by ships of opprotunity; Fieux and Stomme1 (1) have discussed the accuracy of these observations in representing the environment. In general, the sheer quantity of observations makes the data suitable for most projects where average results are desired.

While the National Climatic Center has made an attempt to validate all the observations, users are cautioned to perform their own reasonability tests before or during processing. Instances have been recorded where temperature has not been converted from Fahrenheit to Celsius. Other discrepancies, although also rare, have been found in almost all other parameters. For this reason, and because of the involved format of the data, no general access programs have been written for the TDF-11 series at W.H.O.I. The large number of parameters per record and the use of the "overpunch" make it more efficient for users to interpret only those fields necessary to their studies. The format is adequately described in Appendix A and IPC personne1 can provide aid in decoding the records if necessary. It is further recommended that the user list a few records of a tape to aid in the interpretation of the format and in program development. 


\section{AIR/SEA HEAT FLUX ANALYSIS (PROGRAM ASHFLA)}

In 1973 Andrew Bunker initiated a study of the energy fluxes at the air/sea interface. This study used observations from the Tape Data Family11 (TDF-11) series to compute a variety of climatological averages for environmental parameters as well as for the energy fluxes. The results of this project have been incorporated into the WHOI/CASI files as the ASHFLA component.

\section{II.A Background for ASHFLA}

The ASHFLA program was developed to study the mechanism of energy transport between the ocean surface and the atmosphere. Over the course of the project the analysis procedure was occasionally changed to incorporate information learned in earlier processing stages. These changes included a) the effect of sea ice on the albedo, b) the effects of clouds on the incoming and long wave radiation, c) changes in the parameters used and summarized, and d) changes in units (SI) associated with the computed parameters. In most cases the changes have not affected the results which are incorporated into the WHOI/CASI files. The climate study (see Section III below) which ensued from the heat flux project has further standardized that portion of the ASHFLA files which it utilized.

The project generated an abundance of data, which will be discussed in the following sections. ASHFLA data are stored in volumes of computer printout. An interpretation of at least portions of the data has been published by Bunker $(2,3,4)$.

\section{II.A.1 Heat flux spatial coverage}

The ASHFLA program initial1y studied a smal1 region of the western North Atlantic Ocean. The study was gradually enlarged to cover all of the North Atlantic, most of the South Atlantic and Indian Oceans, the Mediterranean and Red Seas. Studies have also been made, based on the contribution of TDF-11 data from other projects, for parts of the Pacific and Southern 
Oceans. Figure 3 shows those areas covered by the heat flux study. The study was conducted on areas $10^{\circ}$ square. There was also the capability to subdivide the area into from 1 to 10 regions based on $1^{\circ}$ squares.

\section{II.A.2 Temporal coverage of heat flux files}

As the heat flux study was derived from the TDF-11 series, the time range was primarily a function of the available data. A further constraint was imposed by the reasonability checking done on each observation (see Section II.B). Heat fluxes were computed for individual $10^{\circ}$ squares starting anywhere from the $1920^{\prime} \mathrm{s}$ to the $1950^{\prime} \mathrm{s}$; ending dates were from the late 1960's to 1973 or 1974 . The time range for a selected $10^{\circ}$ square region is best obtained from the summary of monthly averages near the beginning of each volume. The temporal resolution of the study was one month using a standard 30-day month for some of the annual averages.

II. B Parameters studied in heat flux program

As mentioned earlier, the study of the heat flux at the air/sea interface evolved through a number of different stages. In the outline which follows, reference is made to the latest version of the study and computer program under which the bulk of the data were processed. Table II shows those parameters in the TDF-11 series which were used in the study.

\section{II.B.1 Input parameter acceptability}

The reasonability of the observational data was tested before any heat flux computations were performed. The data were broken down into two classes; variables critical to the heat flux computations must have satisfied the reasonability check. Those variables not as crucial were assigned a default value if the acceptability condition was unsatisfied. 
a. All of the following variables, in addition to being reported, had to satisfy the reasonability conditions ascribed below.

i Wind Speed, $W$ in knots

$0 \leqq W \leqslant 199$ knots

ii Air Temperature, $\mathrm{T}_{\mathrm{a}}$ in ${ }^{\circ} \mathrm{C}$

$$
-40.0^{\circ} \leqslant \mathrm{T}_{\mathrm{a}} \leqslant 45.0^{\circ} \mathrm{C}
$$

iii Dew Point Temperature, $\mathrm{T}_{\mathrm{d}}$ in ${ }^{\circ} \mathrm{C}$

$-70.0^{\circ} \mathrm{C} \leq \mathrm{T}_{\mathrm{d}} \leq 40.0^{\circ} \mathrm{C}$

$\left(\mathrm{T}_{\mathrm{a}}-\mathrm{T}_{\mathrm{d}}\right) \geq 0.1^{\circ} \mathrm{C}$

iv Sea Surface Temperature, $\mathrm{T}_{\mathrm{S}}$ in ${ }^{\circ} \mathrm{C}$

$$
-5.0^{\circ} \mathrm{C} \leq \mathrm{T}_{\mathrm{S}} \leq 40.0^{\circ} \mathrm{C}
$$

V Air-Sea Temperature Difference, $\mathrm{T}_{\text {as }}$ in ${ }^{\circ} \mathrm{C}$

$$
\begin{aligned}
& -40.0^{\circ} \leq \mathrm{T}_{\mathrm{as}} \leq 20.0^{\circ} \mathrm{C} \\
& \left|\mathrm{T}_{\mathrm{as}}-\left(\mathrm{T}_{\mathrm{a}}-\mathrm{T}_{\mathrm{S}}\right)\right| \leq 1.0^{\circ} \mathrm{C}
\end{aligned}
$$

vi Pressure, $\mathrm{P}$ in millibars

$$
890.0 \leqslant P \leqslant 1070.0 \mathrm{mb}
$$

vii Total Cloud Amount, $\mathrm{N}_{\mathrm{T}}$ in oktas

$$
\begin{aligned}
& N_{T} \leq 8 \\
& \text { if } N_{T}>8 \text { then } N_{T}=8
\end{aligned}
$$

b. If the following variables were missing or did not satisfy the acceptability requirements, they were assigned the stated value.

i Lower Cloud Amount, $\mathrm{N}_{\mathrm{L}}$ in oktas

$$
\text { If } N_{L}=\text { blank } N_{L}=0 \text { oktas }
$$$$
\text { If } \mathrm{N}_{\mathrm{L}}>8 \text { oktas } \mathrm{N}_{\mathrm{L}}=8 \text { oktas }
$$

ii Present Weather Code, $W_{C}$

If the present weather code was left blank, a-no rain state was assumed. The following weather codes (from Appendix A) were taken to indicate rain, or more correctly, precipitation.

$14 \leq w_{c} \leq 29$

$50 \leq W_{c} \leq 99$ 
10.

II.B.2 Equations and quantities calculated

The item of primary interest was the net heat flux between the sea surface and the atmosphere. In the study the net flux comprised the latent, sensible, and radiational flux contributions. Each of these terms has additional measures associated with it; this section describes the mathematical expressions used.

a. Calculation of net heat gain by the ocean, A in $\frac{\text { watts }}{\text { meter }^{2}}$

$$
A=R-L E-S
$$

where $R$ is radiational exchange at ocean surface

LE is latent heat flux

$S$ is sensible heat flux

The quantity $A(B)=R_{B}-L_{B}-S_{B}$ is calculated using Budyko's method, which assumes a constant exchange coefficient. (See $h$ below.) An additional quantity $A(B, I)$ is calculated which uses the Budyko calculated radiational exchange and average fluxes based on individual observations as indicated in $\mathrm{c}$ and $\mathrm{d}$ below:

$$
A(B, I)=R_{B}-L E_{I}-S_{I} \text {. }
$$

b. General terms

i Absolute air temperature, $\theta_{a}$ in ${ }^{\circ}$ Kelvin

$$
\theta_{a}=273.16+T_{a}
$$

ii Absolute sea surface temperature, $\theta_{\mathrm{S}}$ in ${ }^{\circ} \mathrm{Kelvin}$

$$
\theta_{S}=273.16+T_{S}
$$

iii Absolute dew point temperature, $\theta_{\mathrm{d}}$ in ${ }^{\circ} \mathrm{Kelvin}$

$$
\theta_{d}=273.16+T_{d}
$$

iv Pressure, P, converted to Pasca1s 
$v \quad$ Vapor pressure of air, e, pascals

$$
\begin{aligned}
\log _{10} e_{a}=10.42926609 & -1.82717843\left(\frac{1000.0}{\theta_{d}}\right) \\
& -0.071208271\left(\frac{1000.0}{\theta_{d}}\right)^{2}
\end{aligned}
$$

vi See Reference 6

Vapor pressure over sea, $e_{s}$, Pascals

$$
\begin{aligned}
\log _{10} e_{s}=10.42926609 & -1.82717843\left(\frac{1000.0}{\theta_{s}}\right) \\
& -0.071208271\left(\frac{1000.0}{\theta_{s}}\right)^{2}-0.008774
\end{aligned}
$$

vii Mixing ratio of air, $\mathrm{q}_{\mathrm{a}}$ in grams/gram

$$
q_{a}=\frac{0.622 e_{a}}{p-e_{a}}
$$

viii Mixing ratio over sea, $\mathrm{q}_{\mathrm{s}}$ in grams/gram

$$
q_{s}=\frac{0.622 e_{s}}{p-e_{s}}
$$

ix Virtual temperature, $\mathrm{T}_{\mathrm{v}}$ in ${ }^{\circ} \mathrm{Kelvin}$

$$
\mathrm{T}_{\mathrm{v}}=\theta_{\mathrm{a}} \cdot\left(1.0+0.61 \mathrm{q}_{\mathrm{a}}\right)
$$

$x \quad$ Density of air at the surface, $\rho$ in $\mathrm{kilogram} / \mathrm{meter}^{3}$

$$
\rho=\frac{\mathrm{P}}{\mathrm{T}_{\mathrm{V}}\left(287.04 \frac{\text { Joules }}{\mathrm{kg}^{\circ} \mathrm{K}}\right)}
$$

$x i \quad X$ component of wind velocity, $U$ in $\frac{\text { meters }}{\text { seconds }}$

$$
X=W \cos \left[270^{\circ}-f\left(D_{1}, D_{2}\right)\right]
$$

where $f\left(D_{1}, D_{2}\right)$ is the direction from which the wind is blowing. See Table III. 
12 .

xii $Y$ component of wind velocity, $V$ in $\frac{\text { meters }}{\text { second }}$

$$
Y=W \sin \left[270^{\circ}-f\left(D_{1}, D_{2}\right)\right]
$$

where $f\left(D_{1}, D_{2}\right)$ is the direction from which the wind is blowing. See Table III.

xiii Mean direction of resultant wind, MD in degrees

$$
M D=270.0-\tan ^{-1} \mathrm{~V} / \mathrm{U}
$$

c. Sensible heat flux, $S$ in $\frac{\text { watts }}{\mathrm{m}^{2}}$

$$
S=-T_{\text {as }} \rho W_{p} C_{p}
$$

where $C_{p}=$ specific heat of dry air $=1004.64 \frac{\text { Joules }}{\mathrm{Kg} \text { Kelvin }}$

and $C_{e}=f\left(W, T_{a s}\right)$. See Table IV.

d. Latent heat flux, LE in $\frac{\text { watts }}{\mathrm{m}^{2}}$

$$
L E=L \rho W C_{e}\left(q_{s}-q_{a}\right)
$$

where $\mathrm{L}=2500297.8 \frac{\mathrm{J}}{\mathrm{kg}}-\mathrm{T}_{\mathrm{a}} \cdot 2365.09 \frac{\mathrm{J}}{\mathrm{kg}^{\circ} \mathrm{C}}$

and $C_{e}=f\left(W, T_{\text {as }}\right) \cdot$ See Table IV.

e. Radiational exchange at ocean surface, $\mathrm{R}$ in $\frac{\text { watts }}{\text { meter }^{2}}$

$$
R=Q(1.0-\alpha)-I_{R}
$$

where $Q=$ solar radiation received at the surface (see II.B.2.h.iii below), $I_{R}=$ effective infra-red radiation of ocean, $\alpha=$ a function of the albedo $[f(m, \phi)]$ from Table $V$. 
f. Effective infra-red radiation emitted by ocean surface, $I_{R}$ in $\frac{\text { watts }}{\text { meter }}$

$$
I_{R}=B \sigma \theta_{a}^{4}\left(11.7-0.0023 e_{a}\right) \cdot\left(1-\frac{C \cdot N_{T}}{8.0}\right)+4 B \sigma \theta_{a}^{3}\left(\theta_{S}-\theta_{a}\right)
$$

where $B=$ fraction of black body radiation, 0.96

$\sigma=$ Stefan Boltzmann's constant (Budyko's modified value)

$$
1.3134 \times 10^{-9} \frac{W}{\mathrm{~m}^{2}{ }^{\circ} \mathrm{K}^{4}}
$$

$C=f(\phi)$ the cloud cover coefficient. See Table VI.

g. Momentum between atmosphere and ocean, $\tau$ in Pascals

$$
\tau=\rho C_{D} W^{2}
$$

where $C_{D}=f\left(W, T_{a s}\right)$. See Table VII.

This is broken down into components in the following manner:

$$
\begin{aligned}
\tau_{X} & =\tau \cdot \cos \left[270-f\left(D_{1}, D_{2}\right)\right] \\
\tau_{Y} & =\tau \cdot \sin \left[270-f\left(D_{1}, D_{2}\right)\right]
\end{aligned}
$$

where $f\left(D_{1}, D_{2}\right)$ is the direction from which the wind is blowing.

See Table III.

h. Budyko equations (see Reference 7)

In calculating the heat flux terms using Budyko's coefficient, average values for the time period were used for all the general variables.

The specific changes in the equations are noted below.

i Sensible heat $f l u x, S_{B}$ in watts/meter ${ }^{2}$

In section II.B.2.c, the exchange coefficient $C_{E}$ is replaced by the value 0.0021 .

ii Latent heat $f l u x, L_{B}$ in watts/meter ${ }^{2}$

In section II.B.2.d, the exchange coefficient $C_{E}$ is replaced by the value 0.0021 . 
iii Solar radiation received at the surface, $Q$ in watts/meter ${ }^{2}$

a) The calculation of $Q_{0}, Q_{0}=f(m, \phi)$, is a function of the latitude and time. $Q_{0}$ for a monthly calculation is given in Tables VIIIa and $\mathrm{b}$.

b) The calculation used in the determination of the surface solar radiation II.B.2.e, is as follows.

$Q=Q_{0}\left(1.0-\frac{A_{c} \bar{N}_{T}}{8.0}-B_{c}\left(\frac{\bar{N}_{T}}{8.0}\right)^{2}\right)$

where $A_{c}=f(\phi)$, is the cloud cover coefficient. See Table IX. $B_{c}=f(\phi)$, and is set $=0.38$.

Average values are used for the total cloud cover.

iv The average albedo for all observations replaces the table value in II.B.2.e.

II.C Output of the heat flux study

Processing was done by $10^{\circ}$ squares. The computer program produced about 75 pages of listed output for each $10^{\circ}$ square area. The listings for each square are contained in a separate volume identified by the Marsden number. Each volume is divided into three main sections. The first section summarizes the input parameters and data tables used in the analysis. Most of these have been described in the preceding section II.B and in Tables II - IX. A $1^{\circ}$ subsquare regional assignment diagram is printed at the beginning of each volume. This chart shows the breakdown of the (up to) 10 regions by $1^{\circ}$ subsquares within the larger $10^{\circ}$ square. Most of the later volumes also contain the area (square meters) covered by each of the regions.

The second section summarizes the averages (sections II.C.1 and II.C.2 below) for selected environmental parameters and energy fluxes by month and by year. The third section is the seasonal region/wind sector summary, contained in section II.C.3 and II.C.4 below. 
A fourth output of the program was a punched card file of the monthly averages. This file forms the basis for the subsequent climatological files, discussed in section III below. As of this writing, only the Atlantic Ocean monthly averages have been incorporated into the climatological files. The remaining $10^{\circ}$ squares are still in punched card form and will be updated as time and money allow.

\section{II.C.1 Monthly averages}

Table X gives a summary of the variables output for the monthly and yearly averages. All variables are average values or are calculated using average values, over all valid observations in a month. The use of the estimated mean technique was made necessary by the large number of observations processed and the limited computer resources available at the time. This component of the output is also used in the climatological files (see section III below). Figure 4 contains an example of these averages.

a. $\quad \bar{x}_{m}=x_{e}+\frac{1}{n_{m}} \sum_{i=1}^{n_{m}}\left(x_{i}-x_{e}\right)$

$$
\begin{aligned}
& \text { where } \mathrm{n}_{\mathrm{m}} \quad \text { is the number of valid observations for the month (output } \\
& \text { variable number } 4 \text { ) } \\
& \mathrm{x}_{\mathrm{e}} \quad \text { is an estimated mean value unique for each variable. }
\end{aligned}
$$

b. The Budyko heat flux terms are found using the assumptions outlined in section II.B.2.h. All the general terms used in the heat flux expressions are the average values as determined in II.C.1.a above. Table VIII is used in the calculation of $Q_{0}$. The mid-latitude of the region being summarized was used in the interpolation for a given month. 
16.

\section{II.C.2 Yearly averages}

The variables output for the yearly averages are almost the same as those output for the monthly averages and are also described in Table $x$. For the yearly average, field three contains the coefficient of variation of the number of observations throughout the year. This is found using the following expression:

a. coefficient of variation $=100.0\left(\frac{1}{12} \sum_{m=1}^{12}\left(n_{m}-\bar{n}\right)^{2}\right)^{\frac{1}{2}} / \bar{n}$

where $\overline{\mathrm{n}}=\frac{1}{12} \sum_{\mathrm{m}=1}^{12} \mathrm{n}_{\mathrm{m}}$

and $n_{m}=$ the number of valid observations for a month.

b. The frequency of rainfall is the number of observations which recorded precipitation divided by the total number of observations in the year.

c. The remaining terms in the summary are found using the monthly averages weighted by the number of days per month. The results are then expressed as 30-day averages.

$$
\bar{X}_{Y}=\sum_{m=1}^{12}\left(a_{m} \bar{x}_{m}\right) / \sum_{m=1}^{12} a_{m}
$$

where $\bar{X}_{m}$ is the monthly average

$$
a_{m}=\frac{f(m)}{30}
$$

and $f(m)$ is the number of days in a given month for all months with valid observations.

d. The wind direction is determined from the east and north components of the yearly average wind velocity as computed by II.C.2.c above.

The net result is that the number of observations has no effect on the yearly averages. The coefficient of variation (in field 3 of the annual summary) does give a measure of the distribution of observations over the year in order to facilitate the comparison of yearly averages. Figure 4 also contains an example of the summary of yearly averages. 
II.C.3 Seasonal region - wind sector summary

a. Each valid observation is classified by a regional subdivision of the $10^{\circ}$ square and by the wind sector, or direction from which the wind is blowing. A11 observations are further grouped by season of the year. Thus, all observations made in a season (e.g., January) over all years are grouped together. In this analysis, a season was defined for each month of the year and this assumption is implicit in the weighting factors defined below. Figure 5 is an example of this kind of output.

i Region assignment

Each Marsden square is divided into ten regions as specified by

- input to the program. These regions may assume any configuration and are composed of the $1^{\circ}$ subsquares. The subsquares within a region may be discontinuous. Observations are assigned by subsquare identifier. Output is from Area 1 (top) to Area 10 (bottom).

ii Wind sector assignment Observations are also categorized by the direction from which the wind is blowing. The wind sectors are broken down into four quadrants. A fifth sector is defined for those winds identified as variable or calm. Table III gives the wind sector definitions. Wind sector 6 is a summary of all observations (all wind sectors) by region.

b. Variable definition. Table XI shows the variables and units which are summarized in the lists.

i The mean values are found using the following expression

$$
\bar{x}=x_{e}+\frac{1}{n} \sum_{a w}^{n_{i=1}}\left(x_{i}-x_{e}\right)
$$

where $\mathrm{n}_{\text {aw }}$ is the number of valid observations for the area wind sector category (output variable 3 ).

$\mathrm{x}_{\mathrm{e}}$ is an estimated mean value, unique for each variable. 
18.

ii The appropriate standard deviation terms are found with the following expression.

$$
S D=\left(\frac{1}{n_{a w}} \sum\left(x_{i}-x_{e}\right)^{2} \cdots\left(\bar{X}-x_{e}\right)^{2}\right)^{\frac{1}{2}}
$$

iii The minimum and maximum values are simply the range of valid terms for a particular classification.

iv The transport ratio is defined as follows:

$$
\text { ratio }=\frac{\overline{\bar{w}} \bar{q}_{a}}{\overline{\bar{w} q_{a}}}
$$

where each mean is defined as in II.C.3.b.i above.

v Budyko terms

The Budyko heat flux terms are found using the relationships outlined in section II.B.2.h. All the general terms used in the heat flux expressions are the average values as determined in II.C.3.b.i above. Table VIII is used in the calculation of $Q_{0}$. The mid-1atitude of the region being summarized was used in the interpolation for a given month.

vi The air density average output is as defined in section II.B.2.b. The calculation is a function of average values rather than being a calculated average density. Thus

$$
\bar{\rho}=f\left(\bar{p}, \bar{\theta}_{a}, \bar{q}_{a}\right)
$$

\section{II.C.4 Annual summary}

The final page contains selected parameters and the heat flux terms summarized over all the seasons. An example of this output is shown in Figure 6. 
a. The first part of the annual summary is broken down by regions of the $10^{\circ}$ squares over al1 wind sectors (sector 6 is the total of sectors 1 through 5). All general terms are then calculated by the following expression for each subregion.

$$
\bar{x}_{\text {annua } 1}=\frac{\sum_{i=1}^{12} b_{i} \bar{x}_{a \sigma_{i}}}{\sum_{i=1}^{12} b_{i}}
$$

where $b_{i}=f(i) / 30$

and $f(i)$ is the number of days in a given month.

Again, the purpose here is to give all seasons over the year equal weight. The number of observations is given only for reference.

The Budyko heat flux terms are found using the above assumptions.

b. The final line of the annual summary is the average over the entire $10^{\circ}$ square. The method is similar to that described in section II.C.4.a, above, except that the seasonal average $\bar{X}$ replaces the regiona1 average $\bar{x}_{a 6}$.

II.D Storage and access to heat flux volumes

The heat flux summaries are stored as a separate volume for each $10^{\circ}$ square. Each volume is identified by Marsden number, latitude-1ongitude range, and sea. The volumes are currently stored in Clark Laboratory, Room 358. A sign-out sheet is located near the volumes. Please list your name, telephone extension, volume taken, date out and date returned. 


\section{Climatological TIME SERIES}

The climatological time series is a component of the wllol/chsi archive which grew out of the heat flux study. The monthly averages of envirommental parameters and fluxes have been organized into a time series for the years 1948 through 1972. The time series for each $10^{\circ}$ square has been further processed to produce a statistical summary over a variety of seasonal time frames. The Atlantic Ocean climatology time series has been documented separately in WHOI-79-3 (see Reference 8). An initial analysis of the Atlantic Ocean climatology has been done by Bunker (9).

At the time of this writing, the processed climate files exist for only the Atlantic Ocean (see Figure 7). During the next phase of the climate study data for the Indian Ocean, Mediterranean, and Red Sea areas will be processed and incorporated into the archive.

\section{III.A Storage and access to climatological data}

The climatological component of the CASI archive is available in both printed and computer storage. The computerized data base has associated with it a variety of access and analysis software described briefly in section IV below.

\section{III.A.1 Listed output}

Both the time series of monthly averages and the seasonal statistics files are kept in volumes stored in Room 358 of Clark Laboratory. The monthly average files are divided into two volumes, one each for the North and South Atlantic. The seasonal statistics files are also separated, two volumes each for the North and South Atlantic. All $10^{\circ}$ squares are identified by their Marsden reference number. A single separate volume contains both the time series averages and the seasonal statistics derived from the reports of ocean weather ships.

Because of the quantity of paper, there is only one copy of all volumes. Please try to leave a11 volumes in Room 358 . 
III.A.2 Computer storage of climatological data

The time series of monthly averages, as well as the seasonal statistics, have all been stored for computerized retrieval. The contents and formats of these files are documented in Reference 8 so are only discussed briefly below.

a. Magnetic tape storage

The tape series (CL) for the climate study is currently being stored in the IPC computer center tape vault. It is recommended that you copy the required file onto your own tape or disc for subsequent processing. The climatological files are stored on the magnetic tape in several different formats. An index of the climatological tapes is in Room 358 of the Clark Laboratory.

b. Disc storage

At the time of this writing, most of the time series and seasonal statistics files are being stored on a private disc pack. Each $10^{\circ}$ square is stored as a separate file. The naming conventions and format are compatible with the Xerox labelled tape storage formats. For extensive studies of the climatological data, it probably will be far more efficient to work from this disc, if available. The user may otherwise create his own disc and index file.

The heat flux and climatology studies, as well as a variety of other projects, have initiated the development of numerous computer programs. These programs involve all components of the archive in both accessing and analysis functions. While it is not expected that the analysis programs will meet every researcher's requirements exactly, they may provide a base upon which modifications can be performed. Listed in the following sections are some of the software routines that have been developed or are currently available. 
IV.A Programs using TDF-11 observations

The following programs were developed to read and analyze observations from the TDF-11 series. While the programs have been developed for specific applications or areas, they could be adapted to work on other parameters of $10^{\circ}$ squares.

ASHFLA-M

A. Bunker IPC\#7479 1974-5

This program, in several versions including ASHFLA, performs the heat flux analysis described in section II above. A separate version of the program exists for $10^{\circ}$ squares in the southern hemisphere.

HEFLUVS

A. Bunker IPC\#7353 1973

Computes the mean, standard deviation, minimum, maximum, and number of observations for various environmental parameters.

\author{
ASHVSUM \\ A. Bunker IPC\#7541 1975 \\ An extension of program HEFLUVS to process more parameters. \\ MARSAN 114 \\ Stomme1/Fieux IPC\#7342 1973 \\ Provides a (line printer) graphical and statistical \\ summary of sea surface temperature for Marsden $10^{\circ}$ \\ square 114. \\ AWASTAS \\ M. Fieux IPC\#7467 1974 \\ Graphical depiction of daily average wind velocity over \\ a period of time. \\ ARABSEA \\ M. Fieux IPC\#7437 1974 \\ A printed summary of the air and sea temperatures and \\ wind velocity in the Arabian Sea. \\ Air/Sea Wind Strees Analysis P. Saunders IPC\#7504 1975 \\ Computes the time and geographic distribution of wind \\ stress on the sea surface.
}




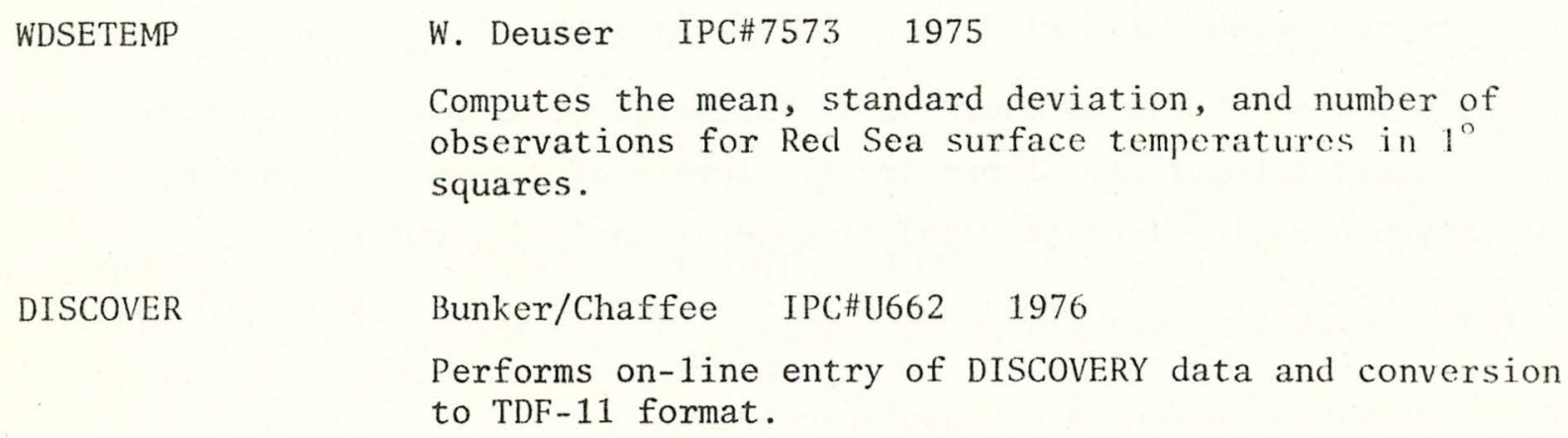

IV.B Programs using heat flux study data

The following programs were developed to process the time series of monthly averages generated by the ASHFLA programs. In general, they are used to establish the data base for the ongoing climatology study.

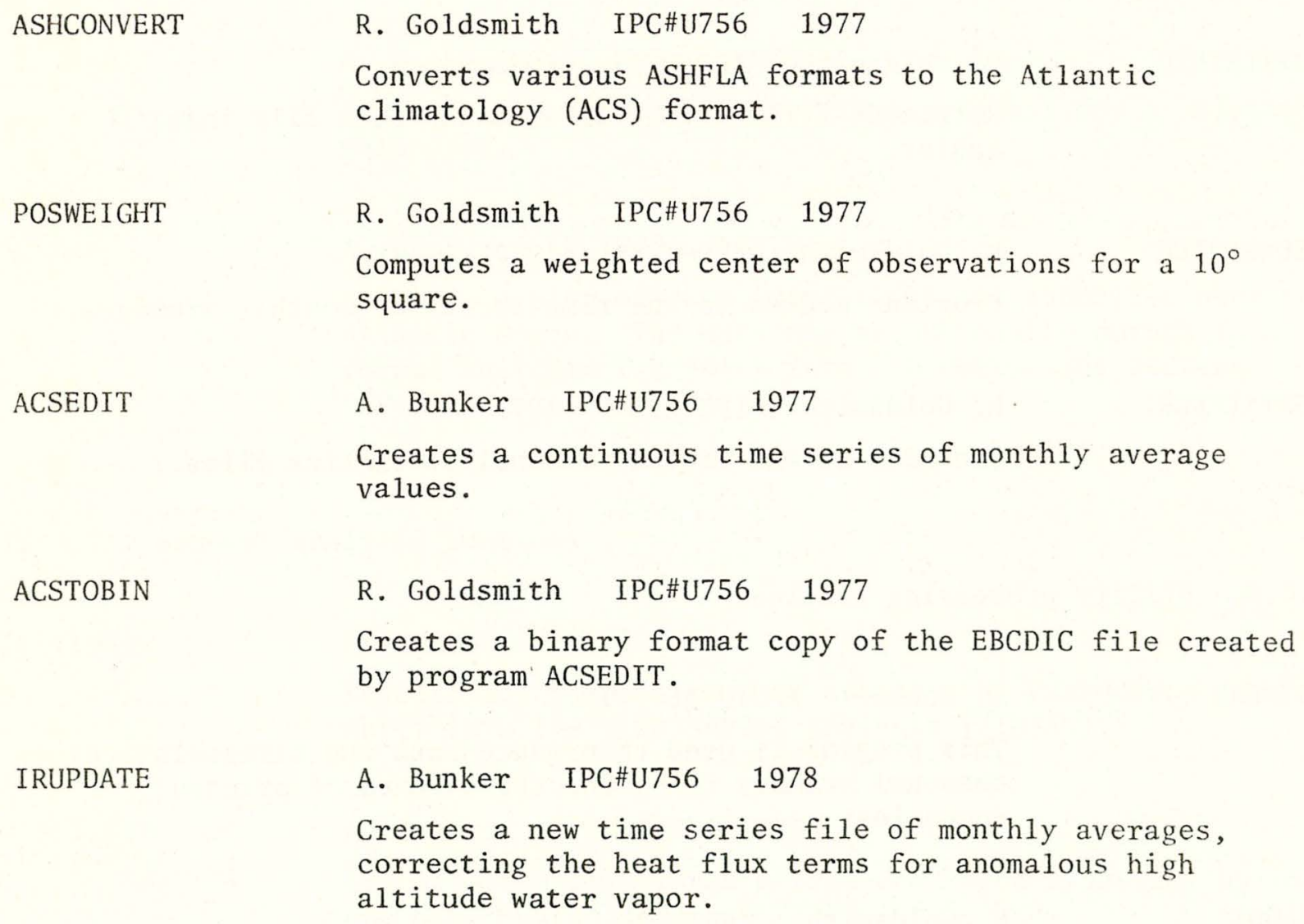

IRUPDATE

A. Bunker IPC\#U756 1978

Creates a new time series file of monthly averages, correcting the heat flux terms for anomalous high altitude water vapor. 
IV.C Programs associated with the climatology study

The study of the climatology of the Atlantic Ocean produced software in three basic categories. These are 1) library of data access routines, 2) utility processing routines, and 3) general analysis routines.

IV.C. 1 Routines to access climatological data

STARTDAT

R. Goldsmith IPC\#U756 1977

Computes the number of months from some initial starting month.

ACSLABEL

R. Goldsmith IPC\#U930 1979

Retrieves parameter, units, and season labels.

ACSFI LEINFO

R. Goldsmith IPC\#U756 1978

Retrieves file storage information from file index tables.

ACSDATAFILE

R. Goldsmith IPC\#U756 1977

Provides access to the time series of monthly averages.

ACSSTATFILE

R. Goldsmith IPC\#U756 1977

Provides access to the seasonal statistics files.

IV.C.2 Utility processing routines

ACSTREND

A. Bunker IPC\#U756 1977

This program is used to produce both the climatological seasonal sumary files and the volumes of printed summaries.

ACSLOOK

R. Goldsmith IPC\#U930 1979

Allows an on-line user to extract data or statistical values.

PARLIST

A. Bunker IPC\#U756 1978

Produces a parameter listing of data values from the monthly averages file. 


\begin{abstract}
ACSDIF
A. Bunker IPC\#U756 1978

Finds $10^{\circ}$ squares with largest departures from local mean for selected parameters.

ACSSDORD

A. Bunker IPC\#U756 1978

Orders the $10^{\circ}$ squares by the seasonal standard deviation for a selected parameter.

ACSPLOT

A. Bunker IPC\#U756 1978

Plots any selected parameter as a function of time for a $10^{\circ}$ square data file.

ACSQPLOT

R. Goldsmith IPC\#U756 1978

Provides plotting of time series data from an intermediate format.

ACSTRAM

A. Bunker IPC\#U930 1979

Produces trend anomaly maps (line printer) for a selected parameter.

ACSMAP

A. Bunker IPCHU756 1978

Produces a plot of data, statistics, or anomalies over the Atlantic Ocean. The data may be optionally output in a format suitable for entry into the contouring routine OPCONT.
\end{abstract}

IV.C.3 General analysis routines

ACSTIMSAN

R. Go1dsmith IPC\#U756 1978

Selects and formats monthly averages of parameters for entry into the time series analysis (TIMSAN).

ACSBIGEIG

A. Bunker IPC\#U930 1979

Computes the covariance matrix and eigenvalues for up to one hundred $10^{\circ}$ squares.

ACSEIGAN

A. Bunker IPC\#U930 1979

Analyzes the eigenvectors produced by ACSBIGEIG, and ranks the $10^{\circ}$ squares by contribution. 
26.

ACSE I GAMP

R. Coldsmith IPCHIJ930 1979

Computes the eigenvector amplitude function. 
REFERENCES

1. Fieux, M., H. Stomme1 1975 Preliminary look at feasibility of using marine reports of sea temperature for documenting climatic change in the Western North Atlantic. J. Mar. Res., 33. Supp. 83-95.

2. Bunker, A.F. 1976 Computations of surface energy flux and annual airsea interaction cycles of the North Atlantic Ocean. Mon. Wea. Rev., 104. pp. 1122-1140.

3. Bunker, A.F., L.V. Worthington 1976 Energy Exchange Charts of the North Atlantic Ocean. Bul1. Amer. Meteor. Soc., 57. pp. 670-678.

4. Bunker. A.F. 1975 Energy Exchange at the Surface of the Western North Atlantic. WHOI Technical Report 75-3.

5. Payne, R.E. 1972 Albedo of the Sea Surface. J. of Atmos. Sci., 29, no. 5. pp. 959-970.

6. Tobata, S. 1973 A simple but accurate formula for saturation vapor pressure over liquid water. J. of App. Meteor., 12. pp. 1410-1411.

7. Budyko, M.I. 1963 Atlas of heat balance of the Earth (in Russian). Academy of Sciences, Moscow, 69 pages. (Also: Budyko, M.I. 1964 Guide to the Atlas of the Heat Balance of the Earth. Translated by I.M. Donehoo. U.S. Dept. of Commerce, WB/T-106, Washington, D.C. 25 pages.)

8. Bunker, A.F. and R. A. Goldsmith 1979 Archived Time Series of Atlantic ocean Meteorological Variables and Surface Fluxes. WHOI-79-3.

9. Bunker, A.F. 1979 Trends of variables and energy fluxes over the Atlantic Ocean from 1948 to 1972. Submitted to Mon. Wea. Rev. 
28.

\section{ACKNOWLEDGMENTS}

The authors would like to acknowledge and thank the following persons who have aided in the development of various components of and assembly of this archive: Dr. Woollcott Smith for his guidance in statistical techniques, Dr. Melvin A. Rosenfeld for his editorial comments in the preparation of this report, Emily Evans for her invaluable aid in typing all the necessary documentation. 
TABLE I.

Parameters most often available from TDF-11 of the Surface Marine observations:

\begin{tabular}{|c|c|c|}
\hline Field & $\begin{array}{l}\text { Character } \\
\text { position }\end{array}$ & Parameter \\
\hline 1 & $01-03$ & Card deck identifier \\
\hline 2 & $04-06$ & $10^{\circ}$ square Marsden reference number \\
\hline 3 & $07-08$ & $1^{\circ}$ subsquare Marsden reference number \\
\hline 4 & 09 & quadrant \\
\hline 5 & $10-12$ & 1atitude \\
\hline 6 & $13-16$ & 1ongitude \\
\hline 7 & $17-20$ & year \\
\hline 8 & $21-22$ & month \\
\hline 9 & $23-24$ & day \\
\hline 10 & $25-26$ & hour - GMT \\
\hline 11 & $27-29$ & wind direction \\
\hline 12 & $30-33$ & wind speed \\
\hline 13 & $34-36$ & visibility \\
\hline 14 & $37-38$ & present weather code \\
\hline 15 & 39 & past weather code \\
\hline 16 & $40-44$ & sea 1 eve1 pressure \\
\hline 17 & $45-48$ & air temperature \\
\hline 18 & $49-51$ & wet bulb temperature \\
\hline 19 & $52-54$ & dew point temperature \\
\hline 20 & $55-57$ & sea surface temperature \\
\hline 21 & $58-60$ & air-sea temperature difference \\
\hline 22 & 61 & total cloud amount \\
\hline 22 & 62 & lower cloud amount \\
\hline 22 & 63 & type of low cloud code \\
\hline 22 & 64 & cloud height code \\
\hline 22 & 65 & cloud height \\
\hline 22 & 66 & type of middle cloud code \\
\hline 22 & 67 & type of high cloud code \\
\hline 23 & $68-69$ & direction of waves \\
\hline 24 & 70 & period of waves \\
\hline 25 & $71-72$ & height of waves \\
\hline
\end{tabular}


30.

TABLE II .

TDF-11 data requirements for the heat flux study.

Variable

Units

Marsden $10^{\circ}$ square

Marsden $1^{\circ}$ subsquare

Latitude, $\phi$

degrees

Year

Month, m

Day, d

Wind direction code indicator, $D_{I}$

Wind direction code, $D_{2}$

Wind speed, $W$

knots

Present Weather Code, $W_{c}$

Sea level pressure, $P$

millibars

Air temperature, $\mathrm{T}_{\mathrm{a}}$

${ }^{\circ} \mathrm{C}$

Dew point temperature, $\mathrm{T}_{\mathrm{d}}$

Sea surface temperature, $T_{S}$

${ }^{\circ} \mathrm{C}$

Air-sea temperature difference, $\mathrm{T}_{\text {as }}$

${ }^{\circ} \mathrm{C}$

Total cloud amount, $\mathrm{N}_{\mathrm{T}}$

${ }^{\circ} \mathrm{C}$

Lower or middle cloud amount, $\mathrm{N}_{\mathrm{L}}$

oktas

oktas 
TABLE III.

Direction from which wind is blowing, $f\left(D_{1}, D_{2}\right)$, as a function of $D_{1}$, the wind direction code indicator, and $D_{2}$, the wind direction code.

WIND SECPOR CLASSIFICATION

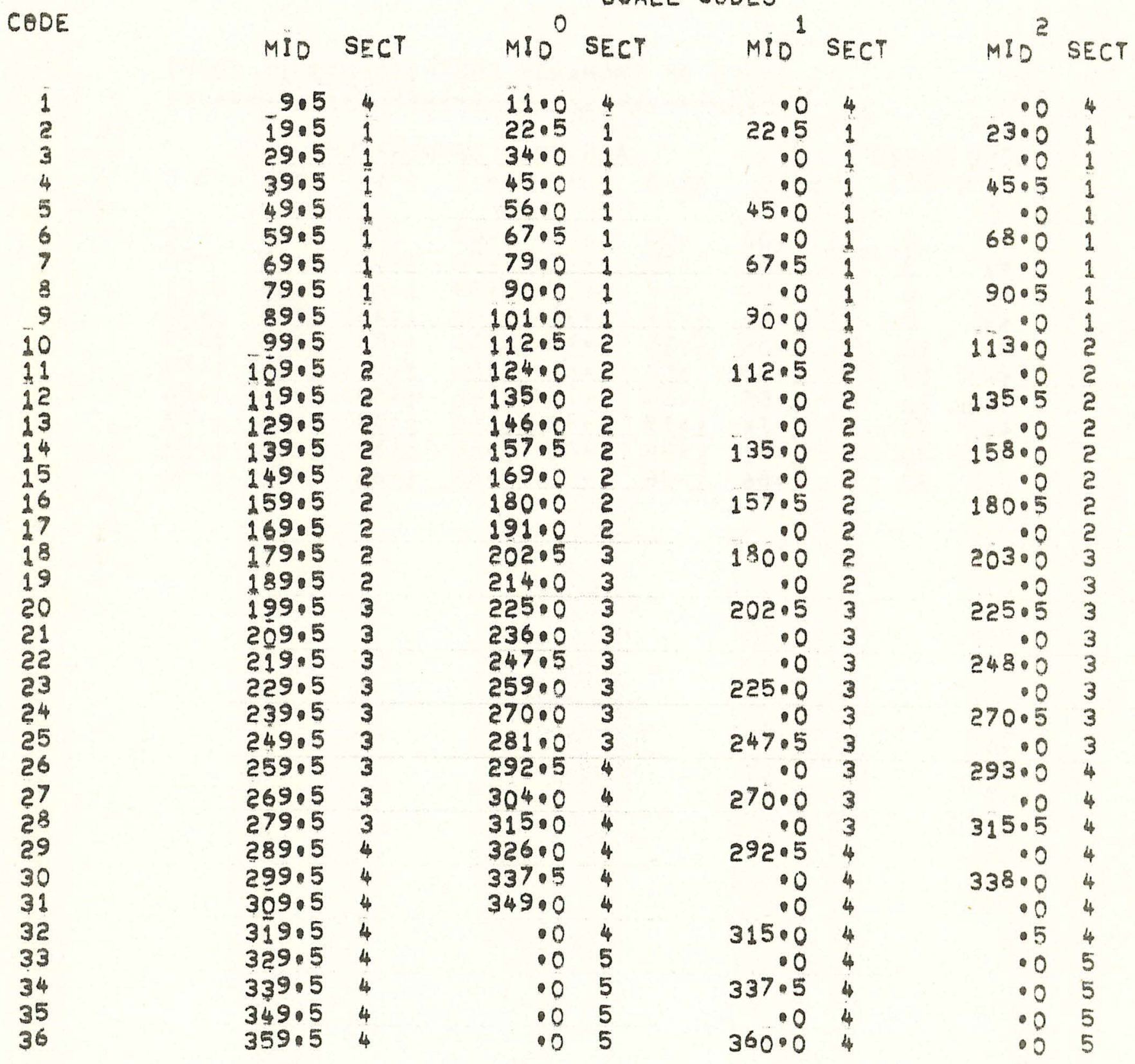


Exchange Coefficient $C_{E}=f\left(W, T_{\text {as }}\right)$

TABLE OF EXCHANGE CQEFFICIENTS (X 1000)

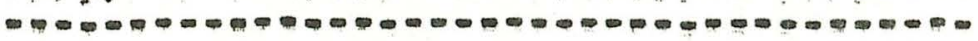

WIND SPEED

( $M / S E C)$

$\begin{array}{rr}r & 0 \\ < & 3 \\ < & 6 \\ <\% & 9 \\ < & 12 \\ < & 15 \\ < & 20 \\ < & 25 \\ < & 30 \\ > & 30\end{array}$

AIRUSEA TEMPERATURE (C)

$\begin{array}{rrrrrrrr}>5.0 & >1.0 & >0.2 & >.02 & >1.10 & >50 & <5.0 \\ .00 & .00 & .00 & .00 & .00 & .00 & .00 \\ .07 & 030 & .72 & 1.32 & 1.65 & 2.05 & 2.52 \\ 022 & .67 & 1.12 & 1.34 & 1.45 & 1.68 & 2.01 \\ .69 & 1.17 & 1.36 & 1.44 & 1.46 & 1.58 & 1.79 \\ 1.06 & 1.36 & 1.48 & 1.53 & 1.58 & 1.65 & 1.79 \\ 1.39 & 1.58 & 1.61 & 1.64 & 1.68 & 1.74 & 1.84 \\ 1.59 & 1.68 & 1.75 & 1.80 & 1.82 & 1.86 & 1.94 \\ 1.74 & 1.79 & 1.83 & 1.86 & 1.88 & 1.86 & 1.93 \\ 1.81 & 1.84 & 1.85 & 1.86 & 1.87 & 1.88 & 1.90 \\ 1.86 & 1.86 & 1.36 & 1.86 & 1.86 & 1.86 & 1.86\end{array}$


Albedo of the sea surface, $f(m, \phi)$, as a function of $m$, the month, and $\phi$, the 1atitude. (From Reference 5.)

For the Northern Hemisphere:

ALBEDO TABLE

- 0 - 00000

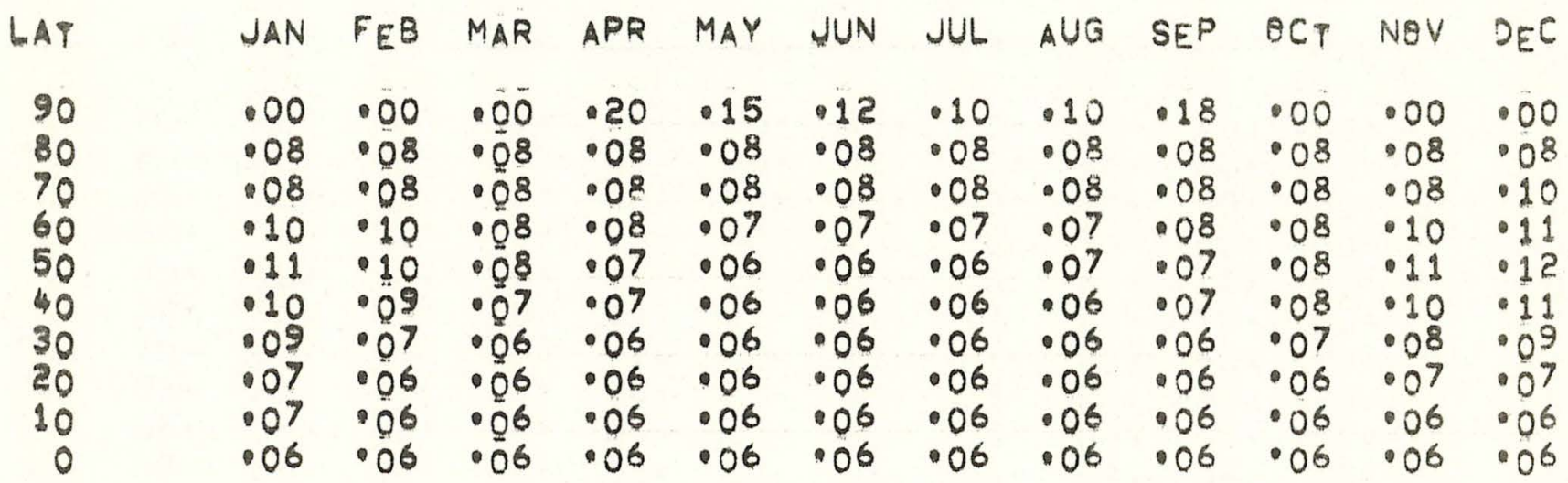


Albedo of the sea surface, $f(m, \phi)$, as a function of $m$, the month, and $\phi$, the latitude. (From Reference 5.)

For the Southern Hemisphere:

ALEEDR TABLF

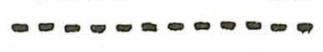

$\begin{array}{rllllllllllll}\text { LAT } & \text { JAN } & \text { FEB } & \text { MAR } & \text { APR } & \text { MAY } & \text { JUN } & \text { JUL } & \text { AUG } & \text { SEP } & \text { ACT } & \text { NQV } & \text { DEC } \\ 0 & .06 & .06 & .06 & .06 & .06 & .06 & .06 & .06 & .06 & .06 & .06 & .06 \\ 10 & .06 & .06 & .06 & .06 & .06 & .06 & .06 & .06 & .06 & .06 & .06 & .06 \\ 20 & .06 & .06 & .06 & .06 & .07 & .07 & .07 & .06 & .06 & .06 & .06 & .06 \\ 30 & .06 & .06 & .07 & .09 & .09 & .09 & .09 & .06 & .07 & .07 & .06 & .06 \\ 40 & .06 & .07 & .08 & .09 & .10 & .10 & .10 & .09 & .08 & .07 & .06 & .06 \\ 50 & .06 & .07 & .08 & .09 & .11 & .11 & .11 & .09 & .08 & .07 & .06 & .06 \\ 60 & .07 & .08 & .09 & .10 & .11 & .11 & .11 & .10 & .09 & .08 & .07 & .07 \\ 70 & .55 & .55 & .55 & .80 & .80 & .80 & .80 & .80 & .80 & .55 & .55 & .55 \\ 80 & .80 & .80 & .80 & .80 & .80 & .80 & .80 & .80 & .80 & .80 & .80 & .80 \\ 90 & .80 & .80 & .80 & .80 & .80 & .80 & .80 & .80 .80 .80 & .80 & .80 & .80\end{array}$


TABLE VI.

\section{C - long wave radiation cloud cover coefficient from Budyko (see Reference 7).}

\begin{tabular}{rc} 
Latitude & C \\
\hline 0 & .48 \\
10 & .52 \\
20 & .59 \\
30 & .63 \\
40 & .68 \\
50 & .72 \\
60 & .76 \\
70 & .80 \\
80 & .84 \\
90 & .88
\end{tabular}


Drag coefficient $C_{D}=f\left(W, T_{\text {as }}\right)$

TABLEE OF DRAG COEFFICIENTS $(X 1000)$

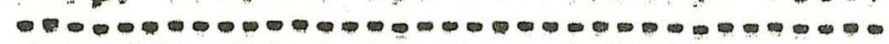

WINO SPEED

( M/SEC)

$>5 \cdot 0$

AIRISEA TEMPERATURE (C)

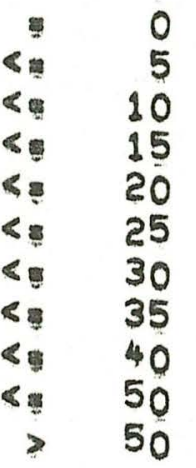

$\begin{array}{rr}.00 & .00 \\ .06 & .60 \\ .77 & 1.30 \\ 1.47 & 1.72 \\ 1.95 & 2.04 \\ 2.26 & 2.30 \\ 2.52 & 2.54 \\ 2.78 & 2.79 \\ 3.00 & 3.00 \\ 3.20 & 3.20 \\ 3.40 & 3.40\end{array}$

$>0.2$

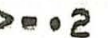

$\rightarrow 10$

$\rightarrow 5 \cdot<5 \cdot 0$

5

$.00 \quad .00$

.00

$.00 \quad .00$

.98

$1 \cdot 20$

1.32

1.561 .80

1043

1054

1.87

1.60

1.90

$1 \cdot 78 \quad 1.86$

2010

2.16

2.22

$2.00 \quad 2.10$

$2 \cdot 35$

2.40

$2 \cdot 42$

2. $25 \quad 2.32$

2.57

2.60

2062

20442.48

2.80

2.80

2080

$2.63 \quad 2.64$

3.00

3.00

3.00

2.80

2.80

3.20

3.20

3.20

3.00

$3 \cdot 00$

3040

$3 \cdot 40$

3.40

3.403 .40 
Solar radiation received at the bottom of the atmosphere under cloudless conditions: $Q_{0}=f(m, \phi)$ where $m$ is the month and $\phi$ is the latitude. Converted to watts meter $^{-2}$ from Reference 7.

For the Northern Hemisphere:

SOLAR RADIATION TABLE

BOTTOM OF. ATMOSPHERE - (WATTS/METER

LAT JAN FEB MAR APR MAY JUN JUL AUG SEP ECT NOV DEC

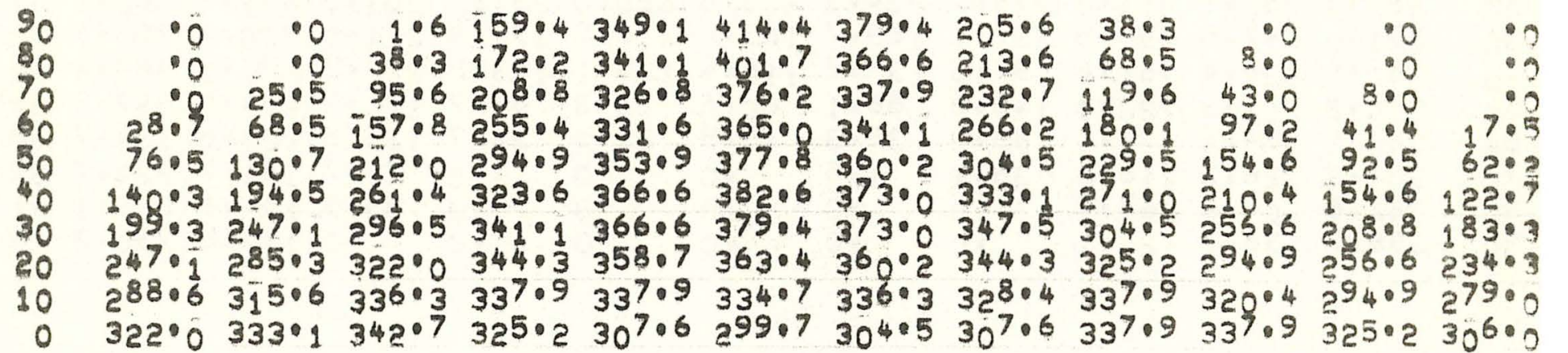


Solar radiation received at the bottom of the atmosphere under cloudless conditions: $Q_{0}=f(m, \phi)$ where $m$ is the month and $\phi$ is the latitude. Converted to watts meter $^{-2}$ from Reference 7.

For the Southern Hemisphere:

SELAQ RADIATION TABLE

BQTTOM OF ATMOSPHERE - (WATTS/METER\#2)

AT JAN FEB MAR APR MAY ULN JUL AUG SEP $D C T$ NGV DEC

- $322 \cdot 0 \quad 333 \cdot 1 \quad 342 \cdot 7 \quad 325 \cdot 2 \quad 307 \cdot 6 \quad 299 \cdot 7 \quad 304 \cdot 5 \quad 307 \cdot 6 \quad 337 \cdot 9 \quad 337 \cdot 9 \quad 325 \cdot 2 \quad 306 \cdot 0$ $10 \quad 350 \cdot 7 \quad 347.5 \quad 336 \cdot 3 \quad 306 \cdot 0 \quad 282 \cdot 1 \quad 259 \cdot 8 \quad 259 \cdot 8 \quad 275 \cdot 8 \quad 325 \cdot 2 \quad 341 \cdot 1 \quad 347 \cdot 5 \quad 350 \cdot 7$

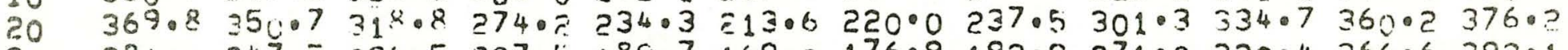

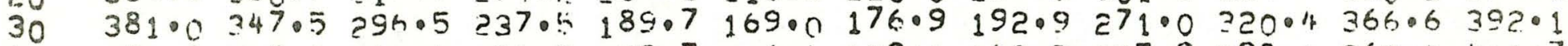
$40 \quad 38.2 \cdot 6 \quad 328.4261 \cdot 4194 \cdot 5 \quad 138.71160412901143 .5227 .929801363 \cdot 4401.7$ $50 \quad 376.2 \quad 301.3220 \cdot 0146.5 \quad 86 \cdot 1 \quad 60.6 \quad 73 \cdot 3 \quad 87.7 \quad 191 \cdot 3 \quad 264 \cdot 6 \quad 347 \cdot 5 \quad 398 \cdot 5$ $60 \quad 360 \cdot 2 \quad 26406 \quad 174.4 \quad 89 \cdot 3 \quad 38 \cdot 3 \quad 15 \cdot 9 \quad 25 \cdot 5 \quad 36 \cdot 7 \quad 135 \cdot 5 \quad 22408 \quad 334 \cdot 7 \quad 388.9$

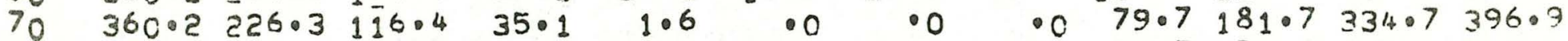

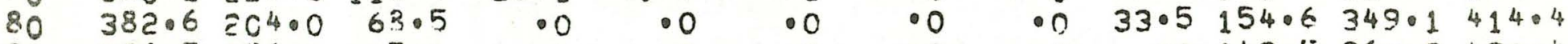

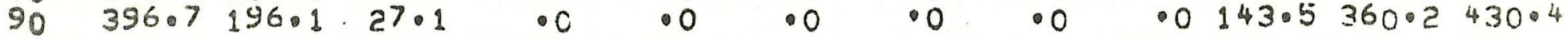



$A_{c}$ - Incoming solar radiation cloud cover coefficient from Budyko (see Reference 7).

\begin{tabular}{c} 
Latitude \\
\hline 0 \\
5 \\
10 \\
15 \\
20 \\
25 \\
30 \\
35 \\
40 \\
45 \\
50 \\
55 \\
60 \\
65 \\
70 \\
75 \\
80 \\
85 \\
90
\end{tabular}

$A_{c} c$ loud cover
.38
.40
.40
.39
.37
.35
.36
.38
.38
.38
.40
.41
.36
.25
.18
.16
.15
.00
.00


40.

TABLE $X$.

Variable key for monthly and yearly averages.
VARIABLE KEY FOR MONTHLY ANO YEARLY AVERAGES

W

FIELD NG. IDENTIFIER DESCRIPTION

UNITS

(C)

$(c / K G)$

(c)

(C)

(BKTAS)

( $M / S E C)$

$(M / S E C)$

$(M / S E C)$

(FRAM O VARTH)

(PASCALS)/120

(NATTS/METER*Z)

(NATTS,METE' D)

(WATYS/METER*\#2)

(WATTS/METE? 吕?)

(WATTS/METEQ*\#?)

(WATTS,METEP \#2)

(WATTSMIMTER* *)

(WATTS/METEPW है?

(WATYS/METER**?)

(PASCALS)

(PASCALS) 
TABLE XI.

Variable key for seasonal summaries by region and sector

VARIABLE KEY FOR SEASENAL SUMNARIES BY AREA ANID SECTOR

FIELC NO. IDENTIFIER DESCRIPTIGN UNITS

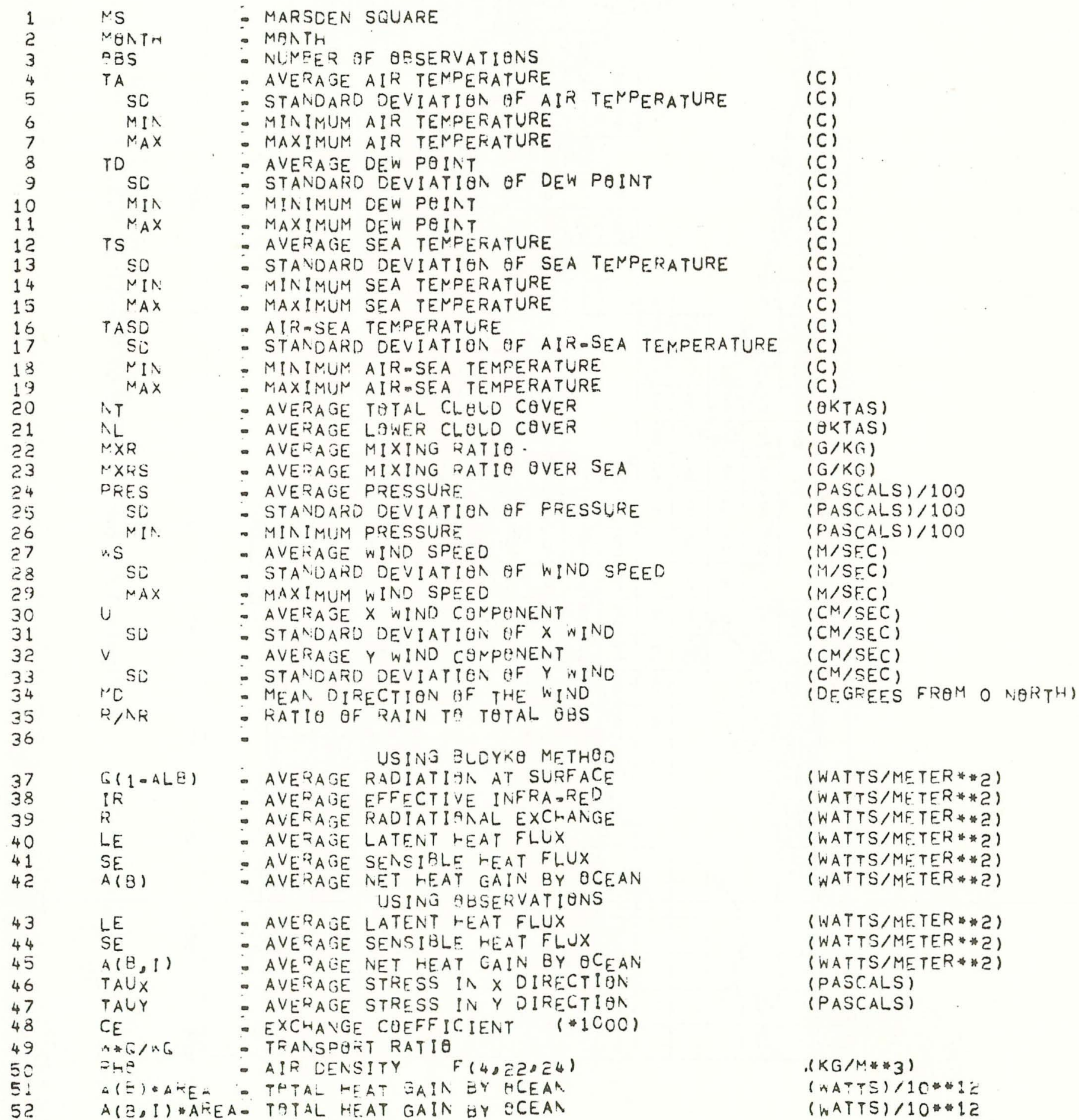




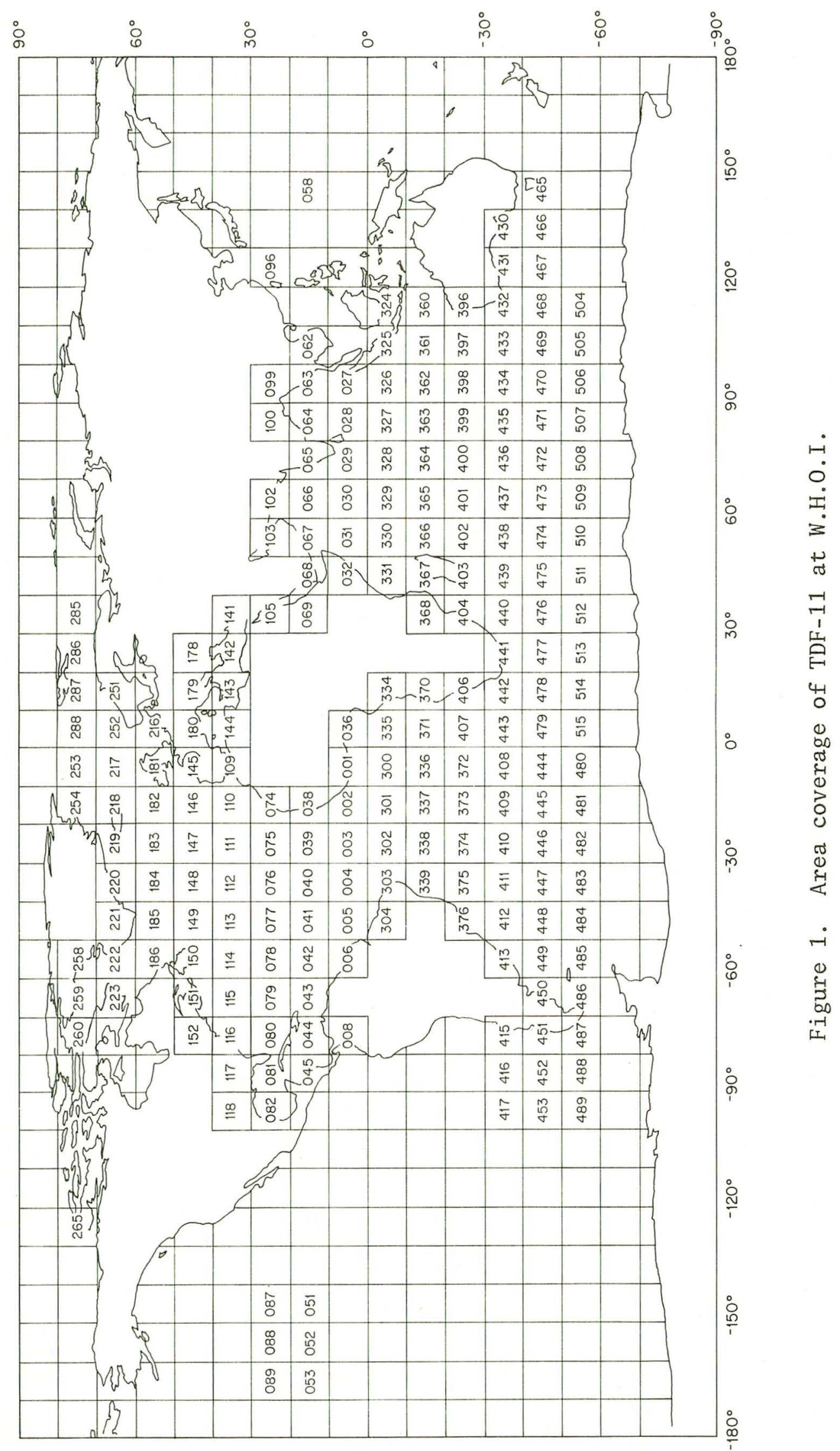


Figure 2. Example of WHOI/TDF-11 Index

\begin{tabular}{|c|c|c|c|c|c|c|c|c|c|c|c|}
\hline \multirow[b]{2}{*}{ MS } & \multirow[b]{2}{*}{$M N /$} & \multirow[b]{2}{*}{$Y R$} & \multirow[b]{2}{*}{ I } & \multirow[b]{2}{*}{ MN / } & \multirow[b]{2}{*}{$Y K$} & \multirow[b]{2}{*}{ IAPE } & \multicolumn{2}{|c|}{ INDICATES } & \multicolumn{2}{|c|}{ A $7 T$ TAPE } & \multirow{2}{*}{$\begin{array}{l}\text { CLRK 358 } \\
\text { LACATIOA }\end{array}$} \\
\hline & & & & & & & LAT & LHNG & F $A E S$ & ONNER & \\
\hline & & & & & & & & & & BUNKER & CLRK 358 \\
\hline 001 & 06 & 1855 & & 04 & 1973 & $B A A 1$ & $5 N$ & 5.4 & 96250 & BUNKER & CLRK 358 \\
\hline 002 & 12 & 1900 & & 13 & 1924 & BAAC & $5 N$ & $15 w$ & 110000 & BUNKER & CLRK 358 \\
\hline 002 & 12 & 1424 & & 12 & 1972 & $B A A 3$ & $5 N$ & $15 w$ & 106890 & SUNKER & CLRK 358 \\
\hline 003 & 01 & 1863 & & 04 & 1923 & $B A A 4$ & $5 v$ & $25 w$ & 110000 & DUNKER & CLRK 358 \\
\hline 003 & 04 & 1423 & & 12 & 1972 & BAAS & 54 & 25. & 8607 & BUNKER & CLRK 358 \\
\hline 004 & 03 & 1923 & & 13 & 1972 & $B A A G$ & $5 N$ & $35 . w$ & 52430 & BUNKER & CLRK 358 \\
\hline 005 & 11 & 15041 & & 04 & 1907 & $\triangle A A G$ & $5 N$ & $35 w$ & 57570 & BUAKER & CLRK 358 \\
\hline 005 & 04 & 1967 & & 13 & 1972 & $\triangle A A 7$ & $5 \mathrm{~N}$ & $45 \mathrm{iN}$ & 29650 & SUNKER & CL2K 358 \\
\hline 006 & 08 & 1941 & & $1=$ & 1972 & $\triangle A A 7$ & $5 \mathrm{~N}$ & $55 w$ & 48500 & BUNKER & CLRK 358 \\
\hline 008 & 01 & 1942 & & 07 & 1908 & $B A A 7$ & $5 \mathrm{~N}$ & $75 w$ & 52000 & DUNKER & CLRK 358 \\
\hline 008 & 07 & 1953 & & 12 & 1972 & $\triangle A A Y$ & $5 N$ & $75 \%$ & 13000 & DUNKER & CLLK 358 \\
\hline 027 & 02 & 1921 & & & & $B A J 3$ & $5 \mathrm{~N}$ & $95 t$ & & BUNKEEK & CLRK 352 \\
\hline 027 & & & & & & $B A J_{4}$ & 51 & 95E & & BUNKER & CLRK 358 \\
\hline 027 & & & & 12 & 1972 & $B A J 5$ & $5 N$ & $95 E_{-}$ & & BUNKER & CLRK 358 \\
\hline 028 & 02 & 1914 & & $0^{\circ}$ & 1934 & $B A J 6$ & $5 N$ & $85 \mathrm{E}$ & 190000 & BUNKER & CLRK 358 \\
\hline 028 & 09 & 1934 & & $\mathrm{O}_{4}$ & 1966 & $B A 99$ & $5 \mathrm{~N}$ & $85 E$ & 210000 & BUAKER & CLRK 358 \\
\hline 028 & 09 & 1934 & & 13 & 1966 & $\forall A J 7$ & $5 \mathrm{~N}$ & प.5E & & DUNKER & CLRK $35 \Omega$ \\
\hline 028 & 12 & 1906 & & 12 & 1974 & $B A J C$ & $5 N$ & K5E & & BUNKER & CLRK $35 \%$ \\
\hline 029 & 11 & $1 \times 55$ & & $\mathrm{OH}$ & 1921 & FMAS & $5 N$ & $75 E$ & 100000 & STAMMEL & PARIS FR \\
\hline 029 & 04 & 1921 & & 22 & 1935 & $F M B Y$ & $5 N$ & $15 E$ & 100000 & STEMMF & PARIS FH \\
\hline 029 & 02 & 1935 & & $0 ?$ & 1906 & FMCY & $5 v$ & $75 \mathrm{E}$ & 100000 & STEMMEL & PARIS FR \\
\hline 029 & 03 & 1966 & & 04 & 1973 & FMDY & $5 \mathrm{~V}$ & $75 E$ & 20bon & SI BMMEL & PARISFQ FQ \\
\hline 030 & 11 & 1356 & & 01 & 1924 & F:10S & $-5 v$ & S5E & 39000 & STEMMEL & PAVIS FE \\
\hline 030 & 01 & 1924 & & 09 & 1954 & $F M A O$ & $5 N$ & $65 E$ & 100000 & STGMMEL & HARIS FR \\
\hline 030 & 09 & 1954 & & $0 ?$ & 1973 & FMBO & $5 \mathrm{v}$ & 65E & 25400 & SIEMPEL & PARIS FE \\
\hline 031 & 01 & $1 \times 57$ & & $1=$ & 1972 & $F M A 1$ & $5 \mathrm{~N}$ & $55 E$ & प्र5200 & ST AMMEL & PARIS FR \\
\hline 032 & 01 & 1857 & & 05 & 1926 & FMA 1 & $5 \mathrm{~V}$ & $45 E$ & 5000 & ST GMMFL & PARIS FR \\
\hline 032 & 06 & 1 प्र6 & & 12 & 1972 & FMBZ & $5 \mathrm{~N}$ & $45 E$ & 1.5500 & STEMMEL & PARIS FR \\
\hline 035 & 01 & 1941 & & 10 & $197 ?$ & $\triangle A A B$ & $5 x$ & $5 E$ & 19170 & SUNKER & CLRK 355 \\
\hline 038 & 09 & 1931 & & on & 1908 & $B A A Y$ & $15 \mathrm{~N}$ & $15 \mathrm{w}$ & 130000 & BUIVKER & CLRK $35 \%$ \\
\hline 038 & 06 & 1968 & & 13 & 1972 & $B A B 1$ & $15 v$ & $15 \mathrm{~N}$ & 53000 & DUNKER & CLRK $35 \%$ \\
\hline $039^{\circ}$ & 04 & 1930 & & $1=$ & 1972 & $B A B 2$ & $15 \mathrm{~V}$ & 25.4 & 120000 & SUNKER & CLKK 358 \\
\hline $0^{4} 0$ & 03 & 2859 & & 12 & 1972 & $B A 63$ & $15 \mathrm{~N}$ & $35 w$ & 83300 & BUNKEK & CLKK $35 \%$ \\
\hline 041 & 07 & 1937 & & $9=$ & 1972 & $\triangle A B 4$ & $15 \mathrm{~N}$ & $45 w$ & 30900 & BUSKER & CLRK 358 \\
\hline 042 & & & & in & 1903 & $B A B 34$ & $15 \mathrm{~A}$ & $55 w$ & 40570 & DUNKES & CLRK 358 \\
\hline 042 & 12 & 1963 & & 12 & 1972 & $B A B 5$ & $15 \mathrm{~N}$ & $55 \mathrm{~N}$ & $\times 9100$ & BUAKER & CLKK 358 \\
\hline 043 & 03 & 1934 & & $0^{9}$ & 1956 & BAAB 6 & $15 \mathrm{~N}^{\circ}$ & $65 \mathrm{~W}$ & $12000 ?$ & BUNKER & CL2K 358 \\
\hline 043 & 09 & 1456 & & $0^{4}$ & 1965 & $B A B 7$ & $15 \mathrm{~N}$ & $65 w$ & 120000 & BUNKER & CL2K 350 \\
\hline 043 & $0^{4}$ & 1965 & & $0^{7}$ & 1972 & SABS & $13 \mathrm{~V}$ & $65 N$ & $12000 ?$ & HUAKER & CLFK $35 \%$ \\
\hline 043 & 07 & $1 y 7 \tilde{c}$ & & 19 & $1 \ni 72$ & BADY & 151 & $65 N$ & 6600 & $51, A K E R$ & CL2K $35 \bar{E}$ \\
\hline 044 & 01 & 1941 & & $0^{\circ}$ & 1949 & $\forall A B Y$ & $15 \mathrm{~N}$ & $75 \mathrm{v}$ & $11337 ?$ & SUAKES? & CLRK 333 \\
\hline 044 & 08 & 1943 & & $0^{\circ}$ & 1960 & BAC1 & $15 \mathrm{~N}$ & $7,5.1$ & 123000 & जIJAKEK & CLRK 358 \\
\hline 044 & 09 & 1400 & & In & 1968 & $\triangle A C Z$ & $15 \mathrm{~N}$ & 75.1 & 123007 & $B U A K E K$ & CLRK $35 \%$ \\
\hline 044 & 10 & 1968 & & 13 & 1972 & $\forall A C 3$ & $15 N$ & $75 w$ & 56600 & DUN.KER & CLZK $35 \%$ \\
\hline 045 & 01 & 1942 & & Or & 1955 & $\triangle A C 3$ & $15 \mathrm{~N}$ & KSW & 16600 & BUAKER & CLFK $35 \%$ \\
\hline 045 & 06 & 1455 & & 04 & 197 ? & $\triangle A C 4$ & $15 \mathrm{~N}$ & $85 n$ & 123000 & $B 1 . M ; K E^{\prime 2}$ & CLKK 358 \\
\hline 045 & 01 & $147 ?$ & & 12 & 1972 & EACS & $15 \mathrm{~V}$ & $85 \mathrm{~N}$ & 1800 & SUNKER & CL2K 358 \\
\hline 051 & 06 & 1057 & & 24 & 1959 & $K(020$ & $15 \mathrm{~N}$ & $145 \mathrm{~N}$ & 74400 & MILLEK & CAYH C.TR \\
\hline 051 & 04 & 1459 & & & & $\mathrm{KC}: 21$ & $15 \mathrm{~N}$ & $145 \mathrm{~N}$ & 1ê00n & MILLER & CANP CTF \\
\hline 002 & & & & & & $+K C ? 1$ & $15 \mathrm{~V}$ & $155 w$ & 8000 & MILLEK & CAMP CTE \\
\hline
\end{tabular}




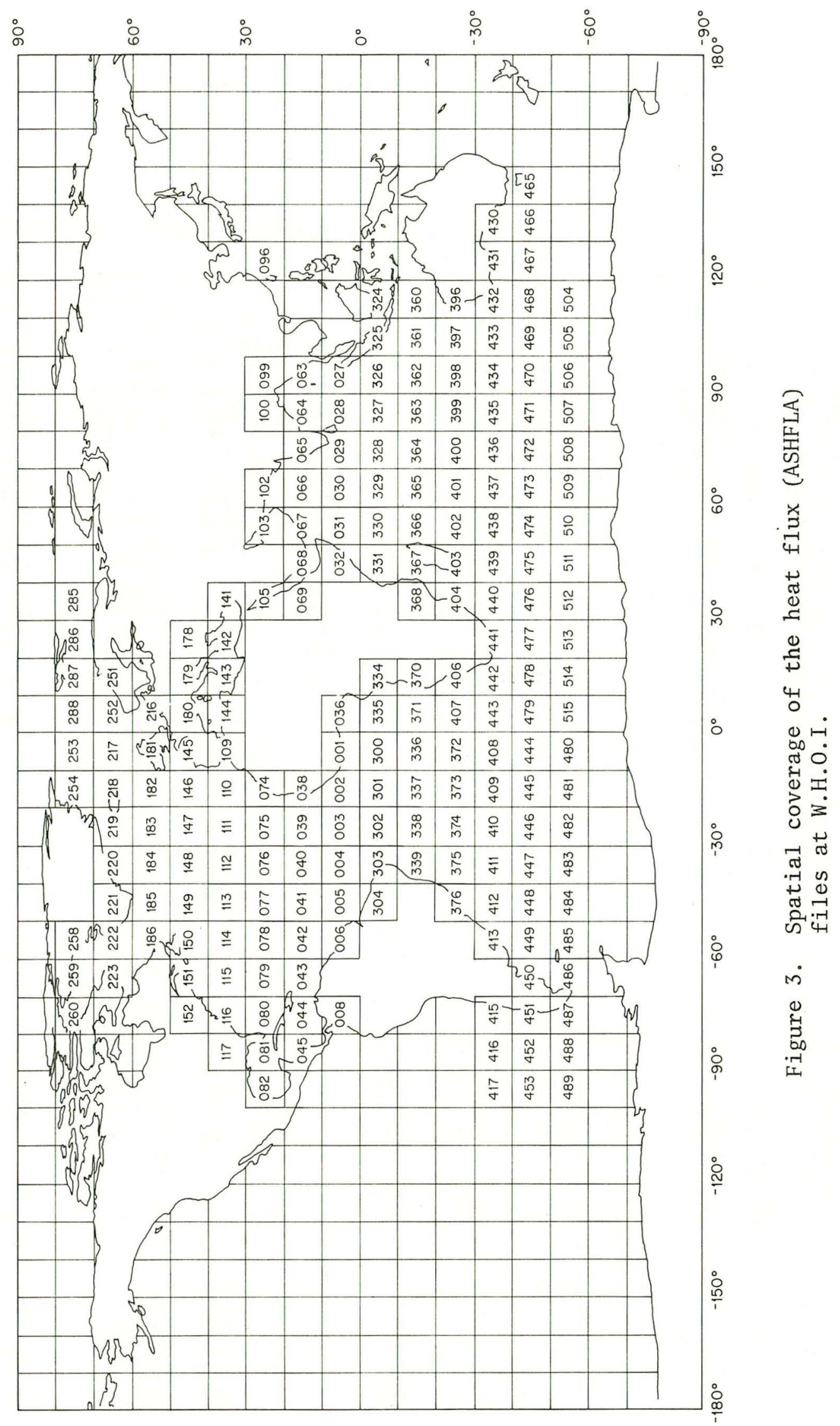




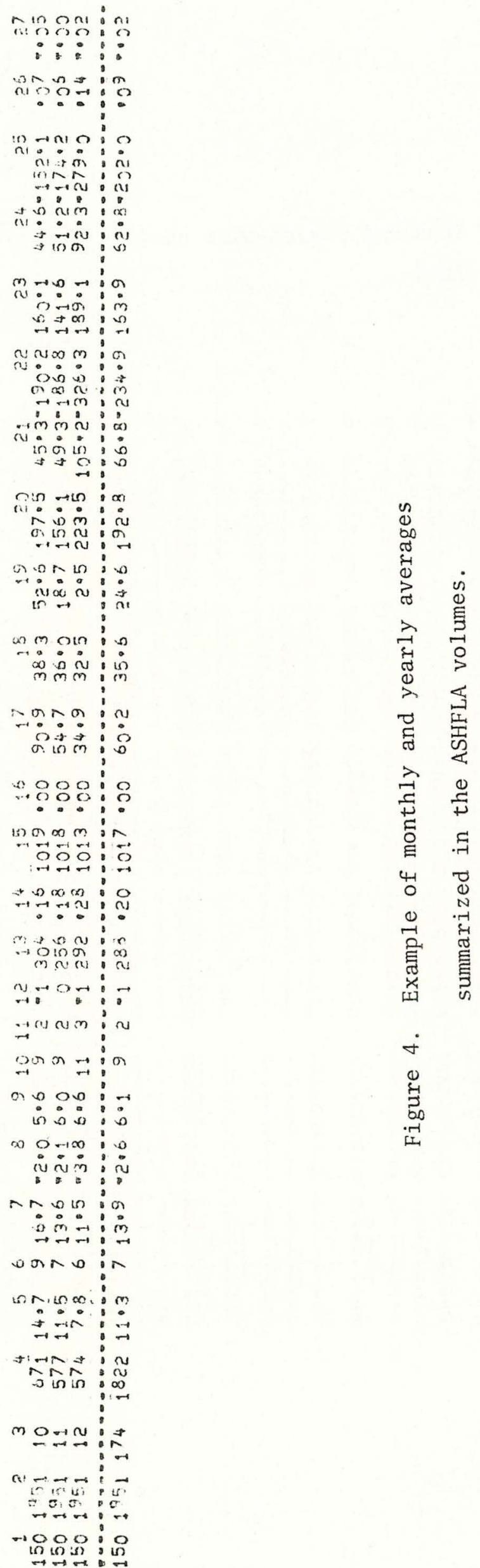


Figure 5. Example of seasonal region-wind sector summary produced in the ASHFLA study.

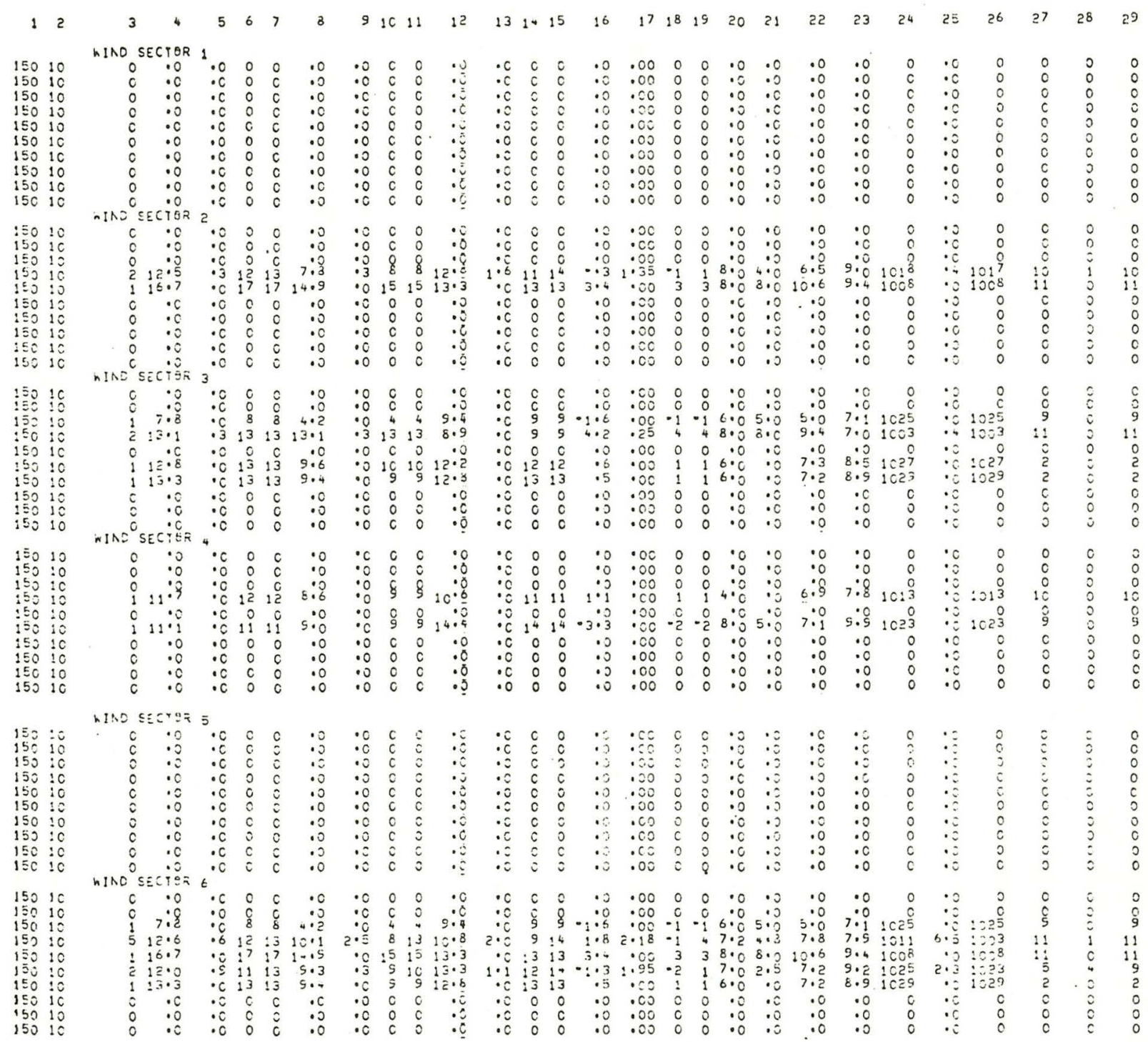




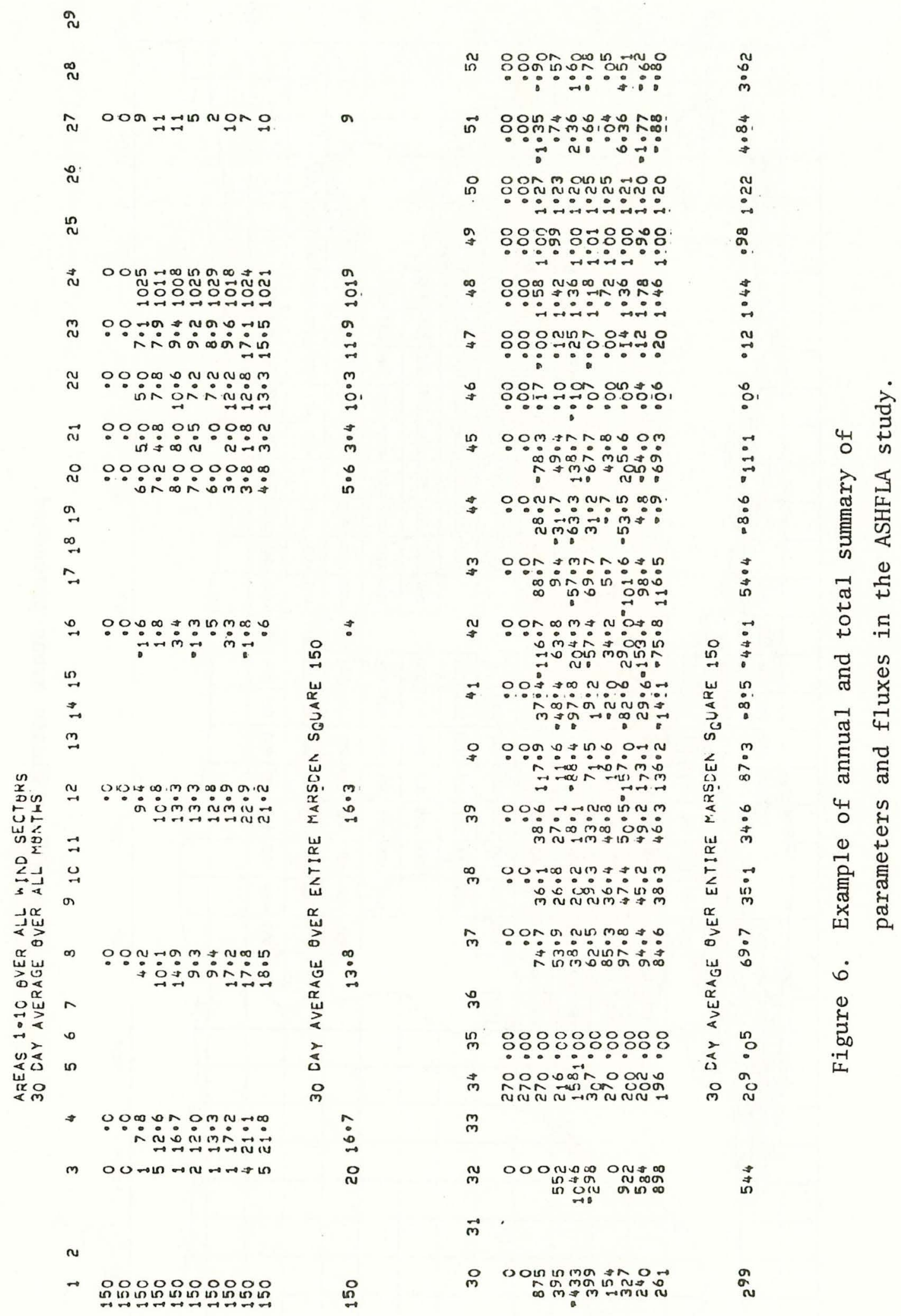


48.

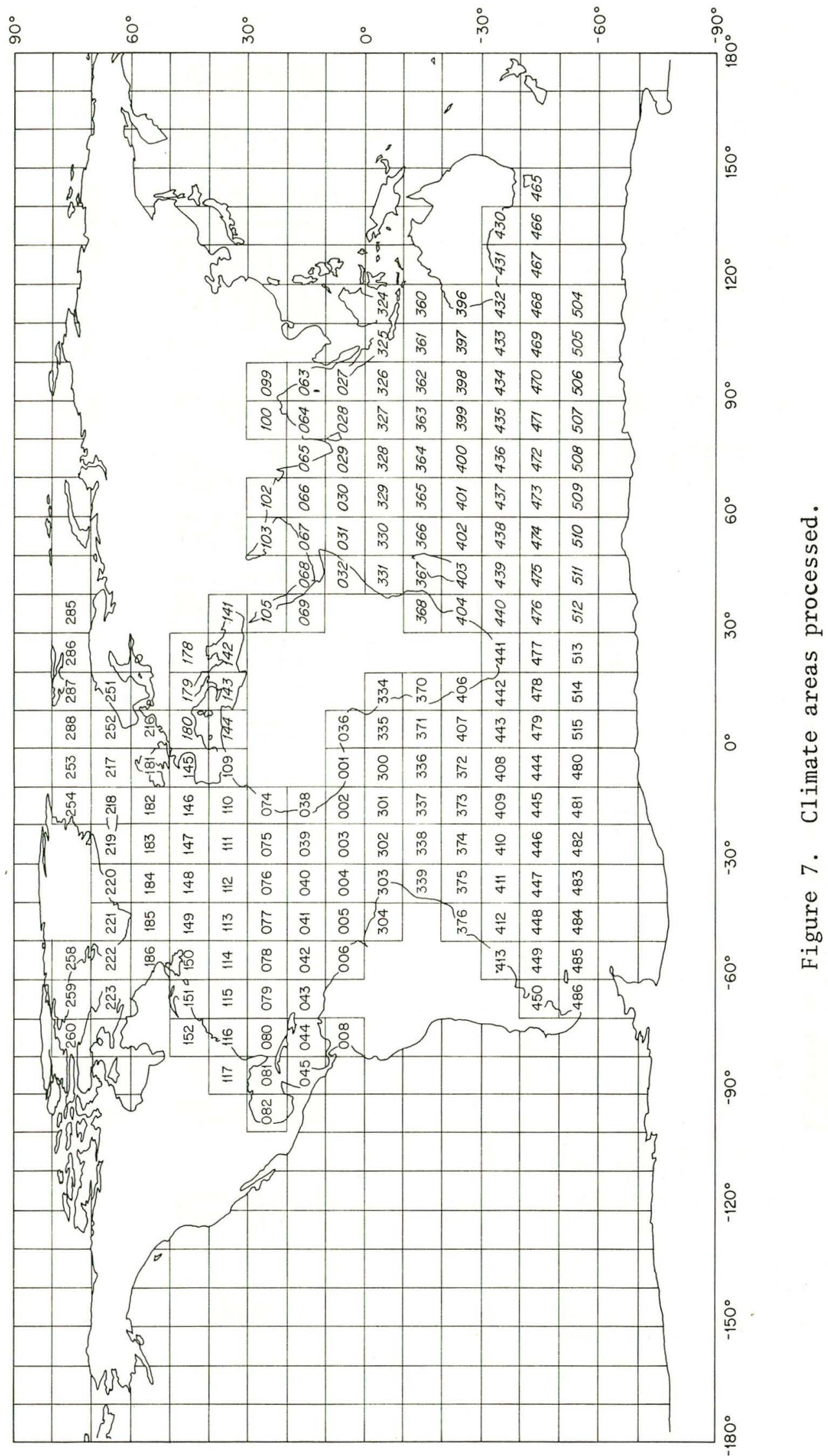


APPENDIX A - National Climatic Center surface marine observations TDF-11 documentation. 
50.

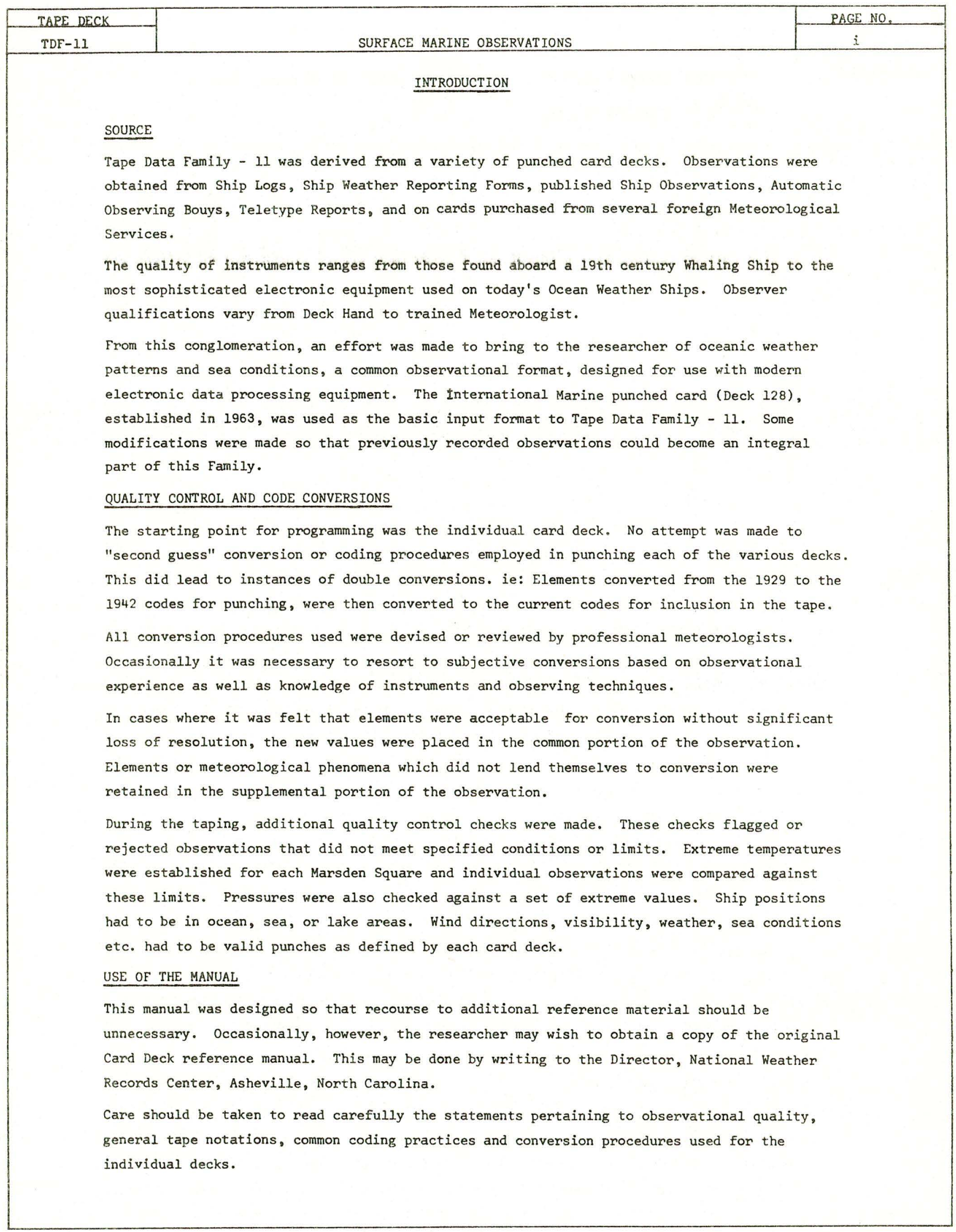


51.

\begin{tabular}{|l|l|l|}
\hline TAPE DECK & PAGE NO. \\
TDF-11 & SURFACE MARINE OBSERVATIONS & ii \\
\hline
\end{tabular}

\section{THE DATA FILE}

Over 31 million Surface Marine observations are currently in Tape Data Family - 1l. They are filed by $10^{\circ}$ Marsden Square, Year, Month without regard to individual deck number. ie: All observations for January 1962 in Marsden Square 051 would be found together, followed by all observations for February 1962 etc. The period 1800- June,1968 is held on 293 reels of 9 channel, $800 \mathrm{bpi}$ tape. It is not anticipated that future acquisitions will be merged into this group, but will be placed on tape in the TDF-1l format and retained as a separate file.

Observations from Ocean Weather Staions were placed in the TDF-ll format but not merged into the common file mentioned above. Currently operating Weather Ships are kept, individually, by station number (See Tape Field 029), while those ships no longer actively reporting have been filed together. Observations are filed by Ocean Weather Station number, Year, Month. These reports were also taken from a variety of card decks.

Funding for the development of TDF-ll was provided jointly by the Naval Weather Service Command, the Environmental Science Services Administration, and the Department of Defense. 


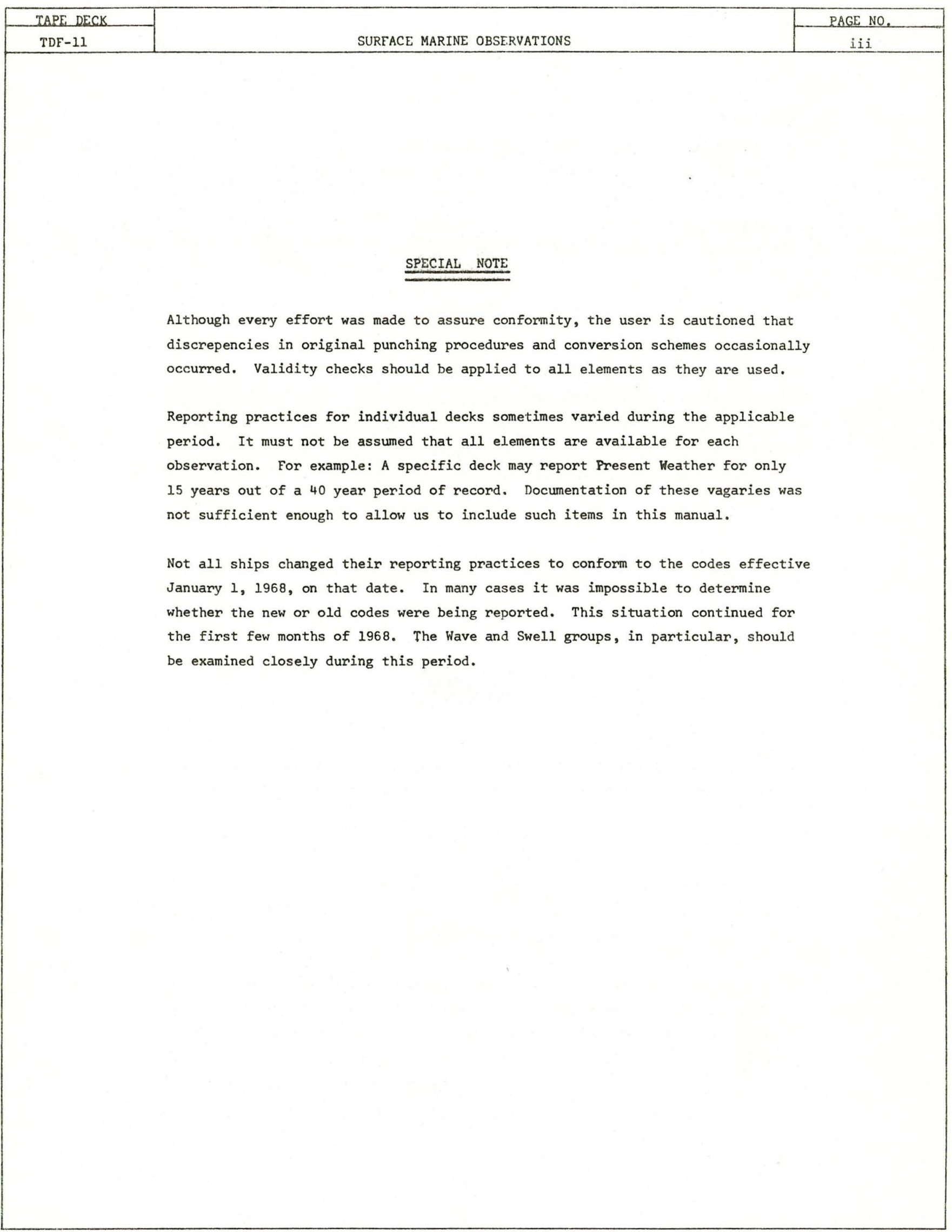


53.

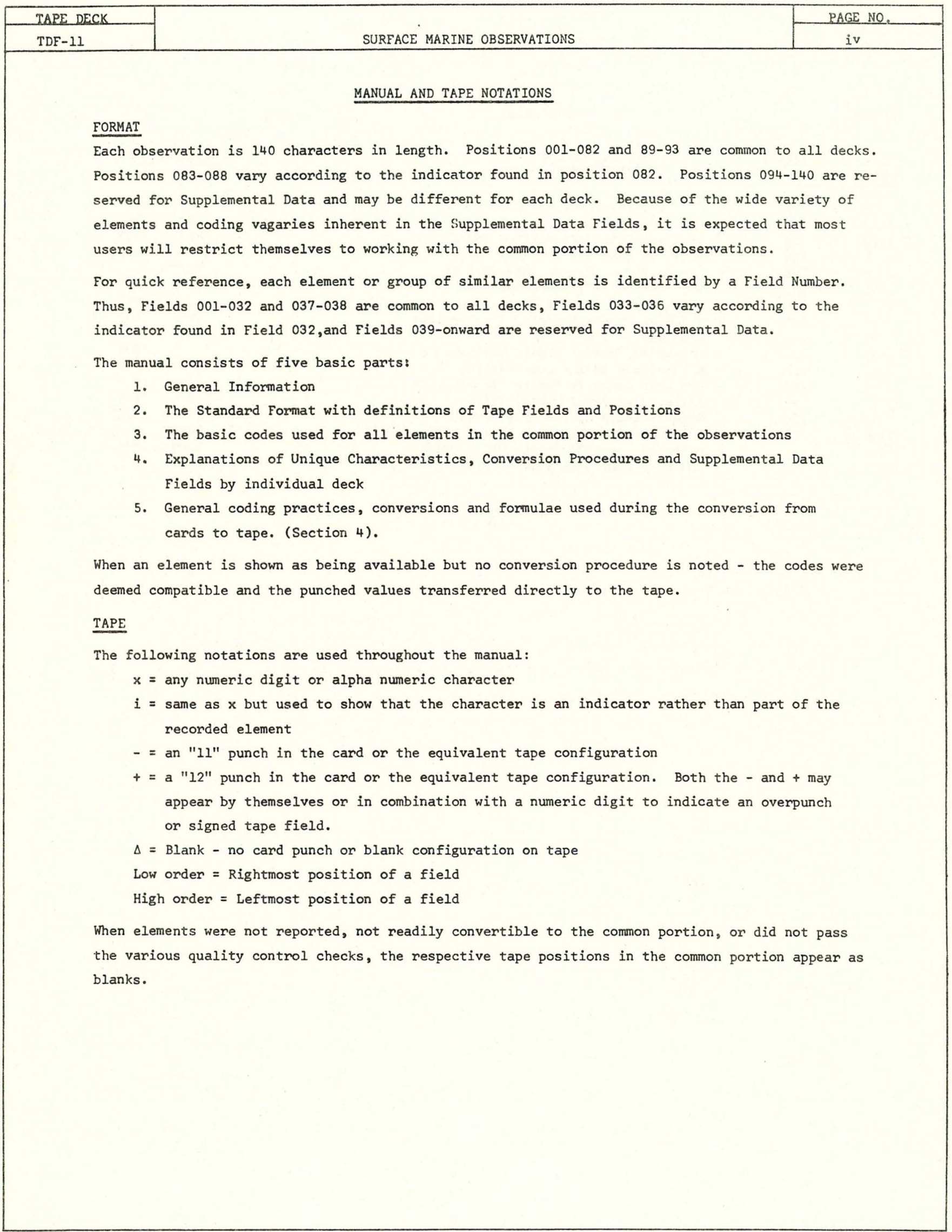


54.

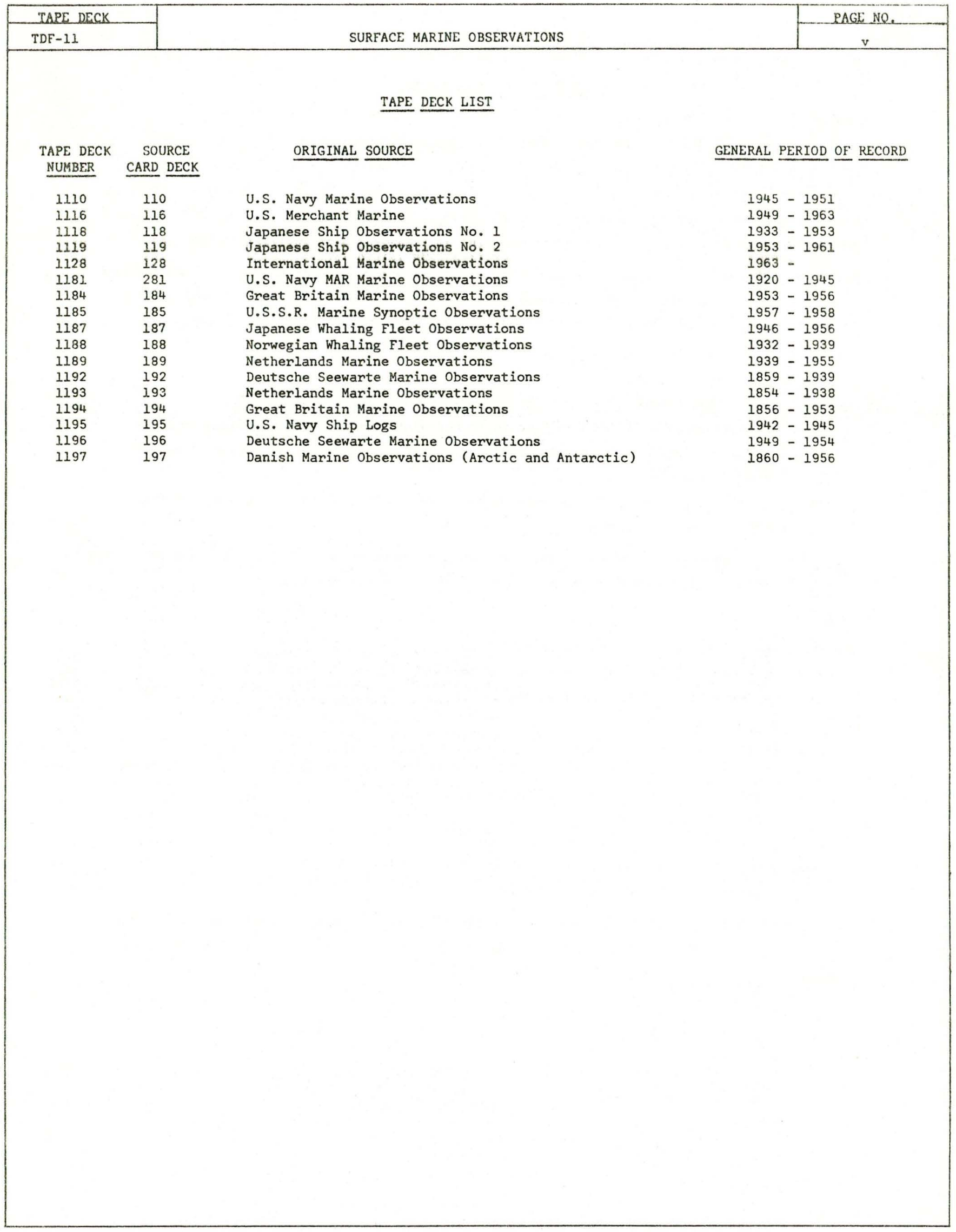


55.

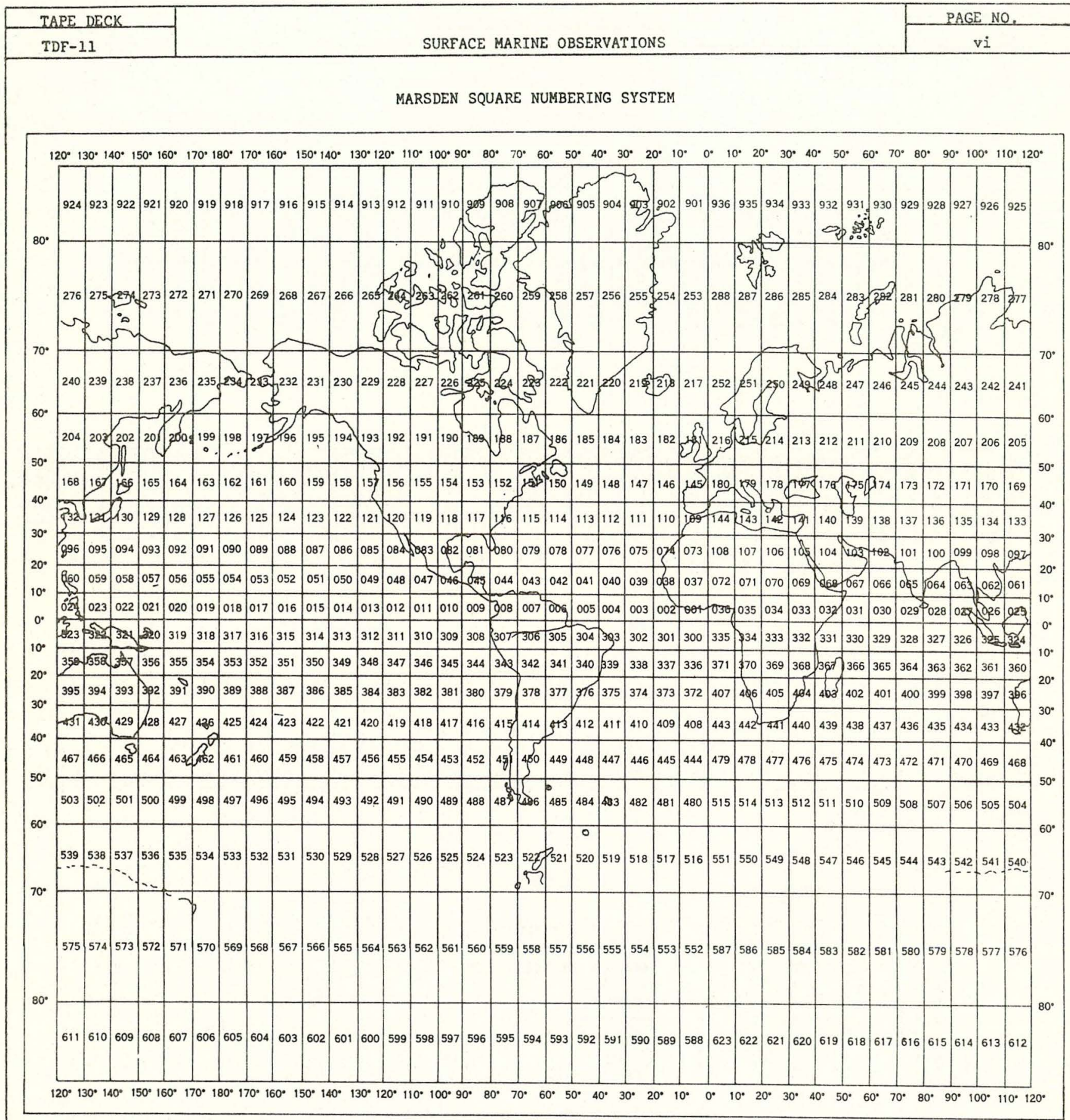

\begin{tabular}{|c|c|c|c|c|c|c|c|c|}
\hline 90 & & & & & & & & 99 \\
\hline 80 & & & & & & & & \\
\hline 70 & & & & & & & & \\
\hline 60 & & & & & & & & \\
\hline 50 & & & & & & & & \\
\hline 40 & & & & & & & & \\
\hline 30 & & & & & & & & \\
\hline 20 & & & & & & & & \\
\hline 10 & 11 & 121 & $\begin{array}{ll}31 \\
\end{array}$ & 4 & 516 & 17 & & 19 \\
\hline 100 & & & & & & 07 & & 09 \\
\hline
\end{tabular}

SOUARES ARE ALWAYS ORIENTED

10 SO THAT THE LOWEST NUMBER IS

NEAREST THE INTERSECTION OF

THE GREENWICH MERIDIAN AND

THE EOUATOR. 


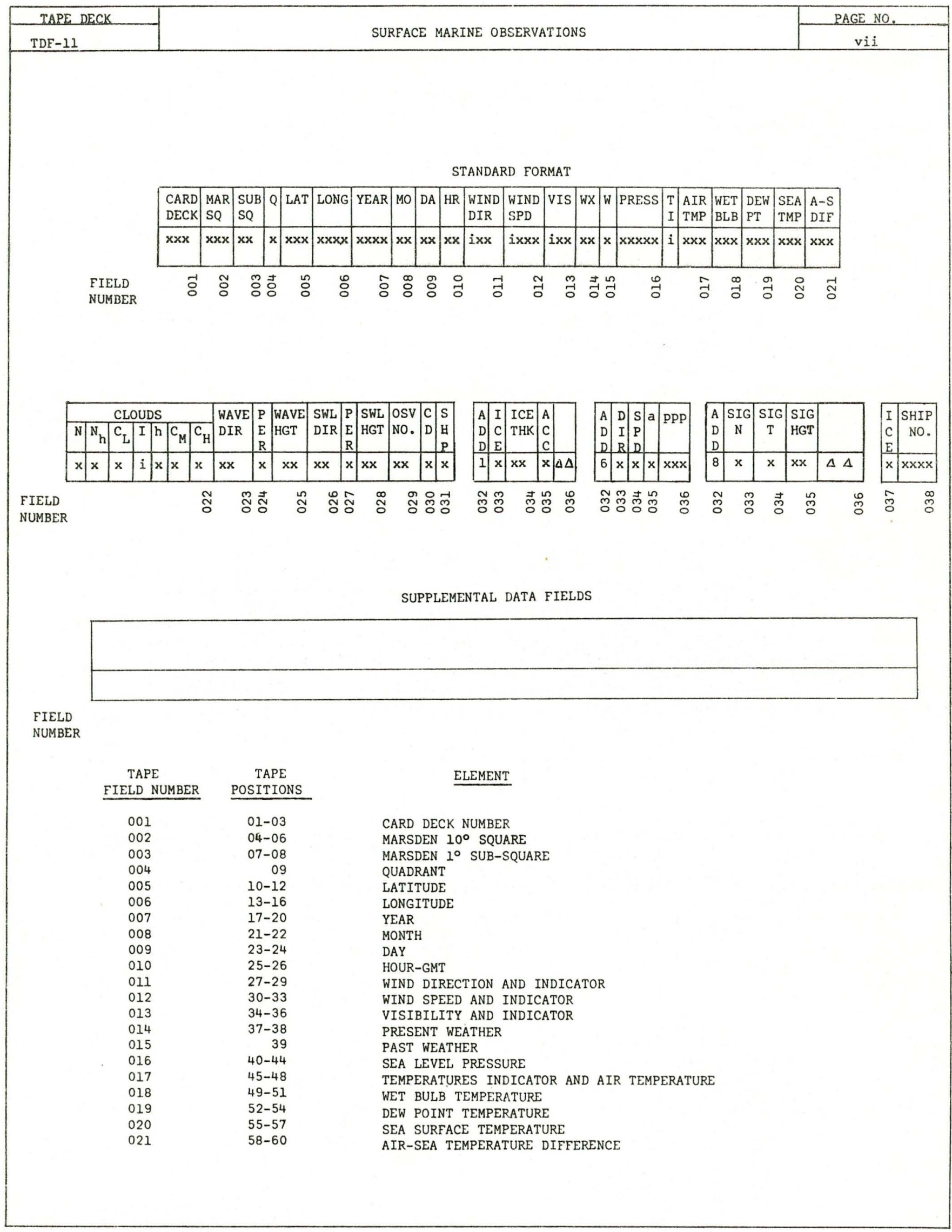


57.

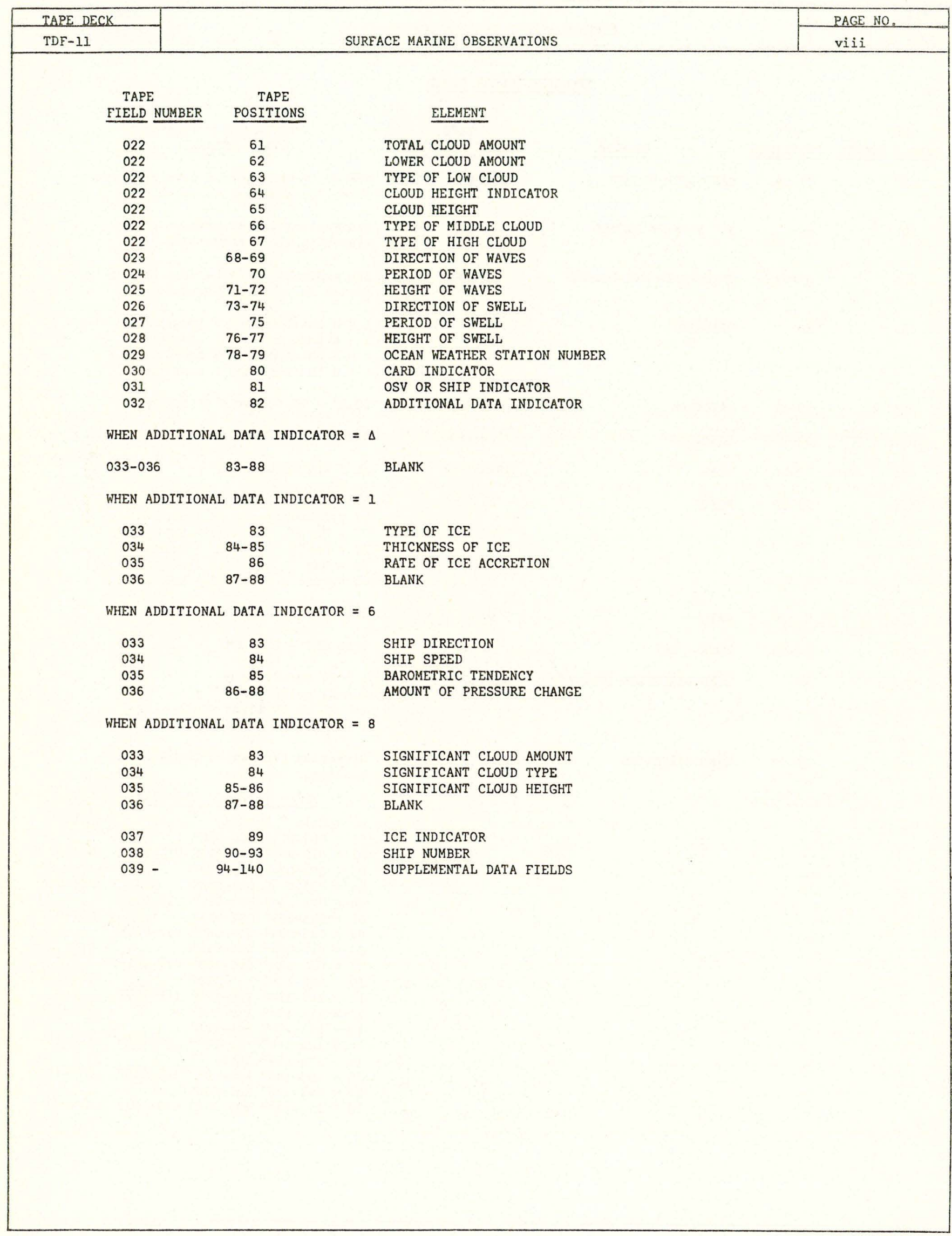


58.

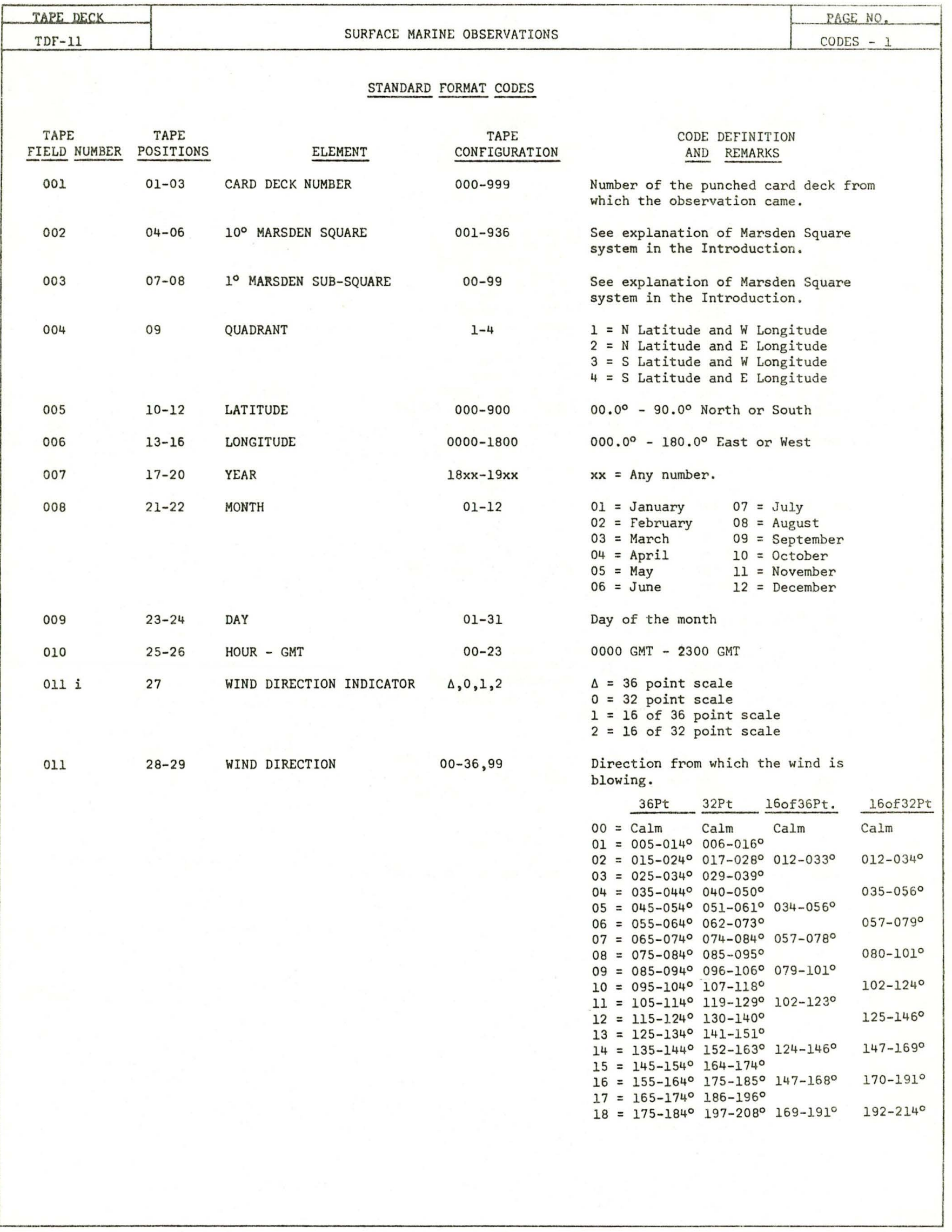


59.

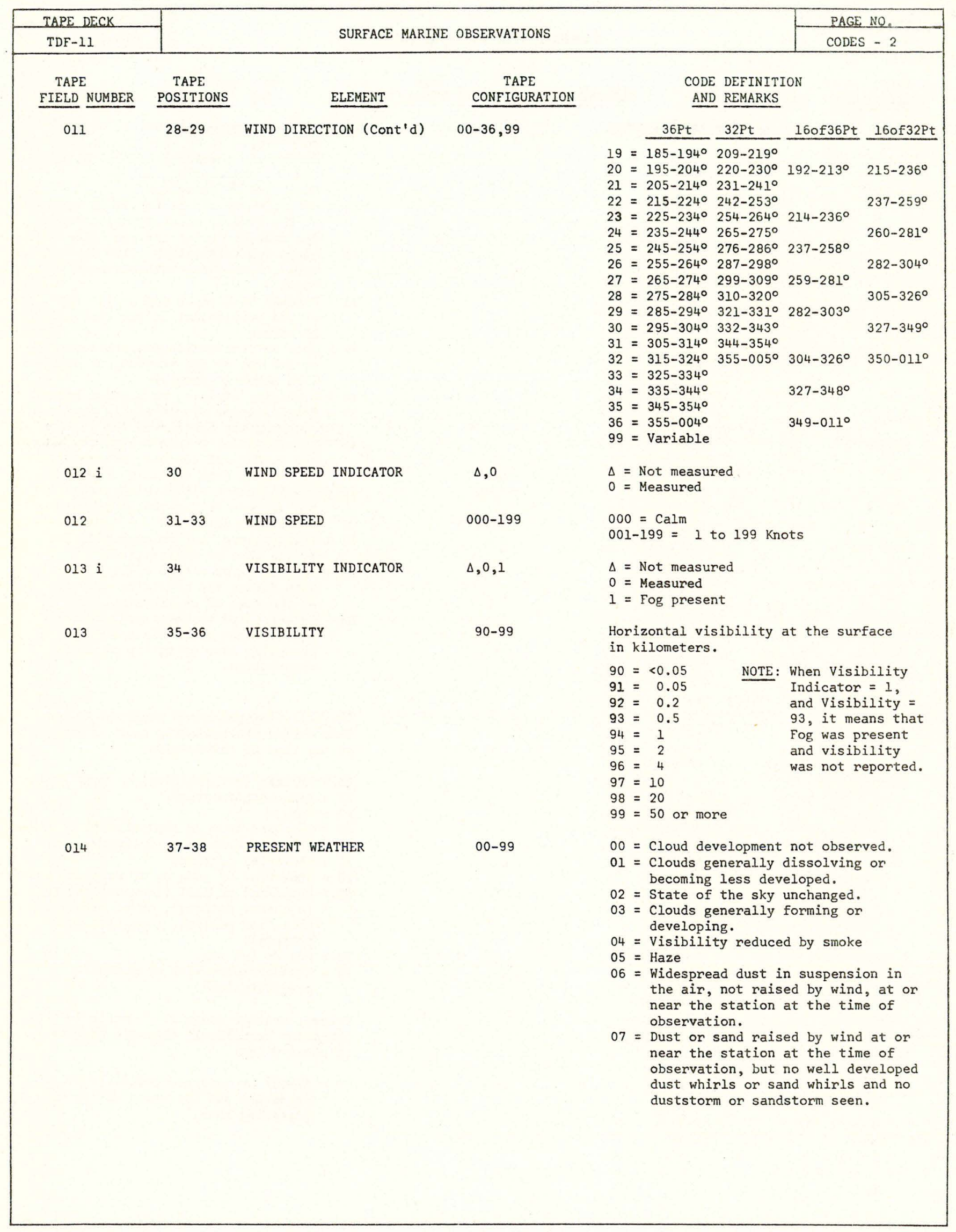


60.

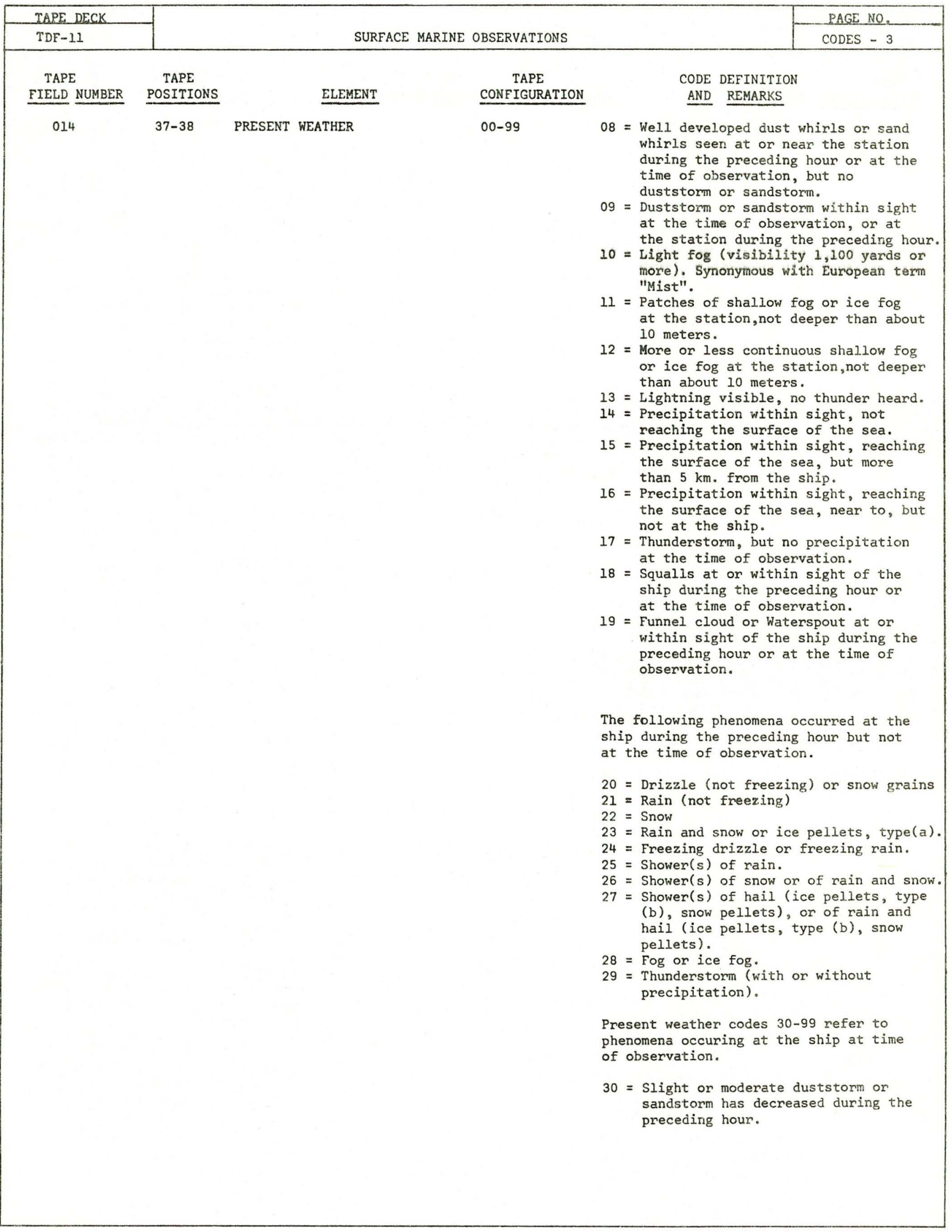


61.

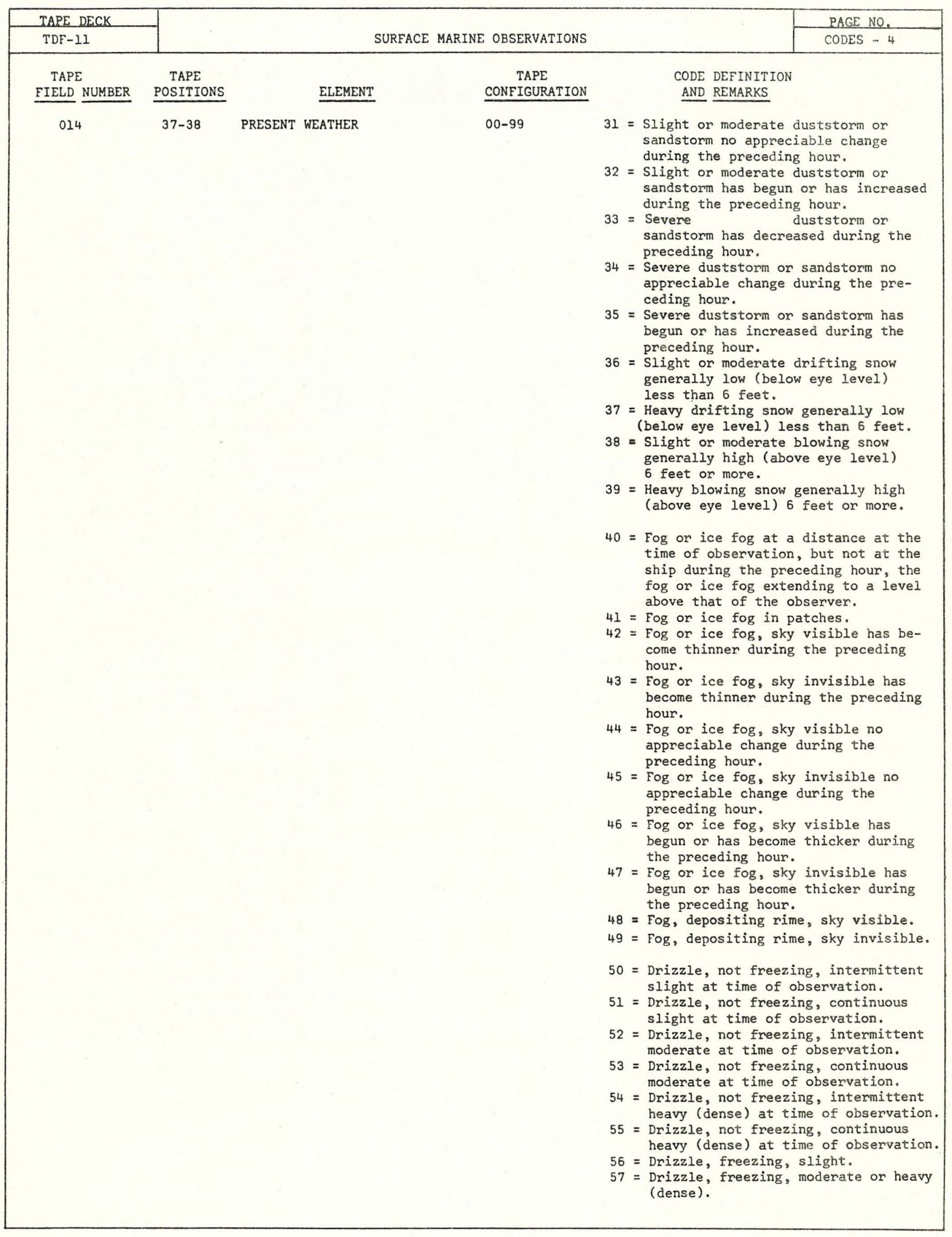


62.

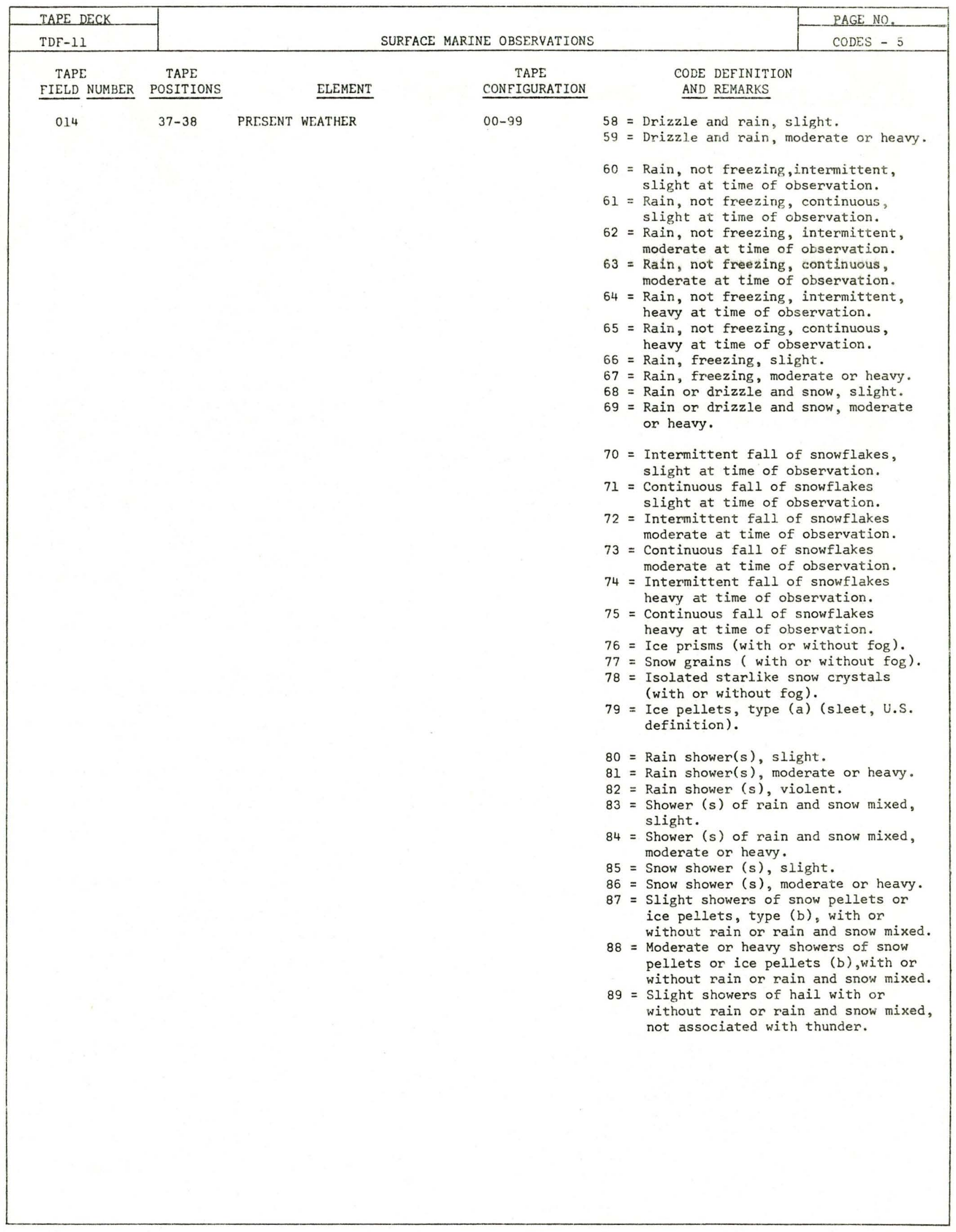


63.

\begin{tabular}{|c|c|c|c|c|c|c|}
\hline TAPE DECK & & \multirow{2}{*}{\multicolumn{2}{|c|}{ SURFACE MARINE OBSERVATIONS }} & & & \multirow{2}{*}{$\begin{array}{l}\text { PAGE NO } \\
\text { CODES - } 6\end{array}$} \\
\hline TDF-11 & & & & & & \\
\hline $\begin{array}{l}\text { TAPE } \\
\text { FIELD NUMBER }\end{array}$ & $\begin{array}{c}\text { TAPE } \\
\text { POSITIONS } \\
\end{array}$ & ELEMENT & $\begin{array}{c}\text { TAPE } \\
\text { CONFIGURATION } \\
\end{array}$ & & $\begin{array}{l}\text { CODE DEFINITION } \\
\text { AND REMARKS } \\
\end{array}$ & \\
\hline 014 & $37-38$ & PRESENT WEATHER & $00-99$ & $\begin{array}{l}90 \\
91= \\
92= \\
93 \\
94 \\
95 \\
96 \\
97 \\
98 \\
99\end{array}$ & $\begin{aligned} &= \text { Moderate or heavy sh } \\
& \text { with or without rair } \\
& \text { snow, slight mixed, } \\
& \text { with thunder. } \\
&=\text { Slight rain at time } \\
& \text { thunderstorm during } \\
& \text { but not at observati } \\
&=\text { Moderate or heavy ra } \\
& \text { observation, thunder } \\
& \text { preceding hour but } \\
&=\text { Slight snow, or rair } \\
& \text { or hail, at time of } \\
& \text { thunderstorm during } \\
& \text { hour but not at time } \\
&=\text { Moderate or heavy sr } \\
& \text { snow mixed, or hail } \\
& \text { observation with thy } \\
& \text { the preceding hour } \\
& \text { observation. } \\
&=\text { Thunderstorm, sligh } \\
& \text { without hail, but w. } \\
& \text { snow at time of obs } \\
&=\text { Thunderstorm, sligh } \\
& \text { with hail at time o } \\
&=\text { Thunderstorm, heavy } \\
& \text { but with rain and/o } \\
& \text { of observation. } \\
&=\text { Thunderstorm combin } \\
& \text { or sandstorm at tim } \\
&=\text { Thunderstorm, heavy } \\
& \text { time of observation }\end{aligned}$ & $\begin{array}{l}\text { owers of hail, } \\
\text { or rain and } \\
\text { not associated } \\
\text { of observation, } \\
\text { preceding hour } \\
\text { on. } \\
\text { in at time of } \\
\text { storm during } \\
\text { ot at observation } \\
\text { and snow mixed } \\
\text { observation with } \\
\text { the preceding } \\
\text { of observation. } \\
\text { ow, or rain and } \\
\text { at time of } \\
\text { nderstorm during } \\
\text { ut not at time of } \\
\text { or moderate, } \\
\text { th rain and/or } \\
\text { rvation. } \\
\text { or moderate, } \\
\text { observation. } \\
\text { without hail } \\
\text { snow at time } \\
\text { d with duststorm } \\
\text { of observation. } \\
\text { with hail at }\end{array}$ \\
\hline 015 & 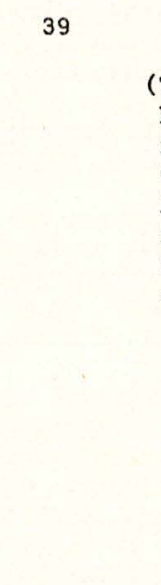 & $\begin{array}{l}\text { PAST WEATHER } \\
\text { (The period covered by } \\
\text { Past Weather is } 6 \text { hours } \\
\text { for observations at } \\
0000,0600,1200 \text {, and } \\
1800 \text { GMT and } 3 \text { hours } \\
\text { for observations at } \\
\text { 0300, } 0900 \text {, 1500, } \\
\text { and } 2100 \text { GMT). }\end{array}$ & $0-9$ & $\begin{array}{l}0 \\
1 \\
\\
2 \\
\\
3 \\
4 \\
5 \\
6 \\
7 \\
8 \\
9\end{array}$ & $\begin{aligned} &= \text { Cloud covering } 1 / 2 \\
& \text { sky throughout the } \\
& \text { period. } \\
&=\text { Cloud covering more } \\
& \text { sky during part of } \\
& \text { period and covering } \\
& \text { during part of the } \\
&=\text { cloud covering more } \\
& \text { sky throughout the } \\
& \text { period. } \\
&=\text { Sandstorm, duststor } \\
&=\text { Fog or ice fog or } t \\
& \text { includes thick smok } \\
&=\text { Drizzle } \\
&=\text { Rain } \\
&=\text { Snow, or rain and s } \\
&=\text { Shower } \\
&=\text { Thunderstorm with } 0 \\
& \text { precipitation. }\end{aligned}$ & $\begin{array}{l}\text { less of the } \\
\text { ppropriate } \\
\text { than } 1 / 2 \text { of the } \\
\text { he appropriate } \\
1 / 2 \text { or less } \\
\text { eriod. } \\
\text { than } 1 / 2 \text { of the } \\
\text { appropriate } \\
\text { or blowing snow. } \\
\text { ick haze (U.S. } \\
\text { ). } \\
\text { now mixed. } \\
\text { without }\end{array}$ \\
\hline 016 & $40-44$ & SEA LEVEL PRESSURE & $08900-10700$ & & $0.0-1070.0$ millibars & \\
\hline $017 \mathrm{i}$ & 45 & TEMPERATURES INDICATOR & $1,3,5$ & $\begin{array}{l}1 \\
3 \\
5\end{array}$ & $\begin{array}{l}=\text { Degrees Celsius and } \\
=\text { Whole degrees Celsi } \\
=\text { Half degrees Celsiu }\end{array}$ & $\begin{array}{l}\text { tenths } \\
\text { us } \\
\text { s }\end{array}$ \\
\hline 017 & $46-48$ & AIR TEMPERATURE & & & & \\
\hline $\begin{array}{l}018 \\
019\end{array}$ & $\begin{array}{l}49-51 \\
52-54\end{array}$ & $\begin{array}{l}\text { WET BULB TEMPERATURE } \\
\text { DEW POINT TEMPERATURE }\end{array}$ & $000-999$ & & $.0-99.9^{\circ} \mathrm{C}$ positive te & mperature \\
\hline 020 & $55-57$ & SEA SURFACE TEMPERATURE & ด0: & & $.1--99.9^{\circ} \mathrm{C}$ negative te & mperature \\
\hline
\end{tabular}


64.

\begin{tabular}{|c|c|c|c|c|}
\hline TARE DECK & \multirow{2}{*}{\multicolumn{3}{|c|}{ SURFACE MARINE OBSERVATIONS }} & \multirow{2}{*}{$\frac{\text { PAGE NO. }}{\text { CODES }-7}$} \\
\hline TDF-11 & & & & \\
\hline $\begin{array}{l}\text { TAPE } \\
\text { FIELD NUMBER } \\
\end{array}$ & $\begin{array}{c}\text { TAPE } \\
\text { POSITIONS } \\
\end{array}$ & ELEMENT & $\begin{array}{c}\text { TAPE } \\
\text { CONFIGURATION } \\
\end{array}$ & $\begin{array}{l}\text { CODE DEFINITION } \\
\text { AND REMARKS }\end{array}$ \\
\hline 021 & $58-60$ & $\begin{array}{l}\text { AIR-SEA TEMPERATURE } \\
\text { DIFFERENCE }\end{array}$ & $\begin{array}{l}000-999 \\
\text { or } \\
00 \overline{0}-99 \overline{9}\end{array}$ & $\begin{array}{l}00.0-99.9^{\circ} \mathrm{C} \text { Air warmer than sea } \\
00.0-99.9^{\circ} \mathrm{C} \text { Sea warmer than air }\end{array}$ \\
\hline $\begin{array}{l}022 \\
022\end{array}$ & $\begin{array}{l}61 \\
62\end{array}$ & $\begin{array}{l}\text { TOTAL CLOUD AMOUNT }(\mathrm{N}) \\
\text { LOWER CLOUD AMOUNT }\left(\mathrm{N}_{\mathrm{h}}\right)\end{array}$ & $0-9$ & $\begin{array}{l}\text { Fraction of celestial dome covered by all } \\
\text { clouds. } \\
\text { Fraction of celestial dome covered by all } \\
\text { the } C_{L} \text { clouds and, if no } C_{L} \text { cloud is } \\
\text { present, that fraction covered by all the } \\
C_{M} \text { clouds present. } \\
\begin{aligned} 0= & \text { Clear } \\
1= & 1 \text { Okta or less, but not zero. } \\
2-8= & 2-8 \text { Oktas } \\
9= & \text { Sky obscured or cloud amount cannot } \\
& \text { be estimated. }\end{aligned}\end{array}$ \\
\hline 022 & 63 & LOW CLOUD TYPE $\left(C_{L}\right)$ & $0-9,-$ & 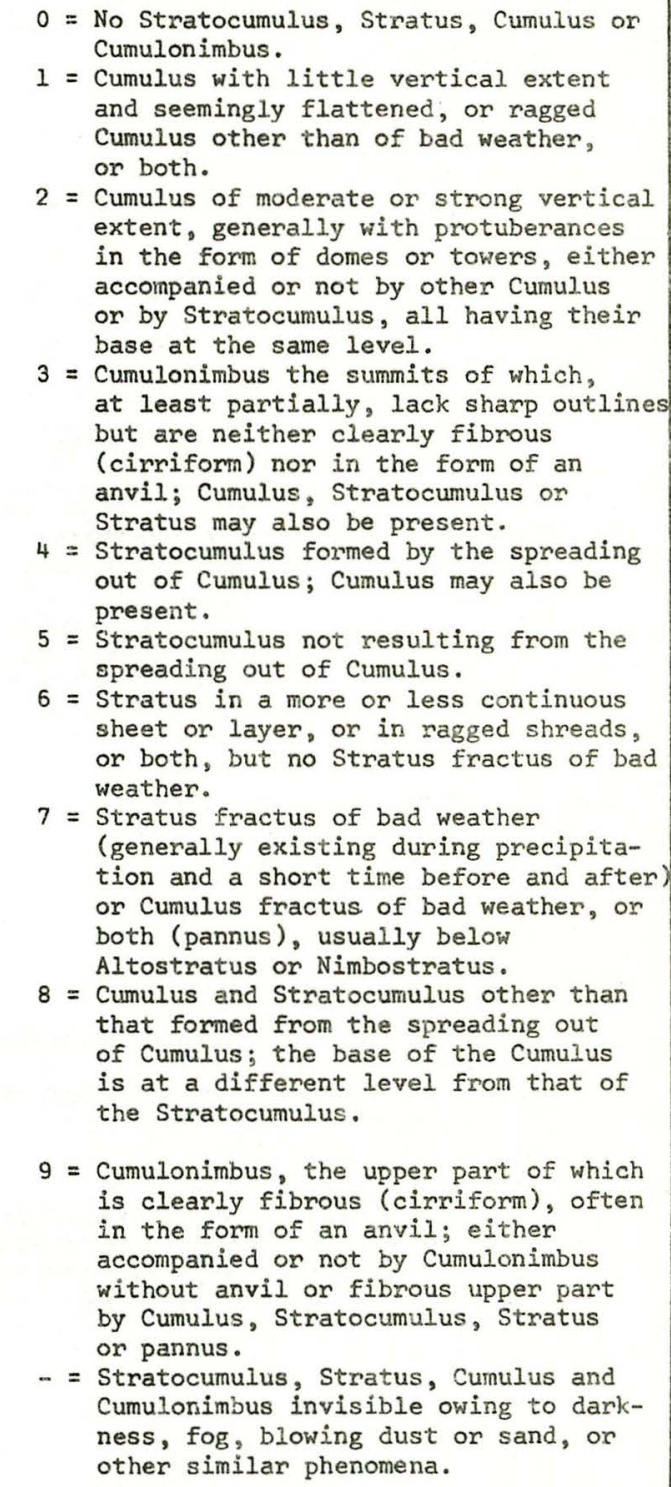 \\
\hline
\end{tabular}


65.

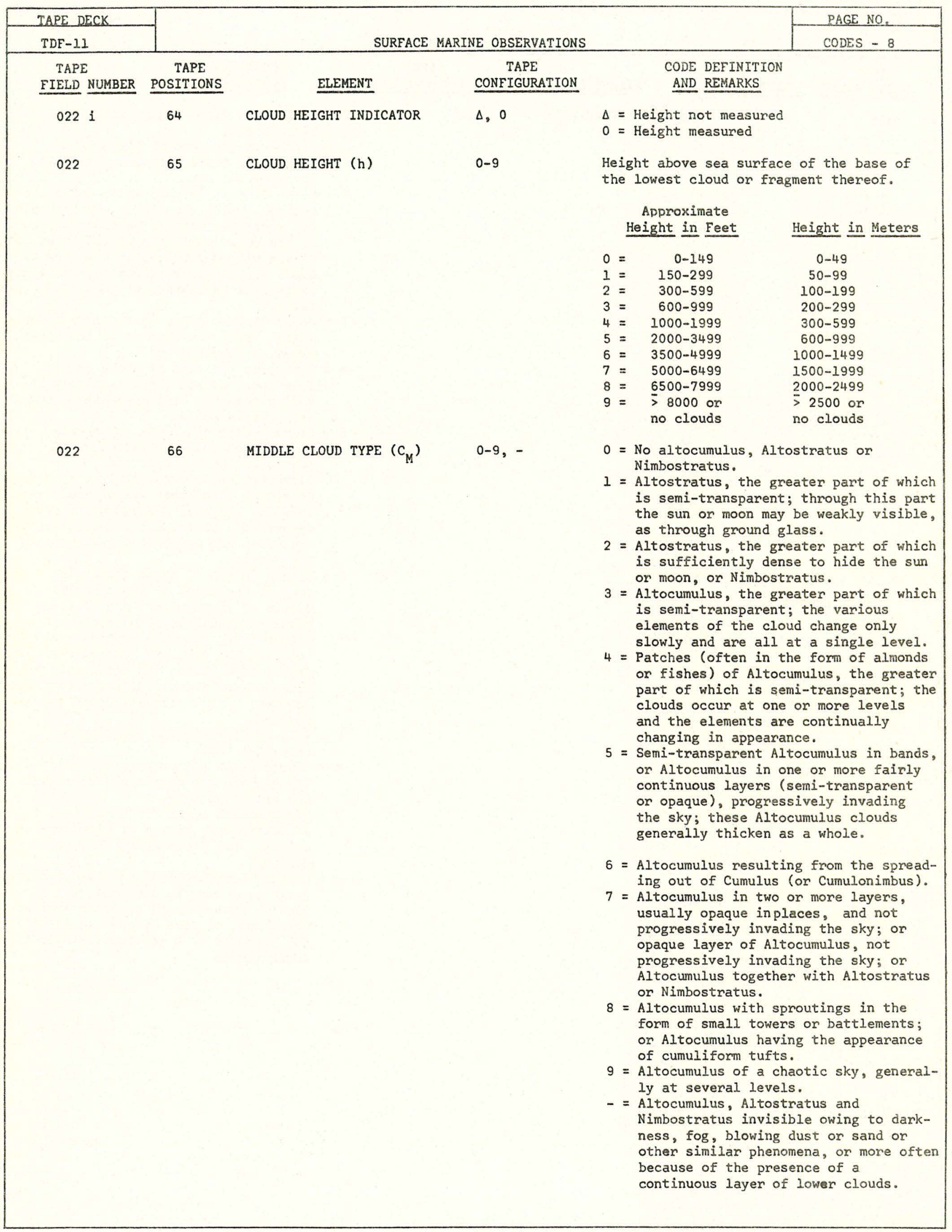


66.

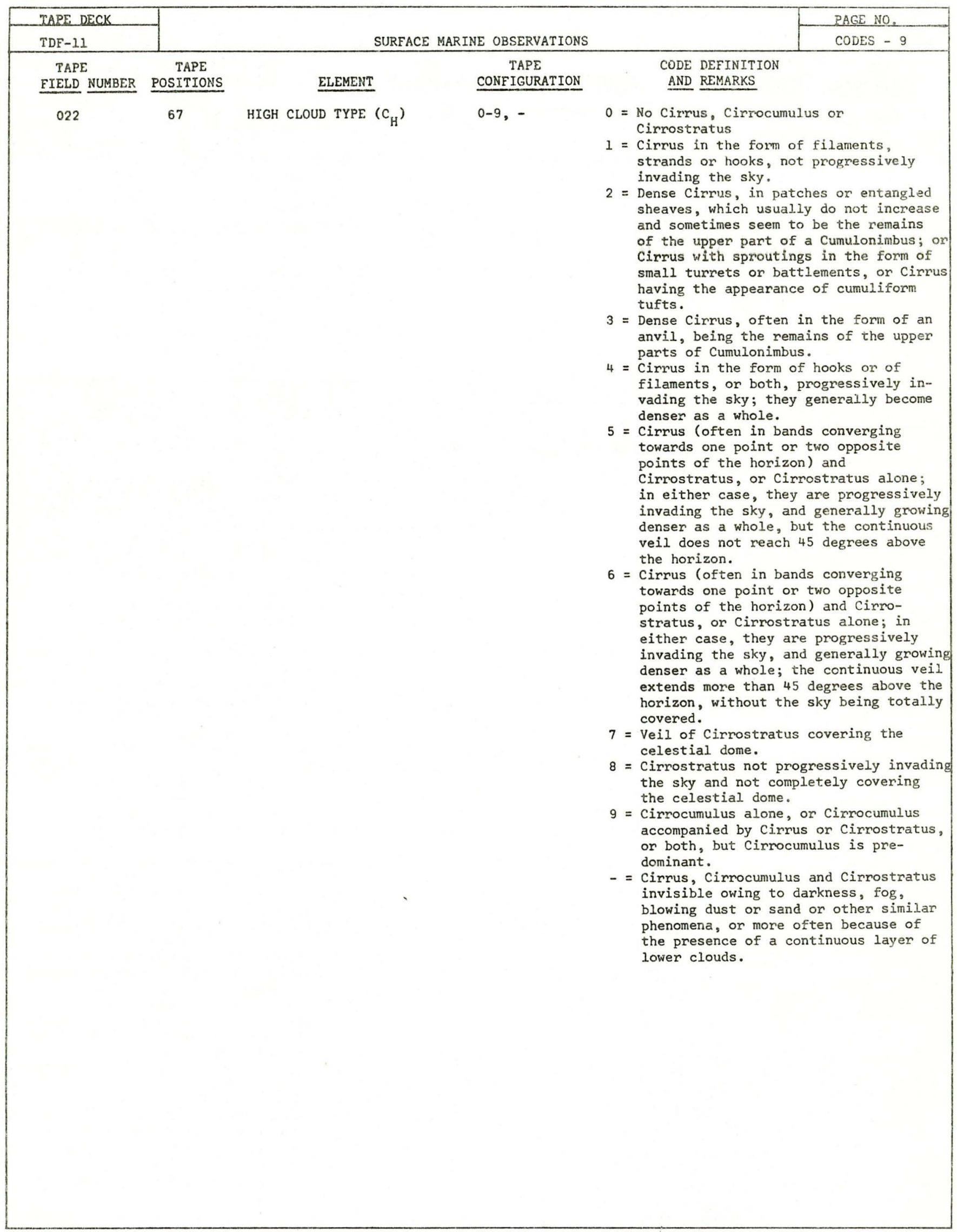


67.

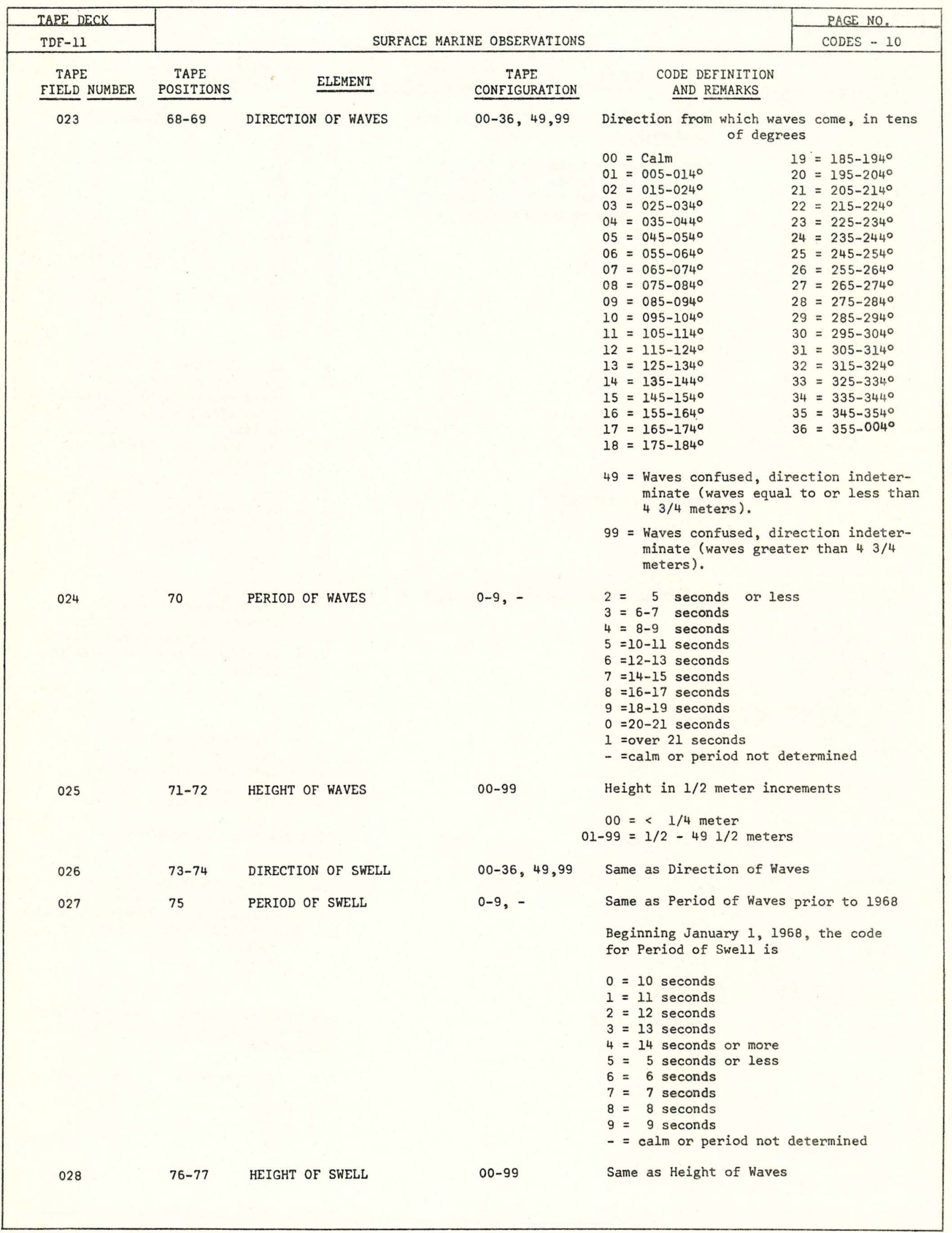


68.

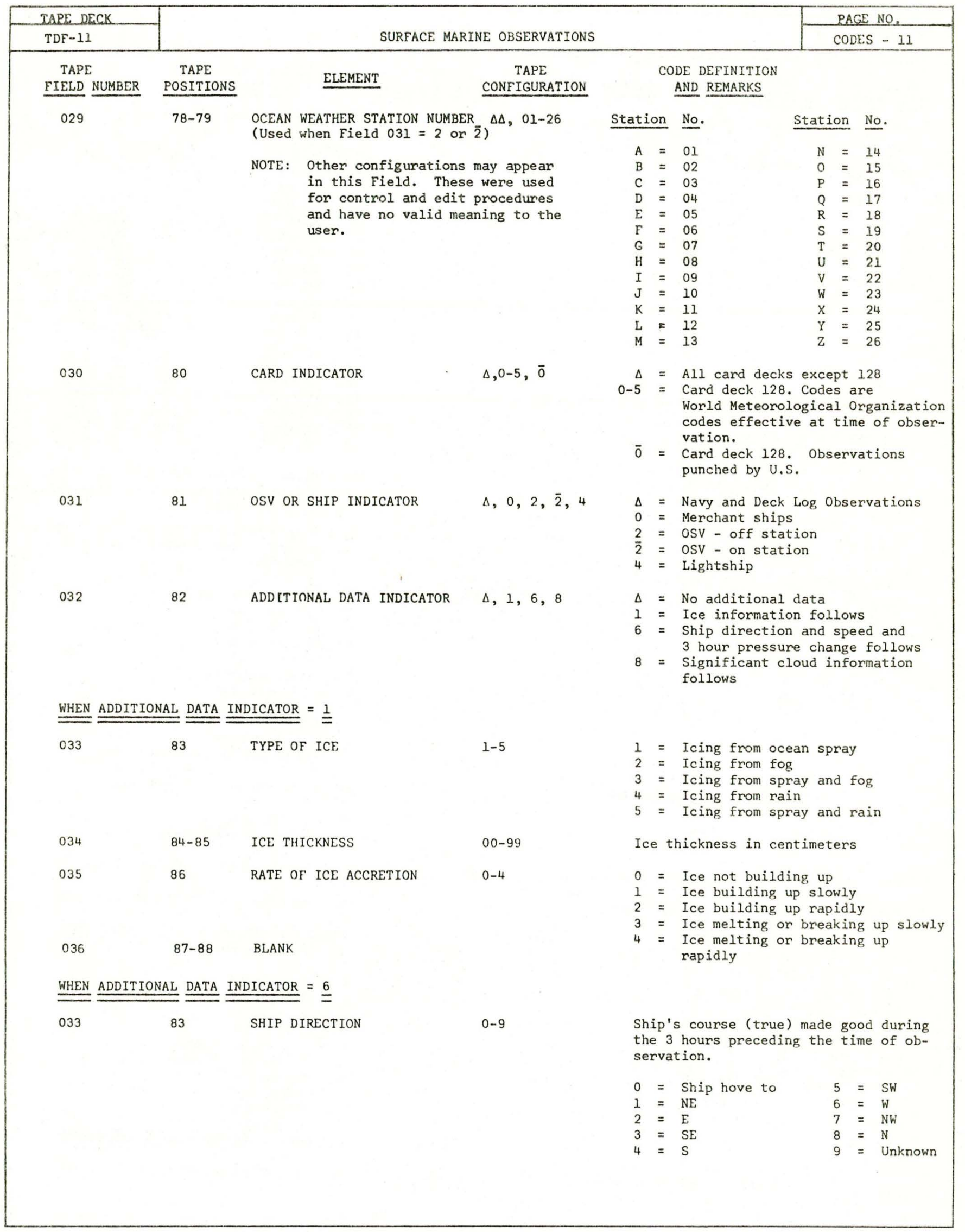


69.

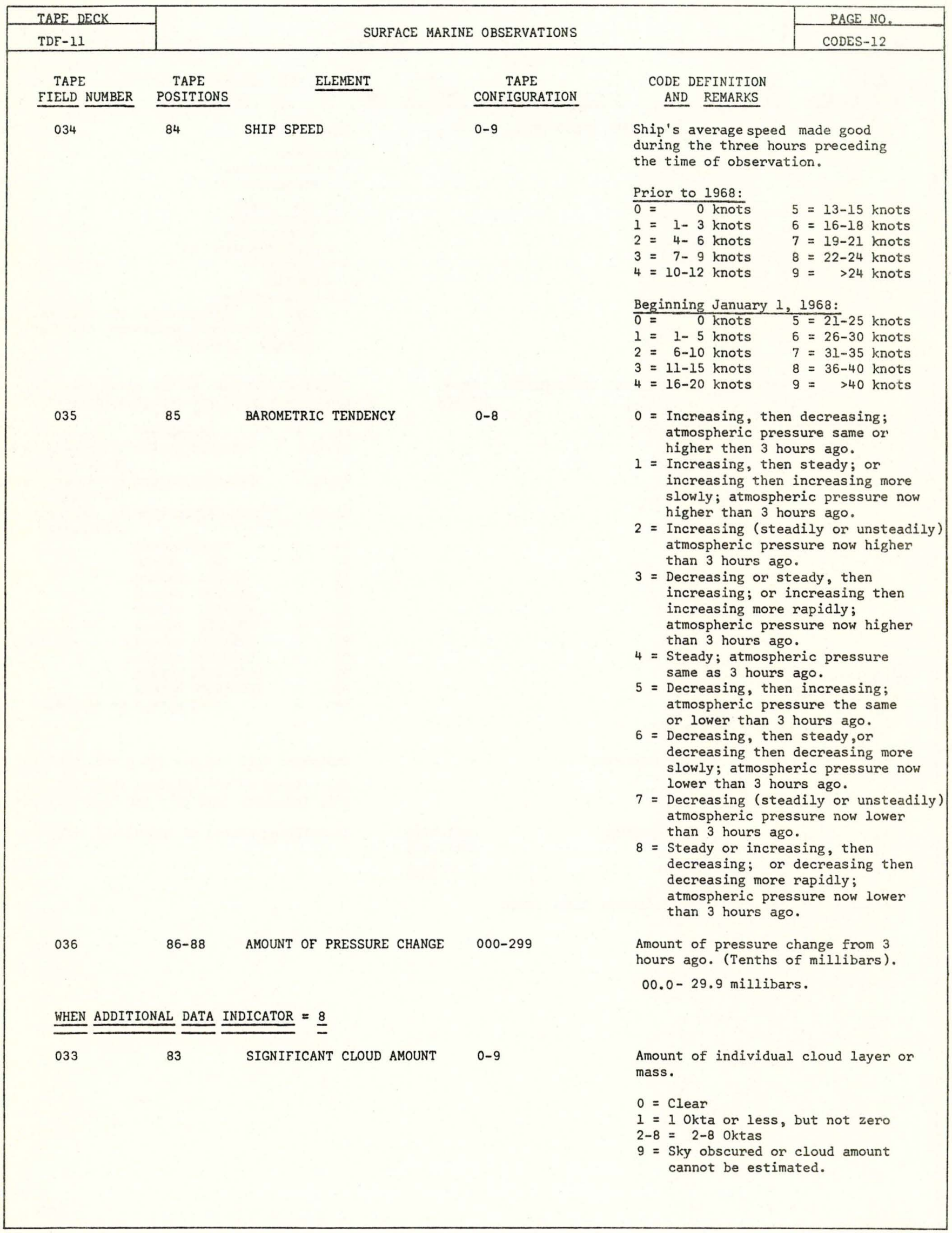


70.

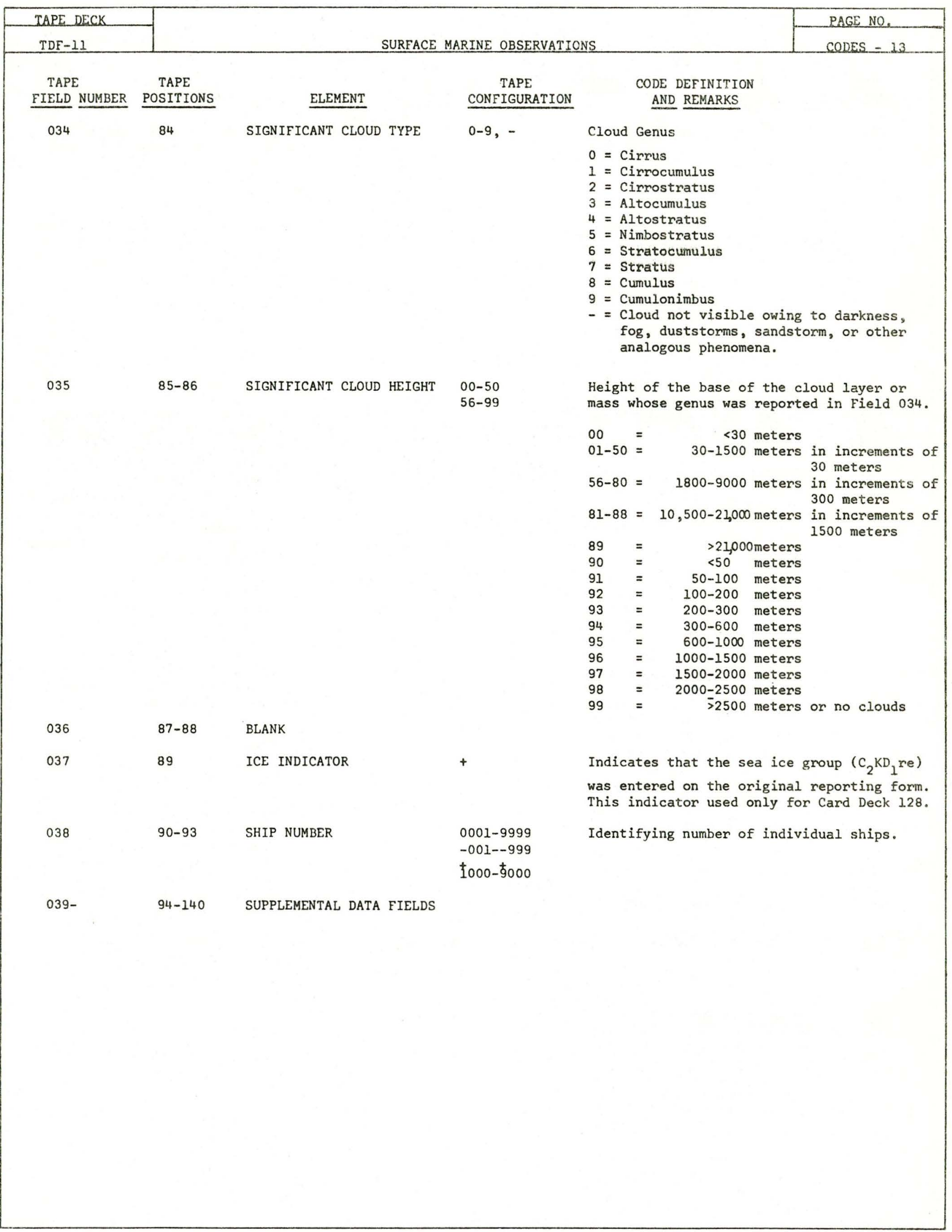


71.

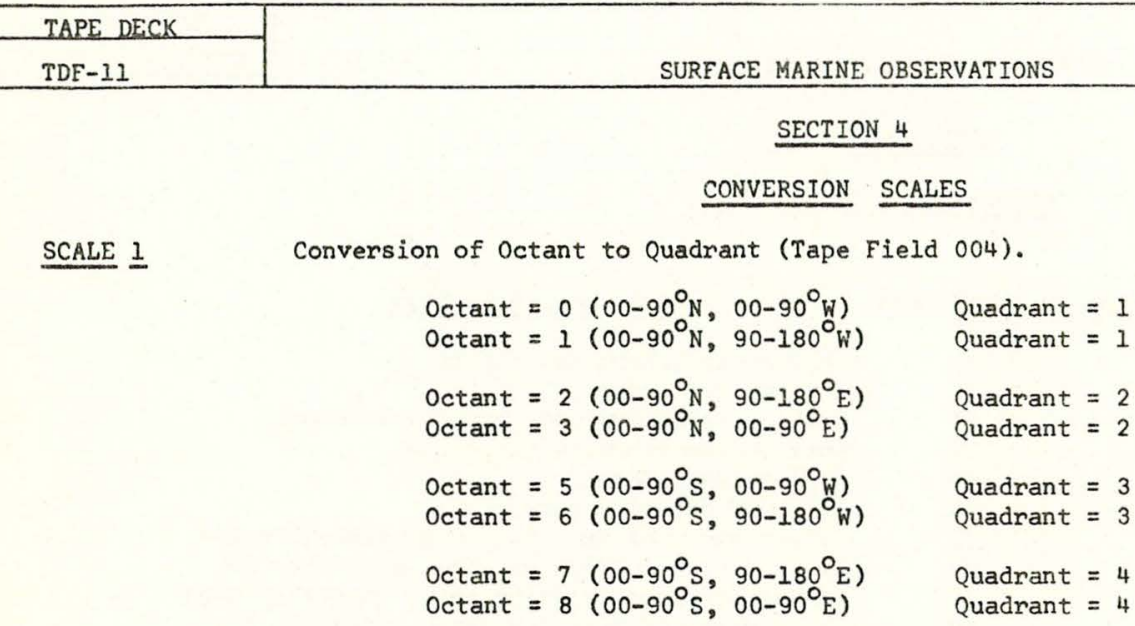

$\underline{\text { SCALE }} \underline{2}$

Conversion of Local Standard Time to GMT. (Tape Field 010).

Starting at $008^{\circ} \mathrm{W}$ and working westward in $15^{\circ}$ increments, one hour was added to the LST for each $15^{\circ}$ of Longitude through $180^{\circ}$.

For example: 1 hour was added for longitudes $008^{\circ}-022^{\circ} \mathrm{W}$ 2 hours were added for longitudes $023^{\circ}-037^{\circ} \mathrm{W}$ etc.

Starting at $008^{\circ} \mathrm{E}$ and working eastward in $15^{\circ}$ increments, one hour was subtracted from the LST for each $15^{\circ}$. of Longitude through $180^{\circ}$.

For example: 1 hour was subtracted for longitudes $008^{\circ}-022^{\circ} \mathrm{E}$ 2 hours were subtracted for longitudes $023^{\circ}-037^{\circ} \mathrm{E}$ etc.

$\underline{\text { SCALE }} \underline{3}$

Conversion of 1942 present weather code to 1960 present weather code (Tape Field 014)

\begin{tabular}{cc}
1960 Code (Taped) & 1942 Code \\
\cline { 1 - 2 }$\Delta \Delta$ & $00-03$ \\
04 & 17 \\
05 & 05 \\
08 & 06 \\
09 & 12 \\
10 & 08 \\
12 & 40 \\
13 & 07 \\
16 & 10 \\
17 & 11 \\
18 & 14 \\
18 & 15 \\
19 & 16 \\
20 & 20 \\
20 & 21 \\
21 & 22 \\
22 & 23 \\
23 & 24 \\
25 & 25 \\
26 & 26 \\
27 & 27 \\
28 & 41 \\
29 & 28 \\
29 & 29
\end{tabular}

State of the sky (not converted to tape)

Visibility reduced by smoke

Haze (Visibility 1000 meters or more)

Dust devils seen

Duststorm within sight but not at ship

Light fog (Visibility 1000-2000 meters)

Fog

Distant lightning

Precipitation within sight

Thunder, without precipitation at the ship

Squally weather

Heavy squalls in last three hours

Waterspouts seen in last three hours

Precipitation Within past hour but not at observation Drizzle

Rain

Snow

Rain and snow mixed

Rain shower

Snow shower

Hail or rain and hail showers

Moderate fog

Slight thunderstorm

Heavy thunderstorm

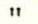

$+$

11

$"$

n

11

"

"1

" 
72.

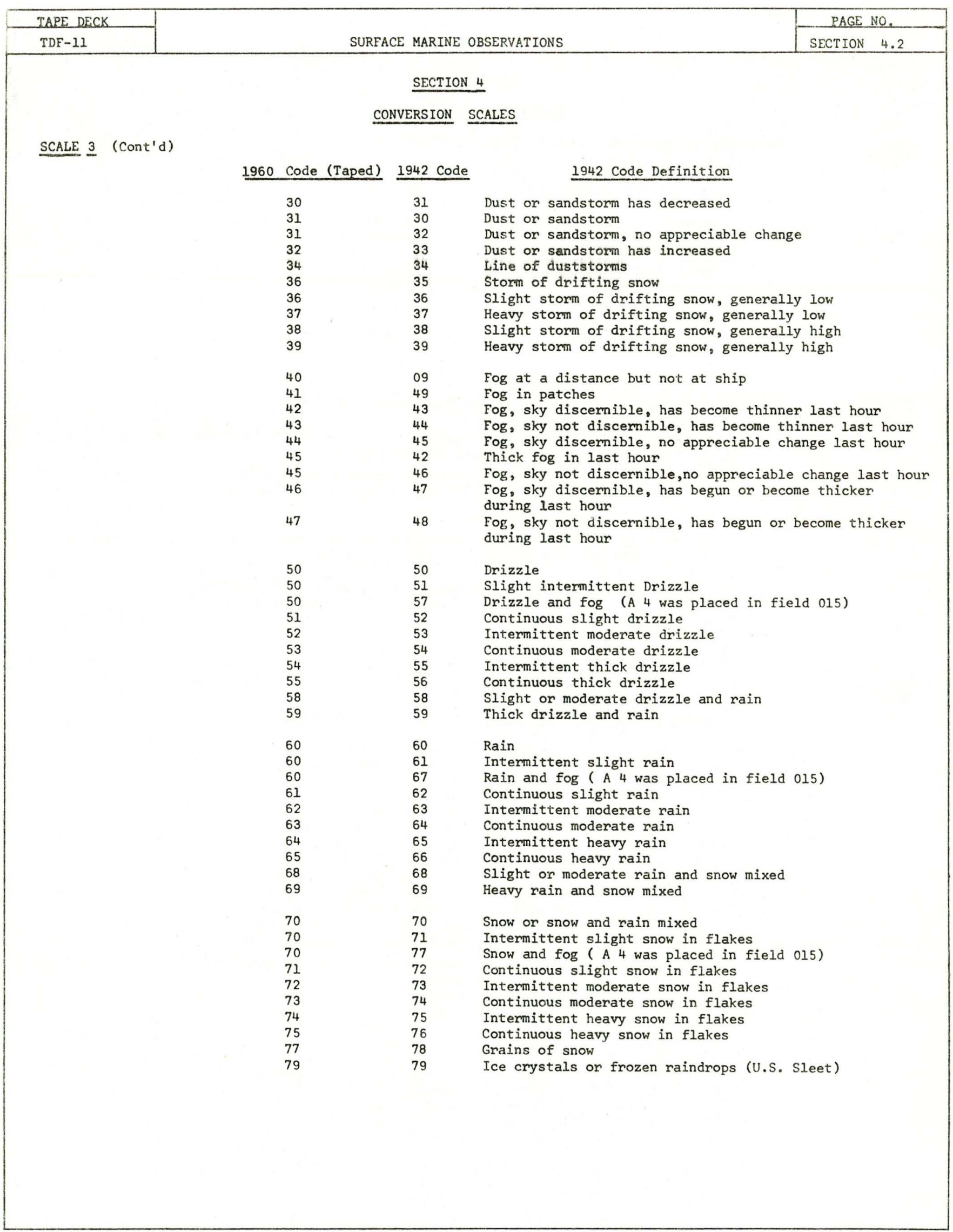


73.

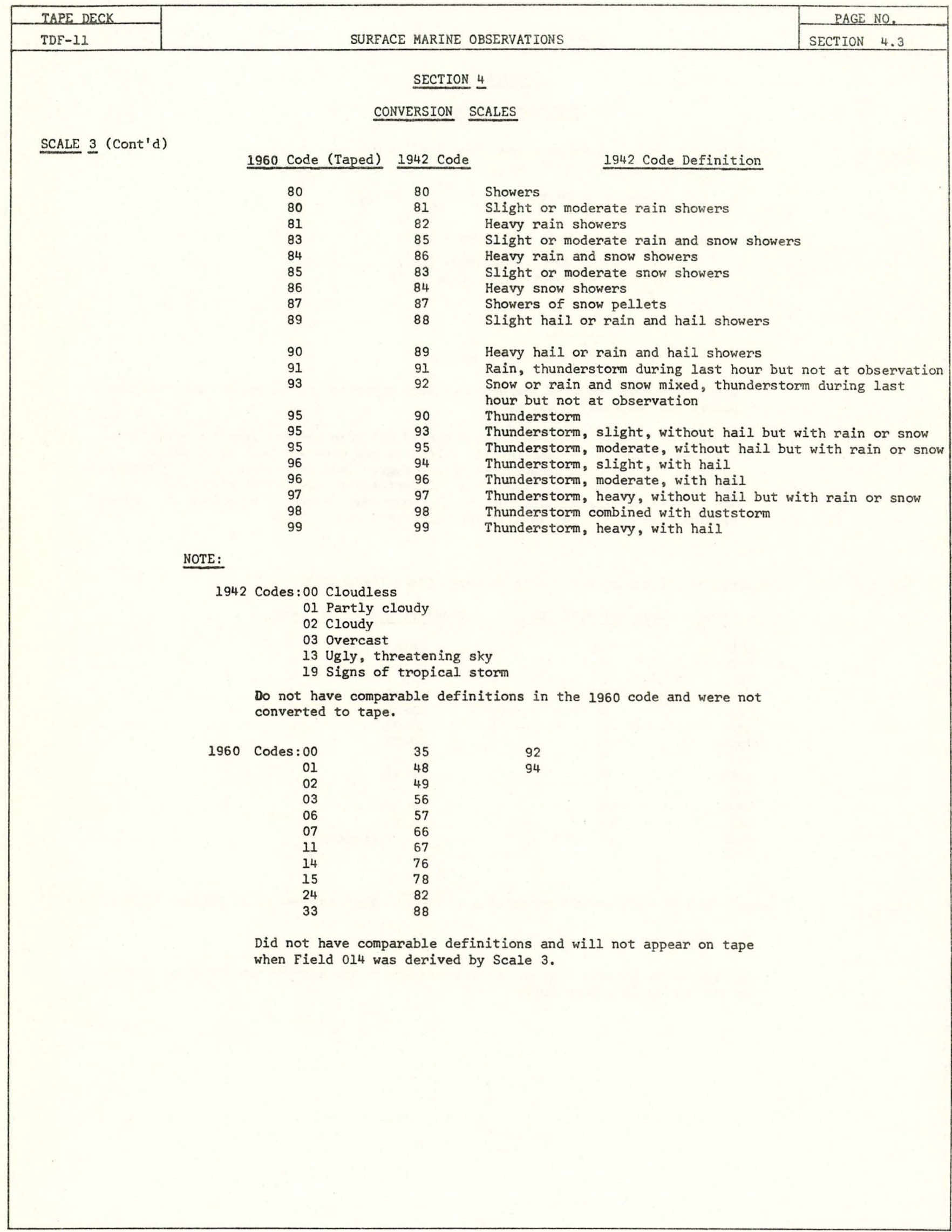


74.

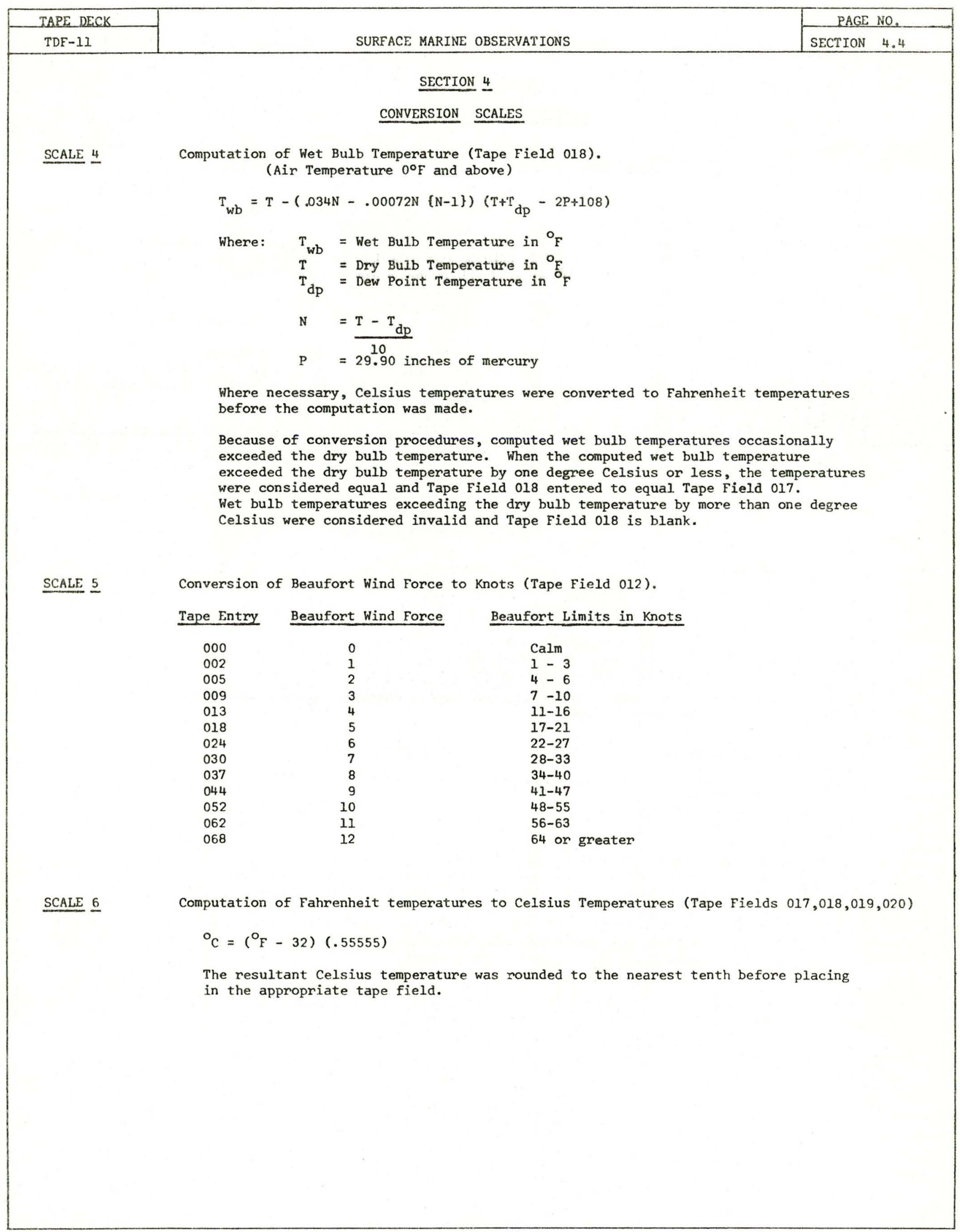


75.

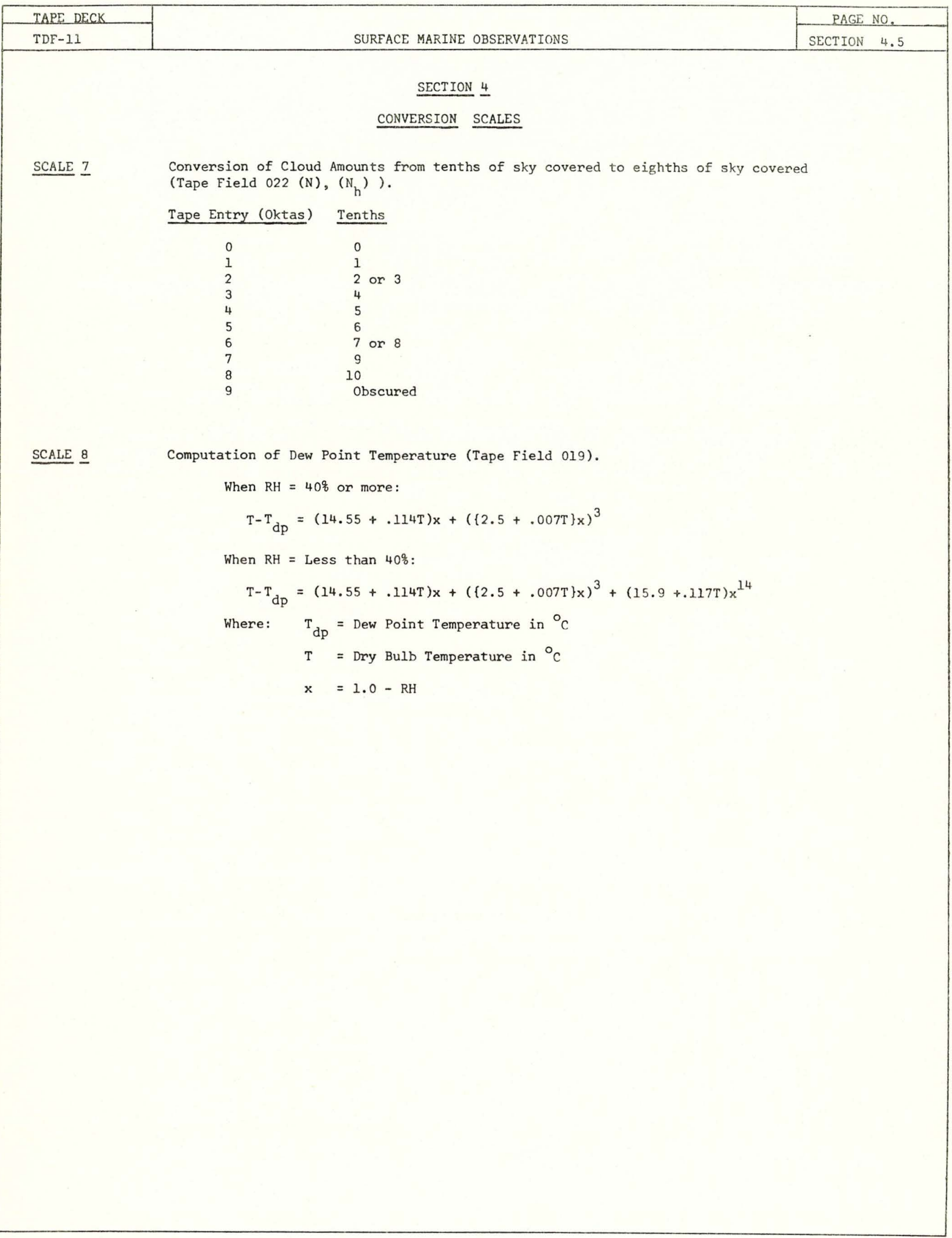


MANDATORY DISTRIBUTION LIST

FOR UNCLASSIFIED TECHNICAL REPORTS, REPRINTS, AND FINAL REPORTS PUBLISHED BY OCEANOGRAPHIC CONTRACTORS

OF THE OCEAN SCIENCE AND TECHNOLOGY DIVISION

OF THE OFFICE OF NAVAL RESEARCH

(REVISED NOVEMBER 1978)

1 Deputy Under Secretary of Defense

(Research and Advanced Technology)

Military Assistant for Environmental Science Room 3D129

Washington, D.C. 20301

Office of Naval Research

800 North Quincy Street

Arlington, VA 22217

3 ATTN: Code 483

1 ATTN: Code 460

2 ATTN: 102B

1 CDR J. C. Harlett, (USN)

ONR Representative

Woods Hole Oceanographic Inst.

Woods Hole, MA 02543

Commanding Officer

Naval Research Laboratory

Washington, D.C. 20375

6 ATTN: Library, Code 2627
12 Defense Documentation Center Cameron Station

Alexandria, VA 22314

ATTN: DCA

Commander

Naval Oceanographic Office

NSTL Station

Bay St. Louis, MS 39522

ATTN: Code 8100

ATTN: Code 6000

ATTN: Code 3300

1 NODC/NOAA

Code D781

Wiscons in Avenue, N.W.

Washington, D.C. 20235 


\begin{tabular}{|c|c|}
\hline REPORT DOCUMENTATION PAGE & $\begin{array}{l}\text { READ INSTRUCTIONS } \\
\text { BEFORE COMPLETING FORM }\end{array}$ \\
\hline \begin{tabular}{l|l} 
1. REPORT NUMBER & 2. GOVT ACCESSION NO. \\
WHOI $-79-70$ &
\end{tabular} & 3. RECIPIENT'S CATALOG NUMBER \\
\hline \multirow{2}{*}{$\begin{array}{l}\text { 4. TITLE (and Subtitle) } \\
\text { WOODS HOLE OCEANOGRAPHIC INSTITUTION COLLECTION } \\
\text { OF CLIMATOLOGY AND AIR/SEA INTERACTION (CASI) } \\
\text { DATA }\end{array}$} & $\begin{array}{l}\text { 5. TYPE OF REPORT \& PERIOD COVERED } \\
\text { Technical }\end{array}$ \\
\hline & 6. PERFORMING ORG. REPORT NUMBER \\
\hline $\begin{array}{l}\text { 7. AUTHOR(s) } \\
\text { Roger A. Goldsmith and Andrew F. Bunker }\end{array}$ & $\begin{array}{l}\text { 8. CONTRACT OR GRANT NUMBER(s) } \\
\text { N00014-74-C-0262; } \\
\text { ATM 77-01475 }\end{array}$ \\
\hline $\begin{array}{l}\text { 9. PERFORMING ORGANIZATION NAME AND ADDRESS } \\
\text { Woods Hole Oceanographic Institution } \\
\text { Woods Hole, MA } 02543\end{array}$ & $\begin{array}{l}\text { 10. PROGRAM ELEMENT, PROJECT, TASK } \\
\text { AREA \& WORK UNIT NUMBERS } \\
\text { NR } 083-004\end{array}$ \\
\hline \multirow{2}{*}{$\begin{array}{l}\text { 11. CONTROLLING OFFICE NAME AND ADDRESS } \\
\text { NORDA } \\
\text { National Space Technology Laboratory } \\
\text { Bay St. Louis, MS } 39529\end{array}$} & $\begin{array}{l}\text { 12. REPORT DATE } \\
\text { August } 1979\end{array}$ \\
\hline & $\begin{array}{l}\text { 13. NUMBER OF PAGES } \\
75\end{array}$ \\
\hline \multirow[t]{2}{*}{ 14. MONITORING AGENCY NAME \& ADDRESS(If different from Controlline Offico) } & $\begin{array}{l}\text { 15. SECURITY CLASS. (of this roport) } \\
\text { Unclassified }\end{array}$ \\
\hline & $\begin{array}{l}\text { 15a. DECLASSIFICATION/DOWNGRADING } \\
\text { SCHEDULE }\end{array}$ \\
\hline \multicolumn{2}{|l|}{$\begin{array}{l}\text { 16. DISTRIBUTION STATEMENT (of this Report) } \\
\text { Approved for public release; distribution unlimited. }\end{array}$} \\
\hline \multicolumn{2}{|l|}{ 17. DISTRIBUTION STATEMENT (of the abotract ontered in Block 20, if difforent from Report) } \\
\hline
\end{tabular}

18. SUPPLEMENTARY NOTES

19. KEY WORDS (Continue on reverse olde if neceesery and identify by block number)

1. Climatology

2. Air/sea interaction

3. Oceanic energy fluxes

20. ABSTRACT (Continue on roverse side if necossary and ldentity by block number)

Scientists at Woods Hole routinely collect and analyze a considerable amount of data relating to the oceans of the world. Of the many different. kinds of data, one particular subset concerns those events occurring at the sea surface. A large number of sea surface environmental observations have been collected at Woods Hole. These data, and the subsequent analyses generated from the Air/Sea Heat Flux and the Climatology study projects, have been collected and archived. This document describes the (Cont. on back) 
W.H.O.I./Climatology and Air/Sea Interaction (WHOI/CASI) data collection and provides an initial index to its various components. 


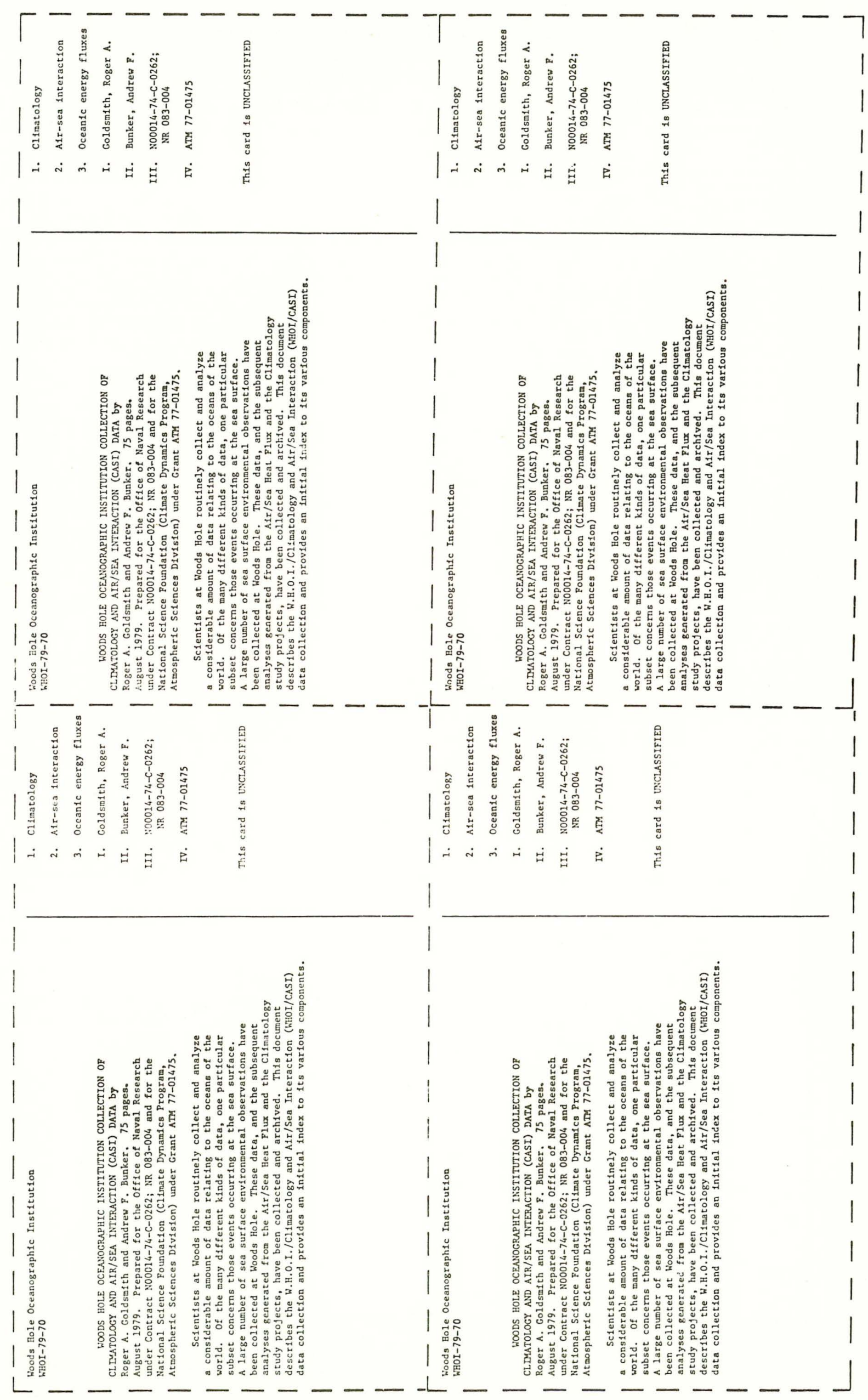

